\title{
EFFECTS OF REAMER-FEMORAL COMPONENT OFFSET ON CEMENT MANTLE PENETRATION IN HIP RESURFACING ARTHROPLASTY
}

\author{
A Thesis \\ Presented to the Faculty of \\ California Polytechnic State University \\ San Luis Obispo
}

In Partial Fulfillment of the

Requirements for the Degree

Master of Science in Engineering

With a Specialization in Biomedical Engineering

\section{By}

Mark Paulick

May 2010 


\section{(C) 2010 \\ Mark Paulick \\ ALL RIGHTS RESERVED}




\section{COMMITTEE MEMBERSHIP}

TITLE:

Effects of Reamer-Femoral Component Offset on

Cement Mantle Penetration in Hip Resurfacing

Arthroplasty

AUTHOR: Mark Paulick

DATE SUBMITTED: $\quad$ May 2010

COMMITTEE CHAIR: $\quad$ Scott Hazelwood, PhD

COMMITTEE MEMBER: Lanny Griffin, PhD

COMMITTEE MEMBER: Robert Crockett, PhD 


\begin{abstract}
Effects of Reamer-Femoral Component Offset on Cement Mantle Penetration in Hip Resurfacing Arthroplasty

Mark Paulick
\end{abstract}

Hip resurfacing arthroplasty has changed the treatment of end stage arthritis without severe deformity for young, active adults. Presently, there are varying clinical approaches to implant design selection and cementation techniques. The purpose of this project is to determine what amount of reamerfemoral component offset allows for the best cement penetration into the femoral head.

Rapid prototyped femoral component models were produced with reamer femoral component offsets of $0.0 \mathrm{~mm}, 0.5 \mathrm{~mm}$, and $1.0 \mathrm{~mm}$. After implantation onto models of reamed femoral heads made from high-density open-cell reticulated carbon foam, cement penetration was assessed from cross-sections of the foam-implant unit. Increased offset was found to decrease the extent of cement over penetration from the dome and chamfer. Increased offset also yielded optimal cement penetration as measured from the walls. Finally, increased offset was found to increase the height of cement mantle formation while maintaining complete seating of all implants. 


\section{ACKNOWLEDGEMENTS}

The author would like to thank Dr. Scott Hazelwood and Dr. Amir Jamali for their significant contributing efforts. And, thanks to Martin Koch and David Laiho for their technical support and assistance in the lab. Also, the highest level of appreciation is due to Robert Paulick and Terri Paulick for their continued love and support throughout the author's life long journey of education. 


\section{TABLE OF CONTENTS}

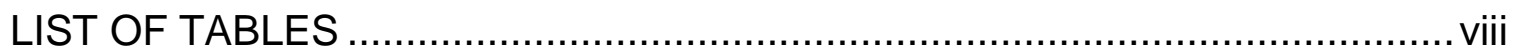

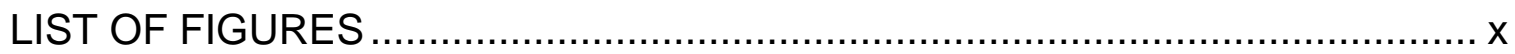

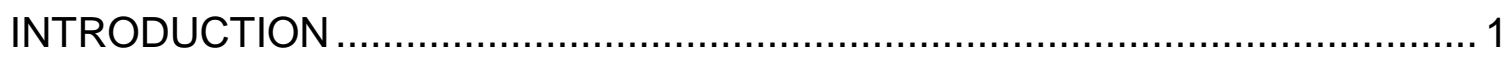

The Development of Hip Resurfacing.................................................... 1

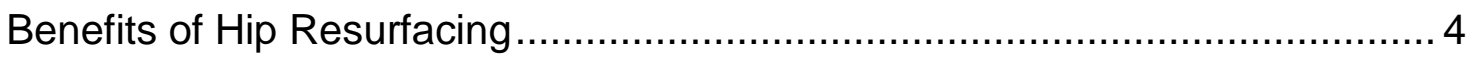

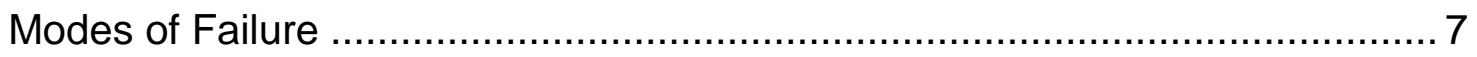

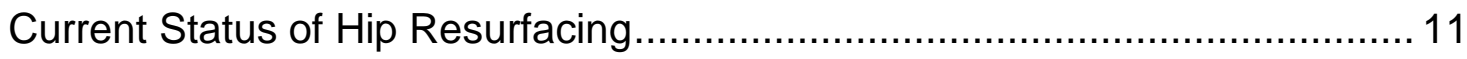

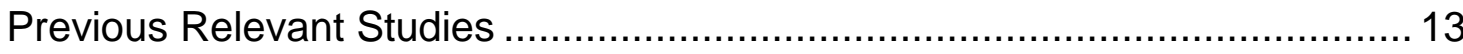

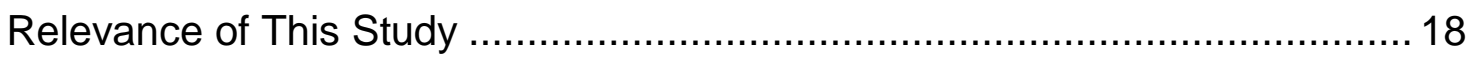

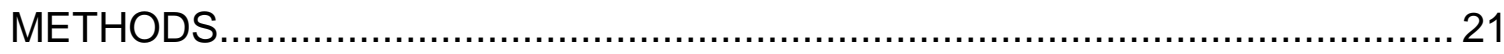

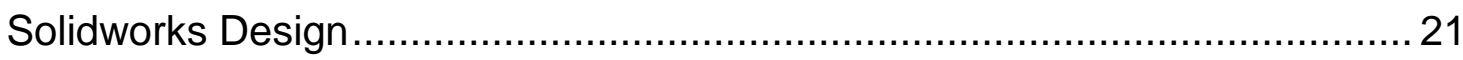

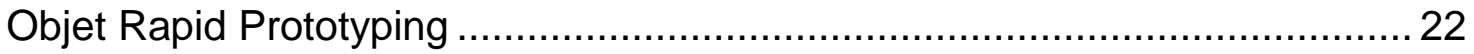

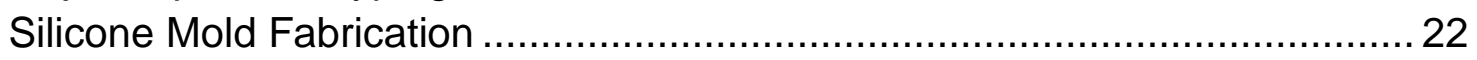

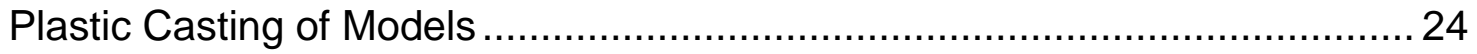

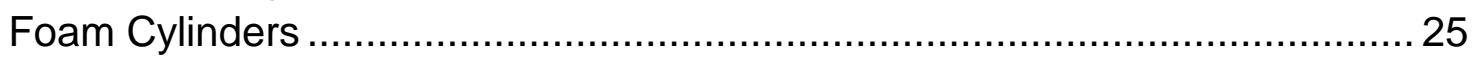

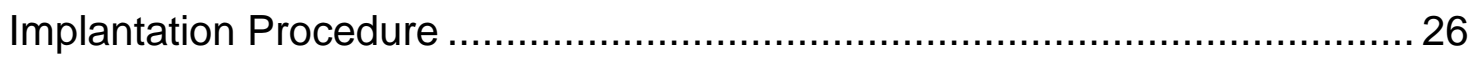

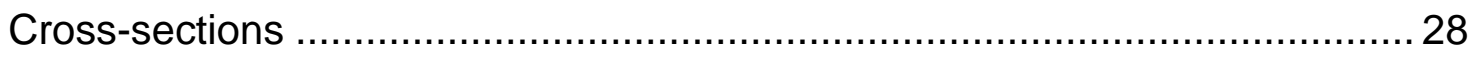

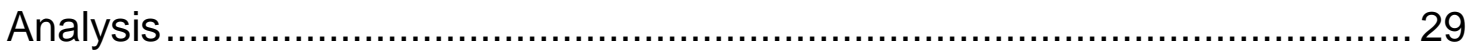

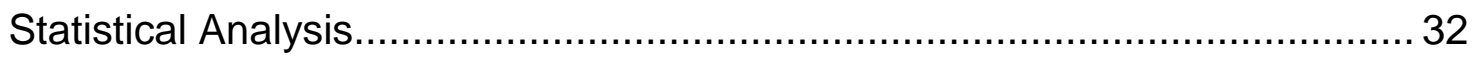

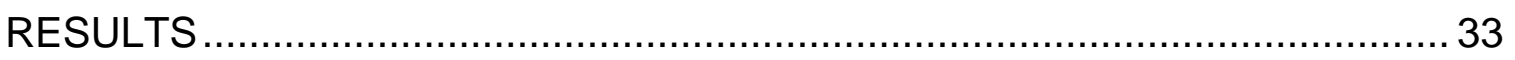

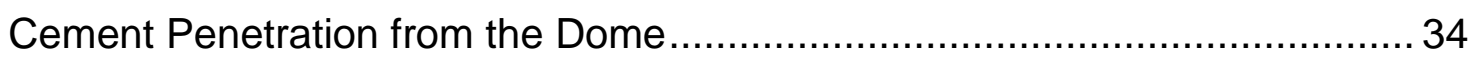

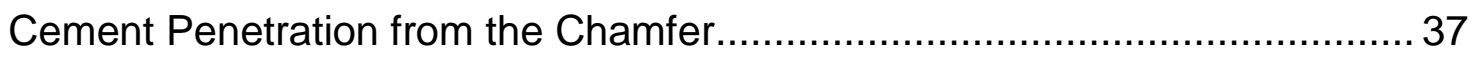

Cement Penetration from the Wall .............................................................. 41

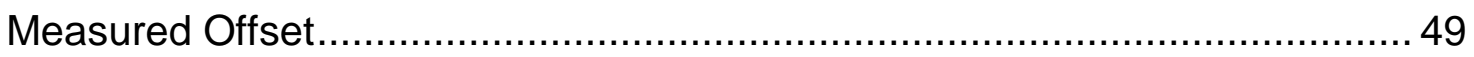

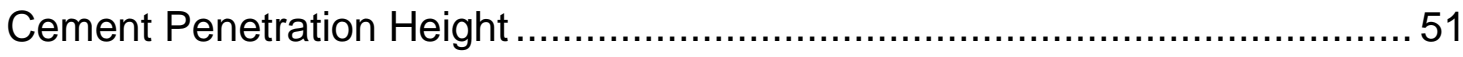

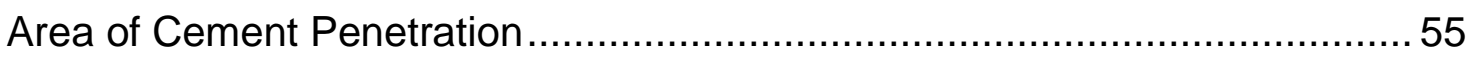




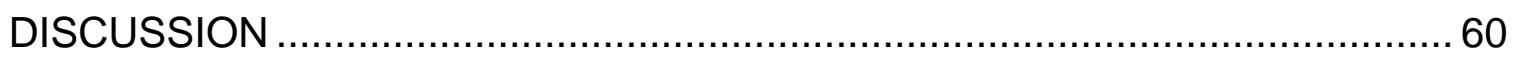

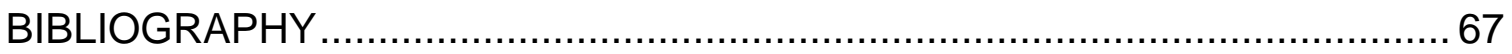

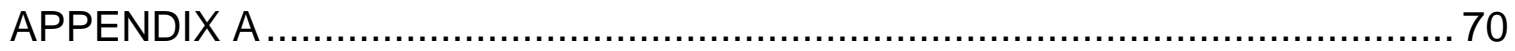

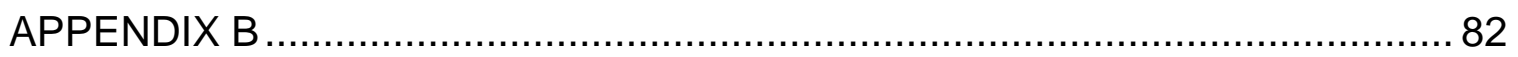

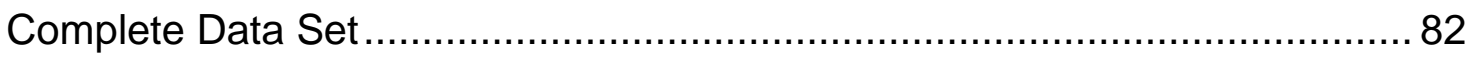

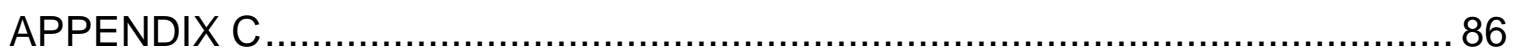

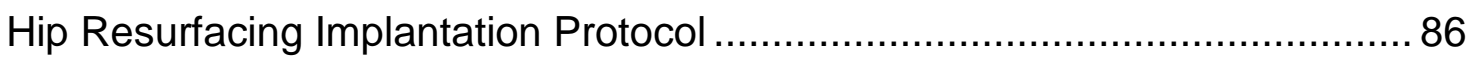

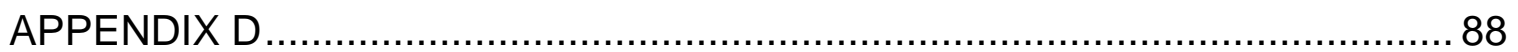

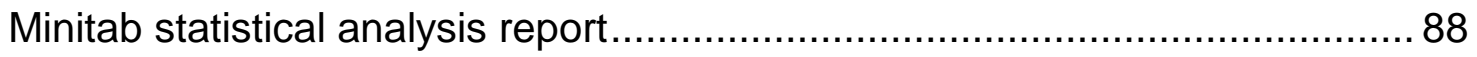




\section{LIST OF TABLES}

Table 1. Data collected as ten measurements taken for each unique surface. . 31

Table 2. Data values comparing measurement 1 of all three implant sizes ....... 35

Table 3. Tukey's 95\% confidence interval ANOVA test of measurement 1 ....... 35

Table 4. Data values comparing measurement 2 of all three implant sizes....... 36

Table 5. Tukey's 95\% confidence interval ANOVA test of measurement 2 ....... 37

Table 6. Data values comparing measurement 3 of all three implant sizes ....... 38

Table 7. Tukey's $95 \%$ confidence interval ANOVA test of measurement 3 .......39

Table 8. Data values comparing measurement 4 of all three implant sizes ....... 40

Table 9. Tukey's 95\% confidence interval ANOVA test of measurement $4 \ldots . . .41$

Table 10. Data values comparing measurement 5 of all three implant sizes..... 42

Table 11. Tukey's $95 \%$ confidence interval ANOVA test of measurement $5 \ldots . . .43$

Table 12. Data values comparing relative penetration (5a) of all three implant

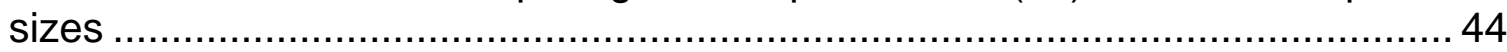

Table 13. Tukey's 95\% confidence interval ANOVA test of relative penetration

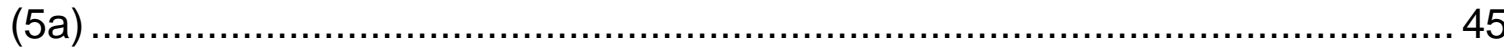

Table 14. Data values comparing measurement 6 of all three implant sizes..... 46

Table 15. Tukey's 95\% confidence interval ANOVA test of measurement $6 \ldots . . .47$

Table 16. Data values comparing relative penetration (6a) of all three implant

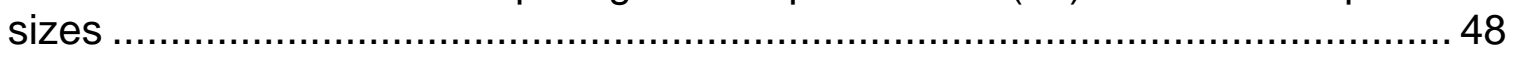

Table 17. Tukey's 95\% confidence interval ANOVA test of relative penetration (6a)

Table 18. Data values comparing measurement 7 of all three implant sizes.... 50

Table 19. Tukey's 95\% confidence interval ANOVA test of measurement $7 \ldots . .51$

Table 20. Data values comparing measurement 8 of all three implant sizes.....52 
Table 21. Tukey's 95\% confidence interval ANOVA test of measurement $8 \ldots . .53$

Table 22. Data values comparing cement height percentage (8a) of all three

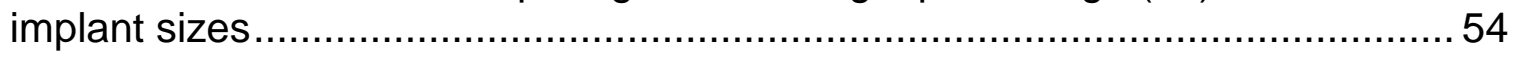

Table 23. Tukey's 95\% confidence interval ANOVA test of cement height

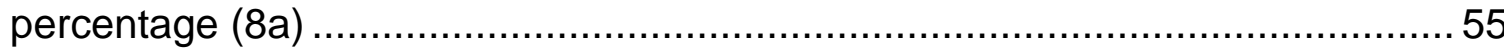

Table 24. Data values comparing measurement 10 of all three implant sizes... 56

Table 25. Tukey's 95\% confidence interval ANOVA test of measurement $10 \ldots 57$

Table 26. Data values comparing cement area percentage (10a) of all three

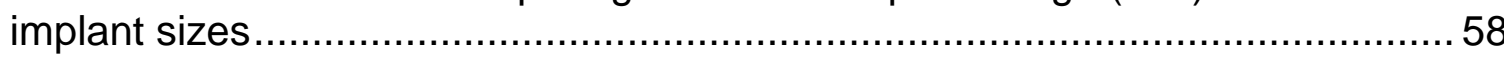

Table 27. Tukey's 95\% confidence interval ANOVA test of cement area

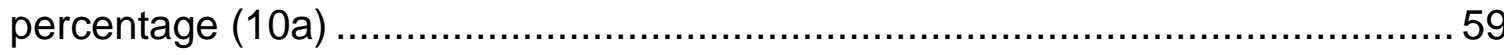

Table 28. Measured distances and areas of the $50 \mathrm{~mm}$ implant series............ 82

Table 29. Measured distances and areas of the $51 \mathrm{~mm}$ implant series............. 82

Table 30. Measured distances and areas of the $52 \mathrm{~mm}$ implant series............. 84

Table 31. Results collected as eleven values for each unique surface.............. 85 


\section{LIST OF FIGURES}

Figure 1. The Birmingham hip resurfacing system (left) and the total hip replacement system (right) by Smith and Nephew (2009) 1

Figure 2. Radiographs of an implanted hip resurfacing implant (left) and a total hip replacement (right) (Jamali 2008)

Figure 3. Diagrams of a cross section of a total hip prosthesis (above) and its radiograph (below) show where osteolysis occurs and the resulting implant

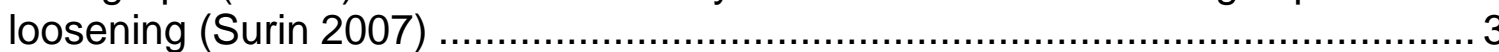

Figure 4. Radiographs of a normal left hip joint (left) compared to one that demonstrates avascular necrosis of the femoral head (right).

Figure 5. Six different cementing techniques (1-6) (Bitsch, Heisel et al. 2007) . 15

Figure 6. A comparison of bone structure of a human femoral head (top left), the 30-PPI material (top middle), and the 60-PPI (top right) open-cell reticulated carbon foam material. And, a comparison of a human femoral head (bottom left), the 30-PPI fat-filled foam model (bottom middle), and the 60-PPI foam model (bottom right) for after implantation and impaction of the femoral component (Bitsch, Loidolt et al. 2008)

Figure 7. Mantle thickness is the result of the reamer and femoral component offset. The offset (3) equals the femoral component diameter (2) minus the reamed foam cylinder diameter (1) ........................................................ 19

Figure 8. Solid model of the $51 \mathrm{~mm}$ hip resurfacing implant ............................21

Figure 9. Two part silicone molds were used to create plastic models of femoral resurfacing components. .............................................................. 23

Figure 10. Plastic model of the Birmingham hip resurfacing implant ................24

Figure 11. Carbon foam after being reamed to the shape of the prepared

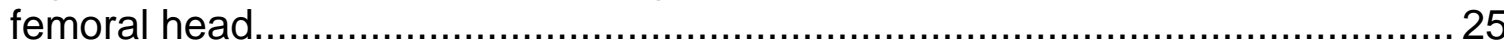

Figure 12. A demonstration of an implant model being filled with PMMA to $50 \%$ of its depth

Figure 13. The Instron testing machine shown with a foam cylinder (top arrow) and the implant holding fixture (bottom arrow) used for implantation

Figure 14. A implant model and foam cylinder specimen after implantation and ready for cross sections. 
Figure 15. Cross sectional view of an implant specimen with added measurement template markings.

Figure 16. Cross sectional view of implant models implanted onto foam. Red markings (left) show lengths measured numbered 1 through 9 to quantify cement penetration. Red outline (right) shows cement area of penetration....... 31

Figure 17. Boxplot comparing measurement 1 of all three implant sizes........... 35

Figure 18. Boxplot comparing measurement 2 of all three implant sizes........... 36

Figure 19. Boxplot comparing measurement 3 of all three implant sizes........... 38

Figure 20. Boxplot comparing measurement 4 of all three implant sizes.......... 40

Figure 21. Boxplot comparing measurement 5 of all three implant sizes.......... 42

Figure 22. Boxplot comparing relative penetration (5a) of all three implant

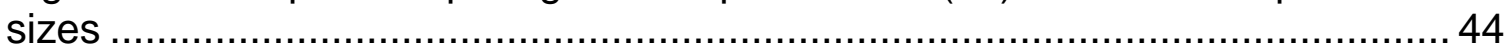

Figure 23. Boxplot comparing measurement 6 of all three implant sizes.......... 46

Figure 24. Boxplot comparing relative penetration (6a) of all three implant sizes 48

Figure 25. Boxplot comparing measurement 7 of all three implant sizes...........50

Figure 26. Boxplot comparing measurement 8 of all three implant sizes.......... 52

Figure 27. Boxplot comparing of cement height percentage (8a) of all three implant sizes

Figure 28. Boxplot comparing measurement 10 of all three implant sizes.........56

Figure 29. Boxplot comparing cement area percentage (10a) of all three implant sizes

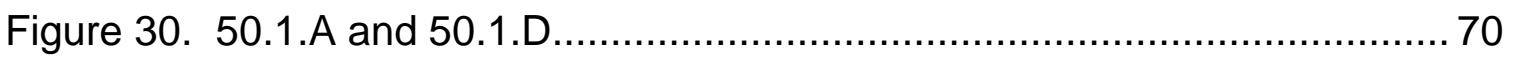

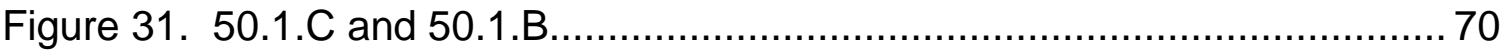

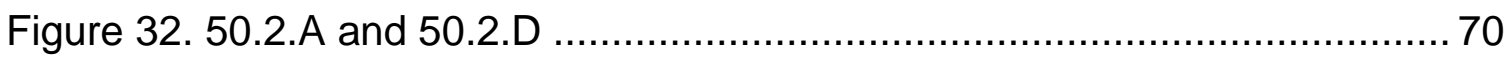

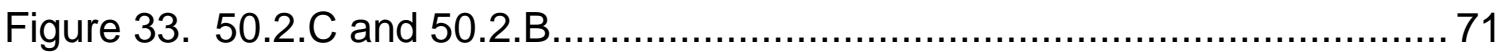




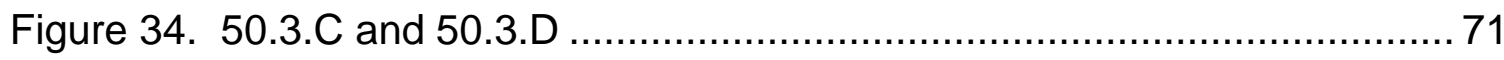

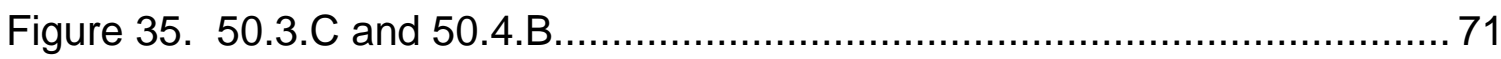

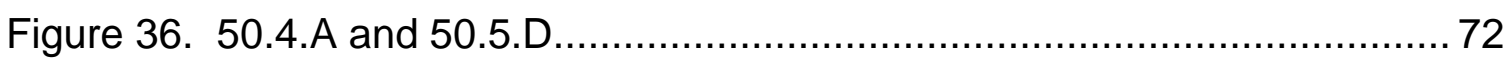

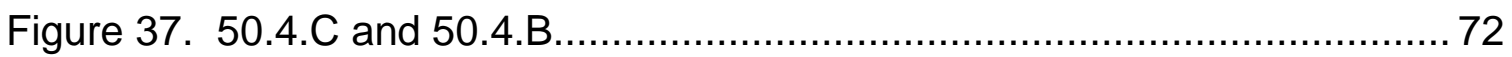

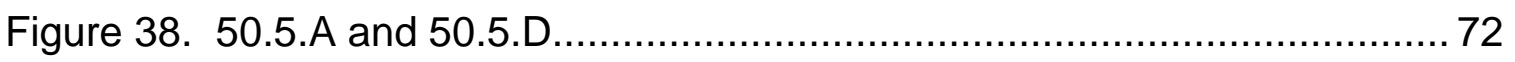

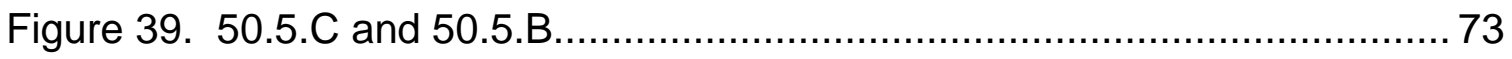

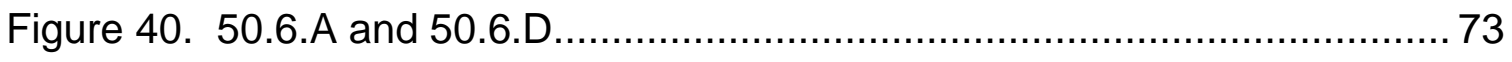

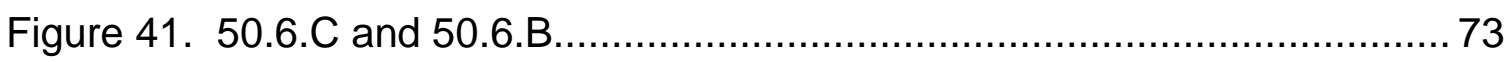

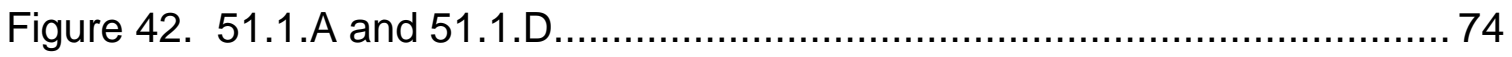

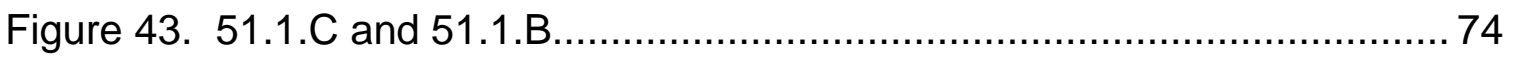

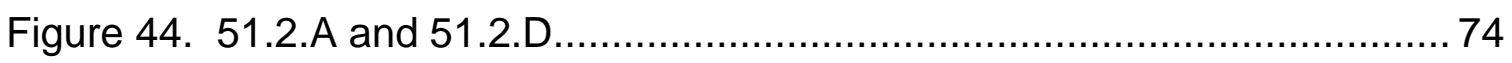

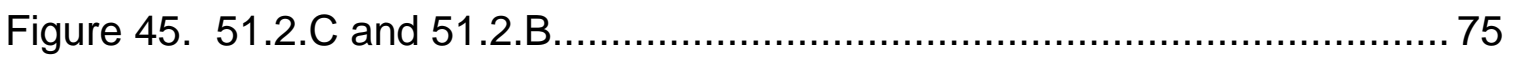

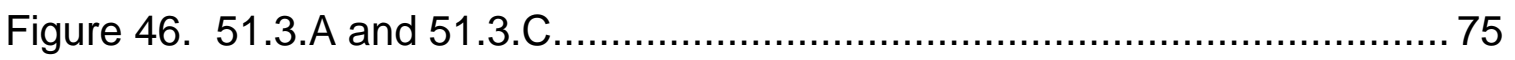

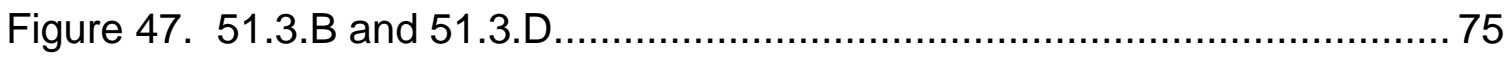

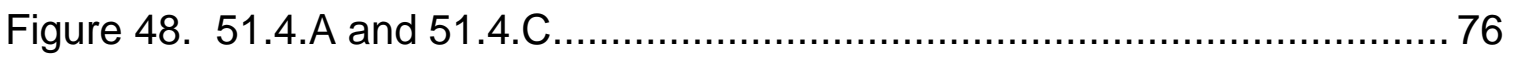

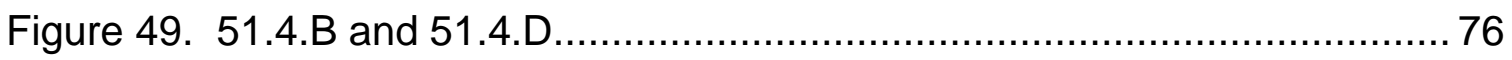

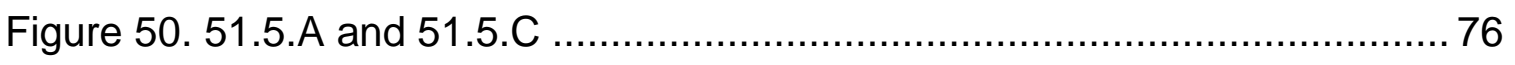

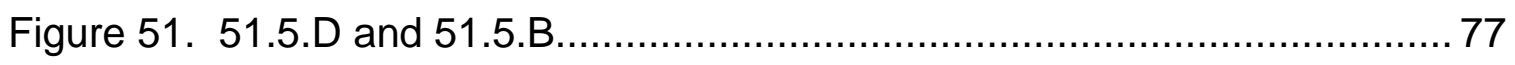

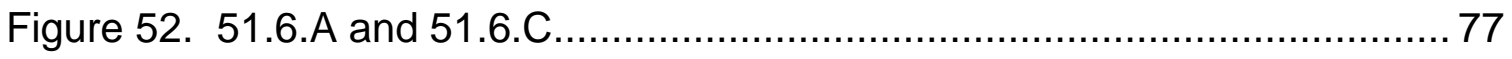

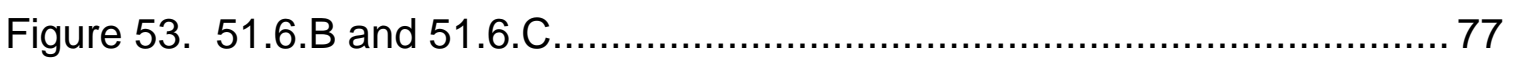

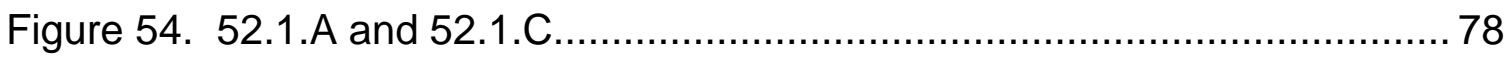

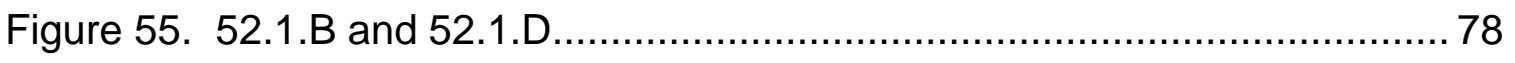

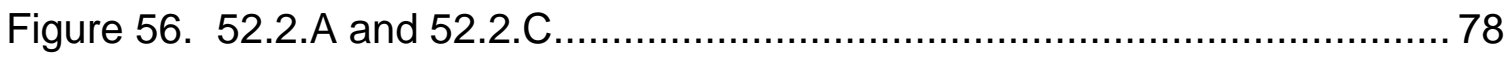




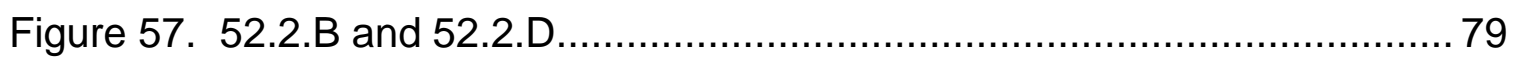

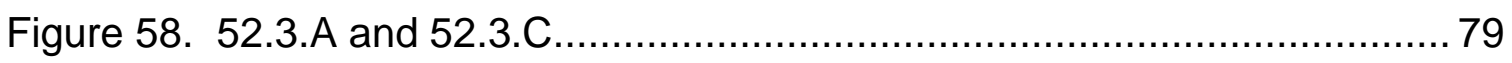

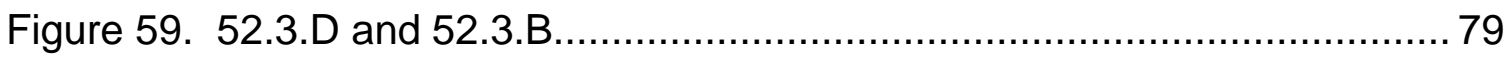

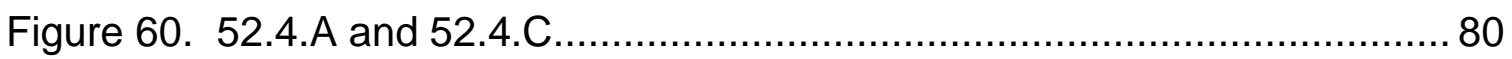

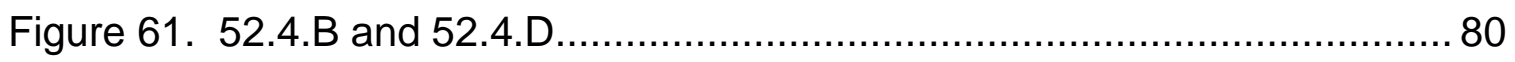

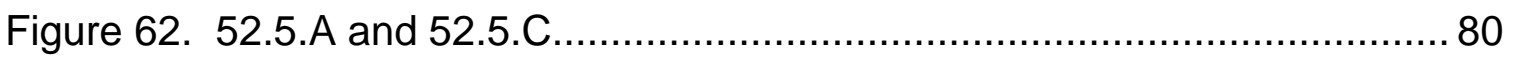

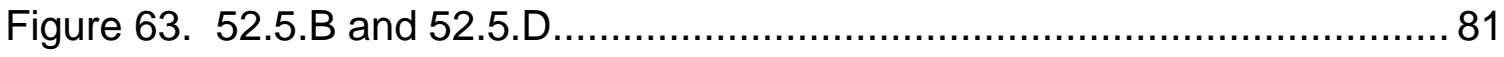

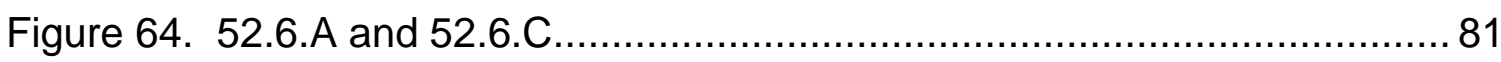

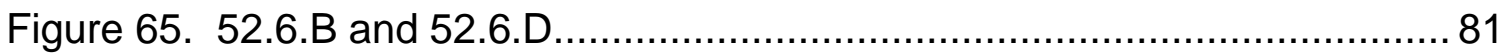




\section{INTRODUCTION}

\section{The Development of Hip Resurfacing}

Hip resurfacing procedures have recently reemerged as an alternative to total replacements for certain population of patients with arthritis of the hip (Schmalzried, Silva et al. 2005). During resurfacing procedures, the femoral component is implanted like a cap onto a prepared femoral head with the rest of the anatomy intact. Hip resurfacing is a type of hip arthroplasty that is commonly compared to total hip replacement. Total hip replacements involve resecting the femoral neck and placing a long stemmed femoral component into the proximal shaft of the femur (Isaac, Siebel et al. 2006). The two types of arthroplasty seen in figure 1 show the fundamental differences between the two systems.
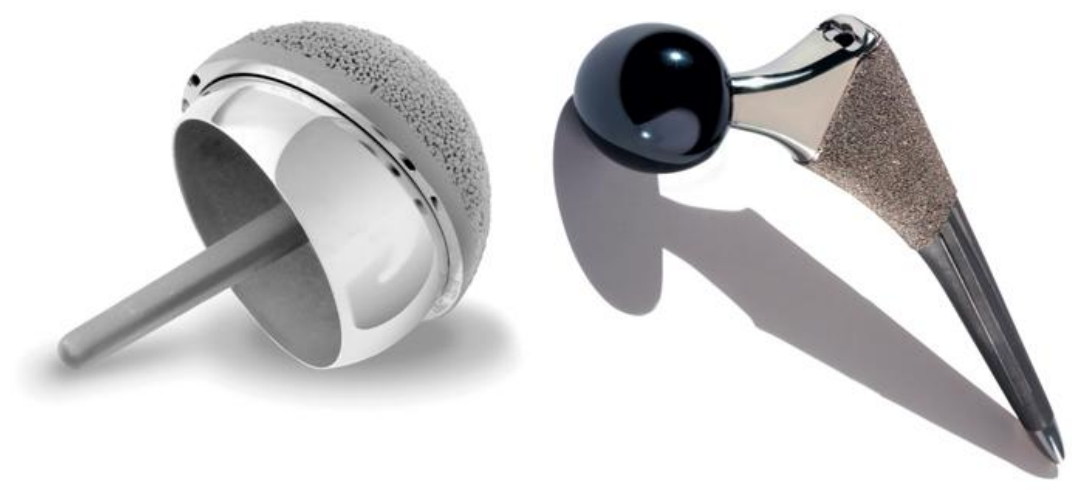

Figure 1. The Birmingham hip resurfacing system (left) and the total hip replacement system (right) by Smith and Nephew (2009)

As a result, hip resurfacing arthroplasty has changed the treatment protocols for end stage arthritis without severe deformity in young, active adults. It has become a good choice for clinicians for many reasons to be discussed later, but fundamentally it is chosen because it maintains as much natural 
anatomy and biomechanics as possible (Silva, Lee et al. 2004). Typically, the procedure is best suited for relatively young and active adults who have end stage arthritis (Heisel, Silva et al. 2004). It is only an option for patients without severe deformity of the femoral head or significant bone loss in the femur(Daniel, Pynsent et al. 2004).

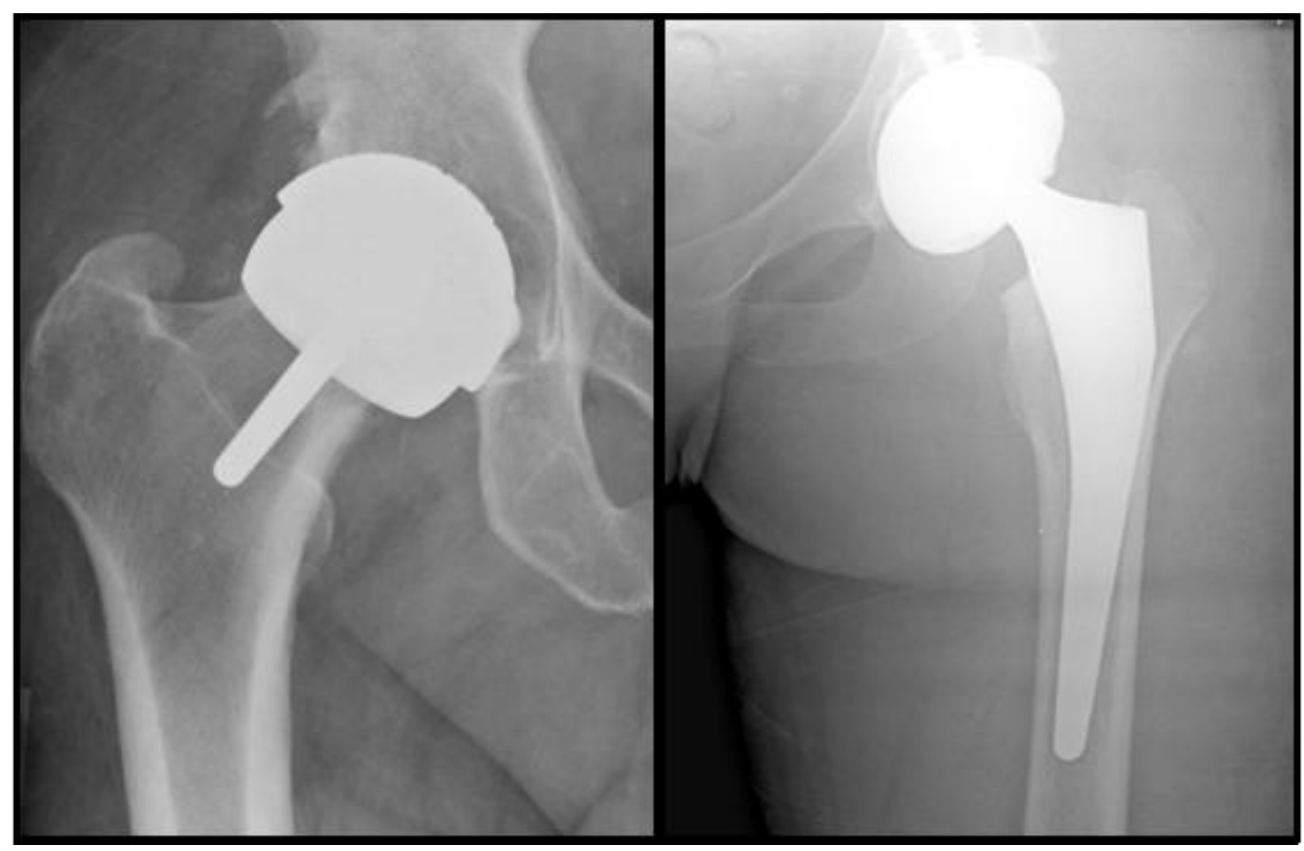

Figure 2. Radiographs of an implanted hip resurfacing implant (left) and a total hip replacement (right) (Jamali 2008)

Total hip replacements have been in use since the 1940s and are easily identified by the long stem implanted into the shaft of the femur (see figure 2). Total hip replacements can be used in a larger patient population and include treatment for severe joint deformity or arthritis and fracture. Fundamentally, total hip replacements significantly alter the biomechanics of the joint and as a result, are associated with several complications. Most common are osteolysis, stress shielding, fracture and aseptic loosening in cemented implants (Amstutz 2008). 
Osteolysis typically occurs as a result of joints with increased wear rates found in arthroplasty systems with plastic articulating surfaces(Agarwal 2004). The presence of wear debris in the joints elicits an autoimmune response that results in more bone resorption than bone remodeling. This leads to loss of bone tissue, called osteolysis, and implant loosening (see figure 3). Also, total hip replacements can be complicated by stress shielding. Stress shielding is an application of Wolff's law that states bone will remodel in response to the loads under which it is placed (Martin, Burr et al. 1998). After a total hip replacement, the surrounding bone is placed under much less stress than it was before the procedure because the stress is now carried by the implant. As a result there is less stimulus to continue remodeling and the bone density decreases. This commonly causes fractures of the neck and shaft of the femur (Harris, McCarthy et al. 1982).
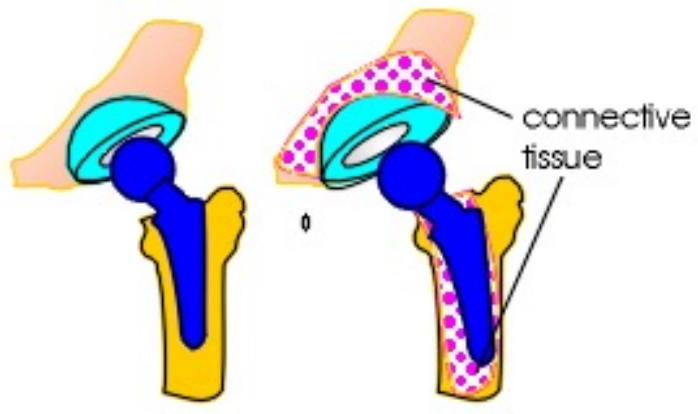

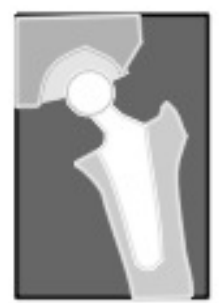

STABLE PROSTHESIS

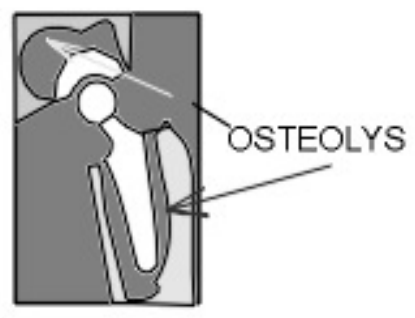

LOOSE

PROSTHESIS

Figure 3. Diagrams of a cross section of a total hip prosthesis (above) and its radiograph (below) show where osteolysis and implant loosening occur (Surin 2007) 
The modern era of resurfacing arthroplasty emerged in the last decade. Advancements were made popular primarily though new uses of metals instead of polymers (Schmalzried, Fowble et al. 1996). Early, development of femoral head resurfacing began in the early 1950's with cementless Teflon components, then ultra high molecular weight polyethylene (UHMWPE) components in 1964, then UHMWPE cups with stainless steel heads in 1971, and then UHMWPE cups with cobalt-chromium in 1973 (Amstutz 2008). Today, mostly cobalt chromium components are used for resurfacing systems (Amstutz 2008). Similar metal on metal bearings have been used in traditional total hip replacements for more than 30 years. This suggests that the long term outcomes of hip resurfacings will also be successful (Amstutz, Campbell et al. 1996).

In the mid-1970's, hip resurfacing with a metal-polyethylene articulation fell out of popularity because of high wear rates of the polyethylene component, which led to osteolysis and loosening (Schmalzried, Fowble et al. 1996). So, it was determined to combine the low wear rates used in total hip replacements with the durable fixation of cemented femoral resurfacing implants (Hungerford, Mont et al. 1998). As a result, it became popular to use a cobalt chromiumcobalt chromium articulation in a cemented femoral component with a non cemented acetabular component.

\section{Benefits of Hip Resurfacing}

The recent development of hip resurfacing led to the wide spread use of metal-on-metal resurfacing since the late 1990's. Its advantages and risk factors compared to total hip replacements have been well documented (Amstutz 2008) 
and will always be dependent on the specific system of the device that is used, as well as the experience of the surgeon. Evidence of the benefits of hip resurfacing implants versus the total hip replacements are shown to a great extent in the literature (Daniel, Pynsent et al. 2004). Most benefits stem from the fundamental difference that a resurfacing technique preserves the maximum amount of bone mass in the femur. Generally it is thought that the less you alter the natural biomechanics and structure of the body, the better. Additionally, it is believed that the more natural bone that remains will reduce the occurrences of osteolysis and maintain naturally occurring bone remodeling. This also encourages surgeons to use larger diameter femoral and acetabular components than the traditional polymer components (Bal, Haltom et al. 2006).

Primarily, hip resurfacing preserves the natural bone tissue of the femoral head and neck and therefore preserves the most normal joint physiology. Resurfacing of the femoral head intends to remove only pathologic bone; this contrasts with total hip replacement which resects the entire femoral head and neck. Resurfacing maintains other important features of the femur such as the greater trochanter, lesser trochanter, and sub-trochanteric areas which maintains normal biomechanical loading of the joint. Also, the acetabular bone is preserved. As a result, leg lengths are equalized more easily in a resurfacing procedure.

Resurfacing techniques also have benefits due to the tribology and wear debris production of the metal-on-metal surface contacts (Rieker, Schon et al. 2005). Inflammatory response is considerably less in metal debris than 
polyethylene debris (Amstutz 2008). Studies have shown that metal-on-metal bearings produce detectable amounts of debris in the form of ions (Firkins, Tipper et al. 2001), but have also shown that wear debris is reduced with the use of metal-on-metal articulations compared to previous generations of resurfacing (Anissian, Stark et al. 1999). The debris is enough to be detectable in the liver, kidney, and urine. However, there have been no cases of cancer reported as a result of the metal-on-metal hip replacement (Daniel, Ziaee et al. 2009). Metalon-metal joints, while still the focus of many studies, continue to be the method of choice in both total and resurfacing hip replacements (Schmalzried, Fowble et al. 1996).

Furthermore, other concerns have surfaced regarding the implementation of cobalt chromium parts and their effect on an unborn child in utero. Most recently it has been determined that placental regulation of cobalt and chromium ions occurs in patients with metal-metal surface replacements (Ziaee, Daniel et al. 2007). It was found that although the placenta does not act as a total barrier to protect the child, it does serve to regulate the concentrations of the metal ions. This is important because it supports the continued expansion of resurfacing applications to young patients.

Also, resurfacing has shown significantly improved joint stability compared to total replacements due to its anatomic component orientation. Occasionally, range of motion of the hip is improved from the original joint (Schmalzried, Silva et al. 2005). It has been determined that postoperative dislocations are uncommon and recurrent dislocations have not been observed (Amstutz 2008). 
Finally, if failure occurs it can more easily be converted into a traditional total hip replacement than a necessary secondary total hip replacement procedure (Amstutz 2008). Because the femoral neck remains intact after a head resurfacing, a revision to the conventional stem-type replacement is essentially the same as a primary joint replacement. Also, the procedure to remove the acetabular socket is simple, suffers minimal bone loss and is rarely necessary.

\section{Modes of Failure}

The generation of hip resurfacing implants that used polyethylene components was marked by poor mid to late-term survivorship. Failure modes included aseptic loosening on the femoral and acetabular side, femoral neck fracture, and osteolysis due to wear debris (Amstutz, Campbell et al. 1991). It is generally agreed that UHMWPE wear debris is primarily responsible for the histiocytic reactions that causes aseptic loosening. As a result, the second generation of wear-resistant, metal on metal bearings for hip resurfacing was introduced in an effort to remove the primary cause of failure of wear induced osteolysis. Now, the primary causes of failure for the modern generation are femoral neck fracture and femoral loosening (Shimmin and Back 2005).

Femoral neck fracture has been reported in about $2 \%$ of modern hip resurfacings (Amstutz 2008). One study found femoral neck fractures were twice as likely in females than males and significantly more prevalent when the implant was placed at a greater inward angle (Shimmin and Back 2005). These findings suggest that neck fracture is influenced by surgeon experience and patient 
selection criteria. A study (Campbell, Beaule et al. 2006) of 98 resurfacing failures showed femoral neck fracture to be the most common cause of failure. They concluded that neck fractures could be caused by improperly seating the femoral component and excessive implantation forces to the implant by the surgeon. Both of these scenarios were found to be exacerbated by components with no cement mantle. Also, it was determined that components with notched designs showed no significant influence on failure rates. Notches are design features used in some arthroplasty systems intended to improve the fixation of the implant. Typically, a notch is designed into the interior surface of the implant dome along the side walls of the femoral head. It has also been proposed that femoral neck fractures occur when the bone is devascularized and weakened by a surgical approach that limits blood supply (Little, Ruiz et al. 2005). Both of these propositions were based on the observation of background necrosis. Background necrosis is where necrotic bone in the femoral head is surrounded by newly formed bone. Image analysis of specimens from the study (Campbell, Beaule et al. 2006) showed a trend of several millimeters of necrotic bone below the cement line with consistently viable bone within the head away from the cement. This trend suggests the influence cement has on the vasculature of the resurfaced femoral head; however more research needs to be conducted.

Similarly, many long-term fractures of the neck that occurred greater than one year after implantation are associated with avascular necrosis. Avascular necrosis is a disease caused by loss of blood supply to the bone. As a result, bone cells die and greatly affect the structure and mechanical properties. This 
disease most commonly takes place in the hip, knee and shoulder (Bilezikian, Raisz et al. 2008). As cell necrosis happens, the bone becomes denser and causes the structure to collapse slightly. In the hip, this manifests as a flattening of the surface of the previously spherical femoral head at the site where the most loading takes place: the superior surface (see figure 4). As the femoral head becomes misshapen, the cartilage in the acetabulum is damaged, and this causes an arthritic joint.

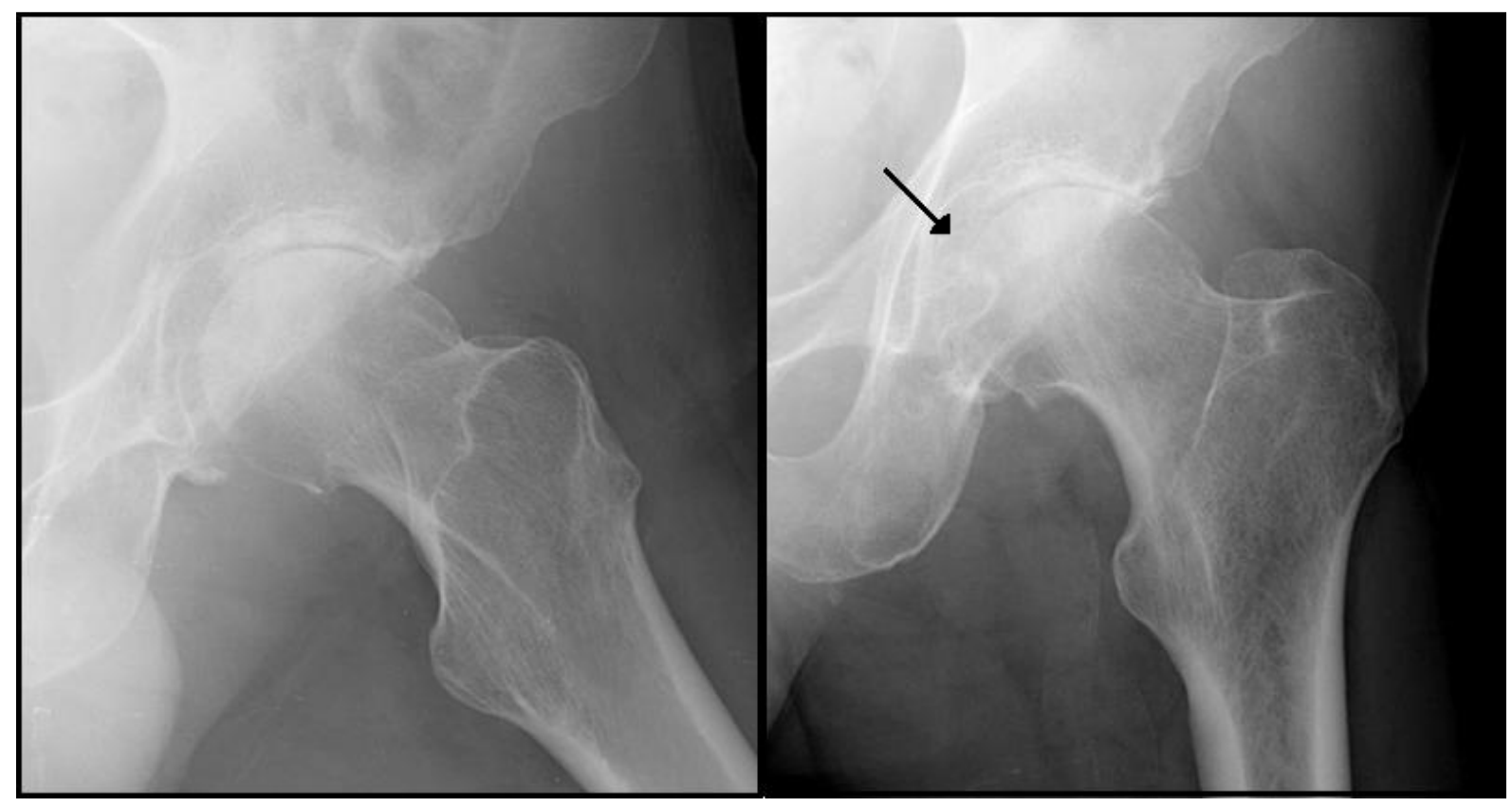

Figure 4. Radiographs of a normal left hip joint (left) compared to one that demonstrates avascular necrosis of the femoral head (right).

In resurfacing procedures, avascular necrosis causes an interface between the dead bone on the proximal head and the viable bone in the femoral neck (Amstutz 2008). Incomplete removal of the dead bone tissue in combination with sites of active bone resorption and formation creates an interface of the two zones. This creates a site of mechanical weakness that can be responsible for failure after several years. Other modes of cellular necrosis 
due to devascularization include dissection of the femoral head or other mechanical trauma, blood flow blockage due to dislocation, microembolism, chemical trauma, and heat trauma (Amstutz 2008).

Loosening of the femoral component can also occur as a mode of failure for resurfacing implants. One study (Amstutz, Campbell et al. 2004) found after 3.5 years of follow-up, seven out of twelve revisions from a group of 400 were due to femoral loosening. All of the joints showed viable femoral heads, but failure took place at the bone-cement interface. It is commonly held that femoral loosening is less common because of early fracture failures and generally shortterm follow up studies. It is believed that as the new generation of resurfaced joints age, there will be more instances of femoral loosening.

The modern resurfacing generation has led to the rise of many questions regarding the best technique for cement fixation of the femoral implant to the bone. Cement fixation needs to be sufficient enough for joint longevity without risking thermal necrosis caused by excessive penetration. There remain varying resurfacing designs and indications for cement volume, timing, and distribution (Campbell, Beaule et al. 2006). Loosening can be caused by insufficient cement fixation due to low volumes, poor cement distribution, and poor bone preparation. Retrieval analysis shows these specimens can be lifted from the bone with cement still inside the implant, suggesting there was insufficient integration of the cement into the bone during the initial fixation.

On the other hand, femoral loosening can also occur from over cementation, or over penetration. During the femoral component fixation step of 
a resurfacing procedure, filling the head with cement creates bonds between the metal-cement interface and the cement-bone interface. This can cause necrosis of the surrounding bone cells. Bone cells are killed when they come in contact with the cement because of an exothermic reaction used to activate the poly methyl methacrylate. There are several different methods to treat thermal necrosis and avascular necrosis secondary to thermal necrosis, but the treatment goal is always to minimize necrosis progression and preserve the natural hip joint as much as possible.

Another study (Breusch, Lukoschek et al. 2001) associated thermal necrosis with 48 resurfacing failures upon retrieval analysis. In the study, three modes of failure were considered: neck fracture, femoral loosening, and other non-femoral reasons. Measurements of cement penetration were taken at the anterior, middle and posterior sections of the femoral head. They concluded that the specimens that failed from femoral loosening had significantly higher amounts of cement than those that failed by other modes. It was suggested that thermal necrosis results in bone tissue loss and replacement by fibrous membranes, which causes component loosening. Further, the practice of filling cystic defects that occur in the bone with cement was found to contribute negatively to fixation because thermal necrosis was increased and cyst areas were lined with soft, sclerotic bone.

\section{Current Status of Hip Resurfacing}

It has been determined that hip resurfacing implants provide significant benefits to certain patient populations and that it can be safe and effective to use 
as a metal-on-metal articulation. However, the literature shows the emergence of several problems in hip resurfacing that need to be addressed with continued research. When the resurfacing technique was originally introduced, the polymers in use were the cause of many failures due to fracture and loosening. However, using metal-on-metal bearing surfaces has now dramatically improved the procedure's effectiveness (Silva, Lee et al. 2004).

Still, early hip failure is caused mostly by fractures, loosening, or avascular necrosis (Amstutz, Beaule et al. 2004). Also, the durability and longevity of the joint for current hip resurfacing procedures still depends on the successful bonding of the femoral component to the cement and bonding the cement to the bone (Morlock, Bishop et al. 2006). An effective amount of cement penetration into the bone is called normal cement penetration (Krause, Breer et al. 2009; Zustin, Amling et al. 2009). Still, overfilling of the femoral head with cement can result in thermal necrosis of the bone in the femoral head. Secondarily, it can lead to avascular necrosis, which will cause a loss of normal remodeling in the bone and the potential for failure. Avascular necrosis continues to be the subject of several papers (Morlock, Bishop et al. 2006) and is thought to be directly related to all types of arthroplasty failure rates. Also, if a patient has low bone mass, all the complications become more likely as a result of a technically difficult surgery.

Presently, there are six different systems of metal-on-metal hip resurfacing designs that are popular in clinical use. Each system has a different approach to the reamer-femoral component offset and cement mantle size, which are further 
explained in figure 7. The Conserve Plus system was introduced by Wright in 1996 and made popular by H. C. Amstutz. It features a 1 millimeter cement mantle. The Birmingham Hip Resurfacing was introduced in Germany in 1997 by Smith and Nephew and features a 0 millimeter cement mantle. These are the two systems that are most commonly used in the literature and represent two opposing schools of thought for the best size of mantle thickness. Also, the Cormet system was introduced in 1997 and uses 0 millimeter cement mantle. The Durom system introduced in 2001, uses and smaller angle of coverage (160 degrees instead of 170-180 degrees of other systems) and a 1 millimeter cement mantle. The Articular Surface Replacement system, introduced in 2003 by Depuy, can be used with a 0 millimeter or 1 millimeter cement mantle. Finally, the ReCap system was introduced in 2004 and uses a 0.5 millimeter cement mantle.

Many improvements are on the horizon for hip resurfacing implants. On the femoral side, improvements need to be made to reduce the risk for fracture, the risk of femoral component loosening, and the occurrence of avascular necrosis.

\section{Previous Relevant Studies}

Previous studies exist on cementing techniques and cement fixation of total hip replacements, on acetabular cup fixation and cement fixation of total knee prosthesis (Mulroy and Harris 1990; Breusch, Lukoschek et al. 2001). From the findings of other previous studies (Krause, Krug et al. 1982), it has been determined that optimal cement penetration into cancellous bone is $2-5$ 
$\mathrm{mm}$. Furthermore, it has been determined that penetration depths over $5 \mathrm{~mm}$ cause thermal necrosis of the bone (Huiskes 1980; Sih, Connelly et al. 1980). It is believed that cement penetration is a major factor in controlling optimal implant seating which will ultimately lead to optimized implant longevity.

Previously, a study (Bitsch, Heisel et al. 2007) developed femoral cementing techniques for hip resurfacing implants. The study was the first to address the effects of femoral cementing techniques in hip resurfacing implants. They used a laboratory model to analyze cement penetration. The study featured six cementing techniques (figure 5): (1) manual cement pressurization on the bone model surface only; (2) manual pressurization of cement on the bone model and filling of quarter of the component cavity with cement; (3) no cement on the bone model and filling of half of the component cavity; (4) manual pressurization of cement on the bone model and filling of half of the component cavity; (5) no cement on the bone model and filling the entire component cavity with cement; (6) and manual pressurization of cement on the bone model and filling of the full component. The study used open-cell reticulated carbon foam with 30 pores per inch and another with 45 pores per inch to approximate the architecture of the reamed femoral head. They also used two different viscosities of cement for the implantation. This study was validated by using fresh-frozen, human femoral heads which were used to perform the same systems of analysis. 


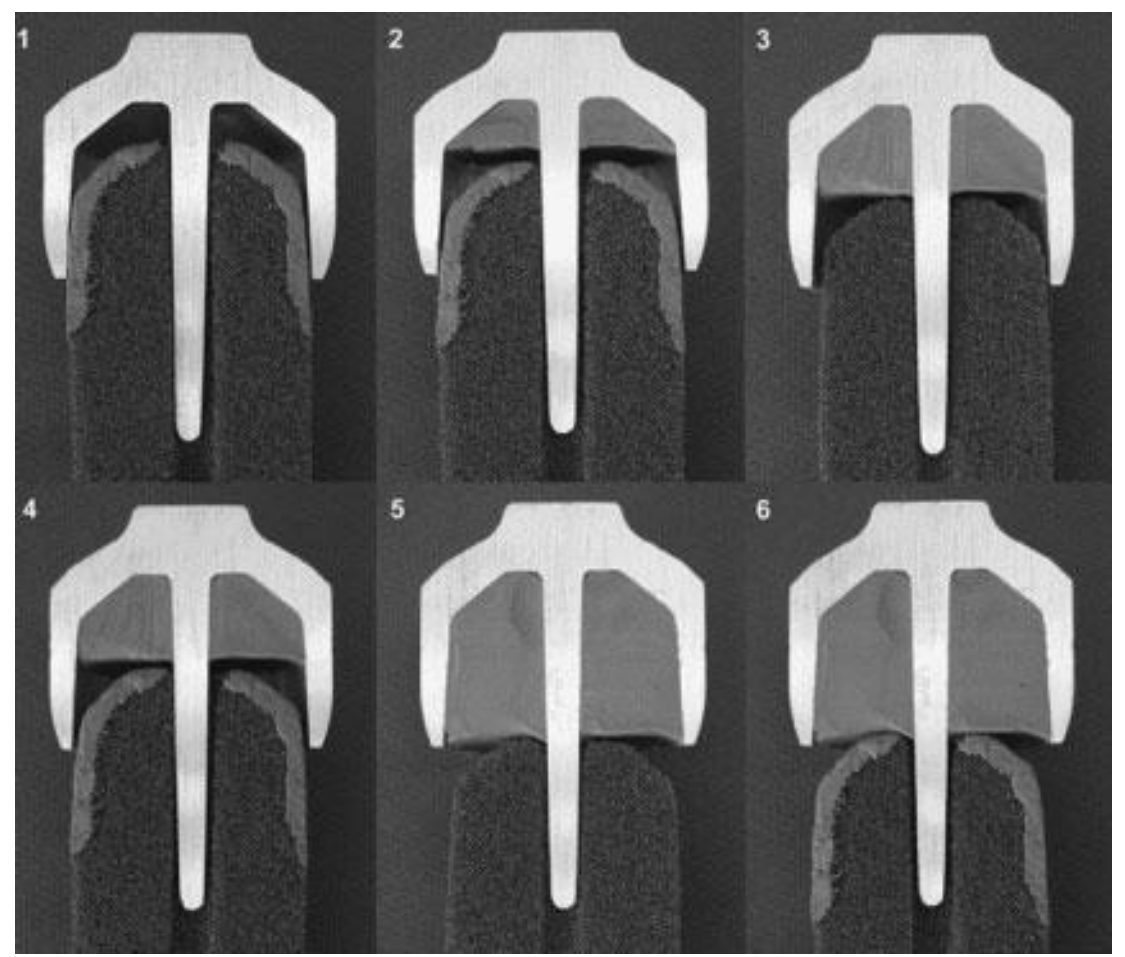

Figure 5. Six different cementing techniques (1-6) (Bitsch, Heisel et al. 2007)

The Bitsch et al. study concluded that only the technique of manual application of cement on the model surface with no cavity filling avoided over penetration of cement, incomplete seating, and the use of excess impaction forces. They also concluded that there was no significant difference between open-cell reticulated carbon foam with 30 pores per inch versus foam with 45 pores per inch. Also, it was determined that there were no significant differences between the different viscosities of cement used in the experiment. Finally, they concluded that the laboratory model was valid because there was no significant difference between the foam bone models and the fresh-frozen human femoral heads. 

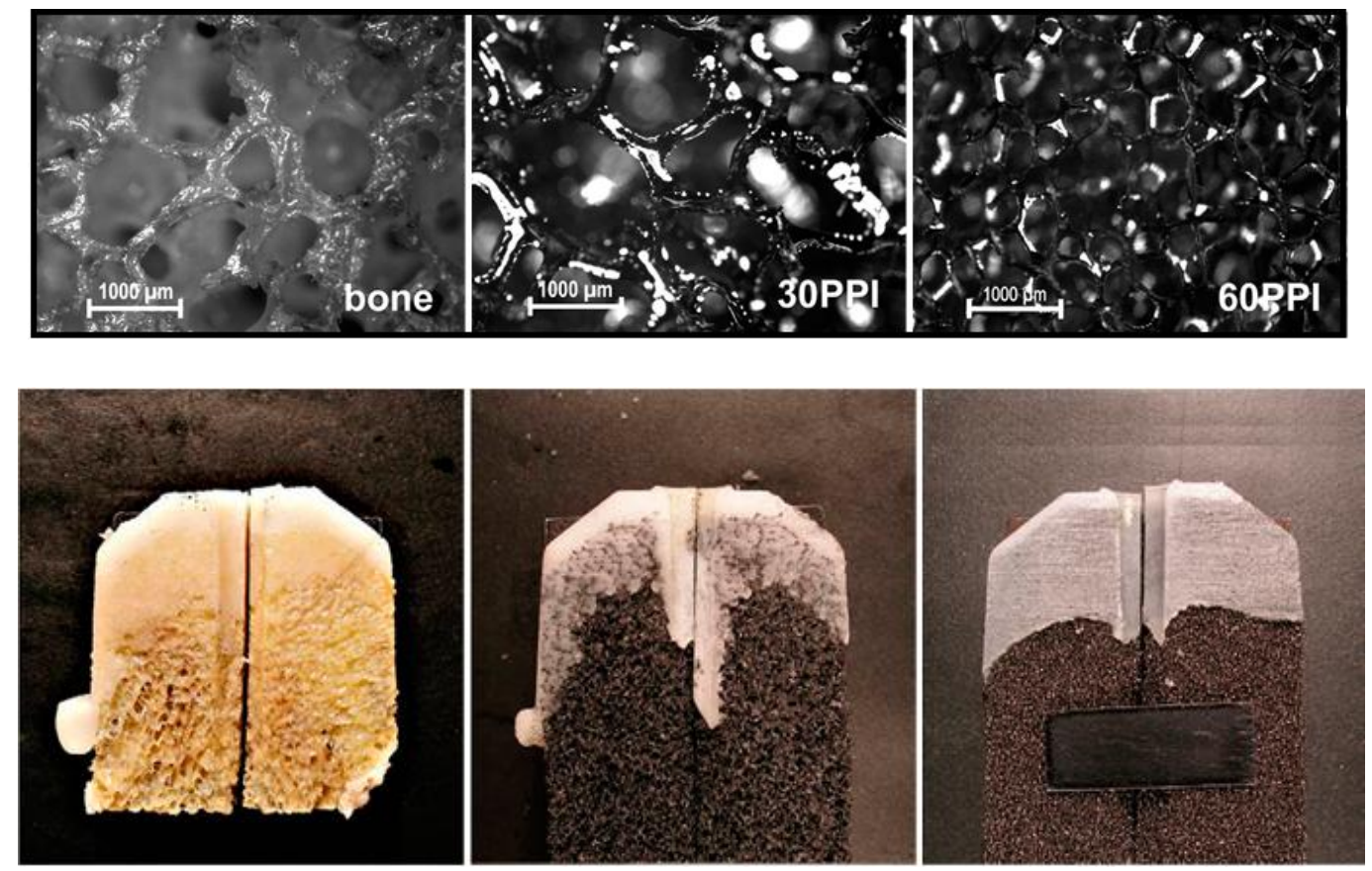

Figure 6. A comparison of bone structure of a human femoral head (top left), the 30-PPI material (top middle), and the 60-PPI (top right) open-cell reticulated carbon foam material. Also, a comparison of a human femoral head (bottom left), the 30-PPI fat-filled foam model

(bottom middle), and the 60-PPI foam model (bottom right) for after implantation and impaction of the femoral component (Bitsch, Loidolt et al. 2008)

This study developed a normalized method that can be used in the lab setting to model the clinical setting. As a result, it was determined that their model is a sufficient tool to studying hip resurfacing implants in the lab. The methodology of the Bitsch et al. study will be used as the basis of the protocol used in our study.

A follow up study of 600 resurfacing implants (Amstutz, Le Duff et al. 2007) investigated the effectiveness of surgical technique modifications on reducing the instance of femoral component loosening. The study looked at procedures that were done between 1996 and 2003 with similar patient demographics, risk factors, and the same post-operative protocol. The study looked at procedures with an evolutionary progression of implementing new 
surgical techniques. It was determined that adding fixation holes to the dome and chamfered areas of the bone significantly reduced femoral loosening. Also, it was determined that the practice of cleansing and drying the stem and dome holes significantly reduced the incidence of femoral loosening. Most importantly and most fundamentally, the paper concluded that rates of femoral loosening are a direct function of surgical technique improvements. This highlights the importance of further research in the area of improving surgical technique of hip resurfacings.

In another study (Campbell, Takamura et al. 2009), fifteen Conserve Plus resurfacing systems were retrieved during revision surgeries. The femoral components were sectioned, radiographed and photographed to measure the amount and distribution of cement. The study noted that the amount, application, and distribution of cement for femoral fixation varies based on the surgeon's preferences and the choice of implant system used. The study looked at the changes in femoral head preparation and cement application techniques done in the primary implantation. Results were admittedly inconsistent but showed that the new cementing techniques helped reduce over-penetration and provided better cement interdigitation. Results were presented as measurements of mantle at walls $(\mathrm{mm})$, mantle at chamfer $(\mathrm{mm})$, mantle at dome $(\mathrm{mm})$, penetration at walls $(\mathrm{mm})$, penetration at chamfer $(\mathrm{mm})$, penetration at dome $(\mathrm{mm})$, and total area of cement (\%). The use of extra fixation holes and cementing the stem in cases with poor bone quality were associated with improved cement-to-bone contact area. 
Currently, research is being done out of Germany that investigates the cement-bone interface in hip resurfacing implants (Krause, Breer et al. 2009). The study surveyed clinical failure cases by retrieving femoral components at the revision surgeries of failed hip resurfacings. One hundred-eighteen specimens were cut with a diamond coated saw leaving the cement interface intact for analysis. Analysis of cement penetration was performed at the dome of the cap, the intermediate region, and at the radial region. The study made quantitative assignments to the labels of no penetration, normal penetration $(1-5 \mathrm{~mm})$, and massive penetration (>5 mm). Analysis was also made regarding the demineralization of the cement interface. The study concluded that female patients showed significantly higher levels of cement penetration which resulted in larger mineralization defects. Further, the study emphasized that cement bone interface changes caused by gender, time of implantation, and cement penetration are of paramount clinical importance to the long term success of hip resurfacing arthroplasty.

\section{Relevance of This Study}

Future research of hip resurfacing arthroplasty will include the effects of cement penetration on the bone cement interface and the resulting long term clinical outcomes. Component design and fixation technique have been shown to effect cement penetration and the cement bone interface. Major factors that will lead to changes in cement penetration are cement characteristics, femoral component design and mantle thickness. Mantle thickness is the direct outcome of reamer-femoral component offset. Mantle thickness is the measured cement 
thickness that fills the space between the reamed femoral head and the femoral component. Reamer-femoral component offset is defined as the interior radius of the femoral component minus the outer diameter of the prepared femoral head. This study will use reamed foam cylinders as a model of human femoral heads.

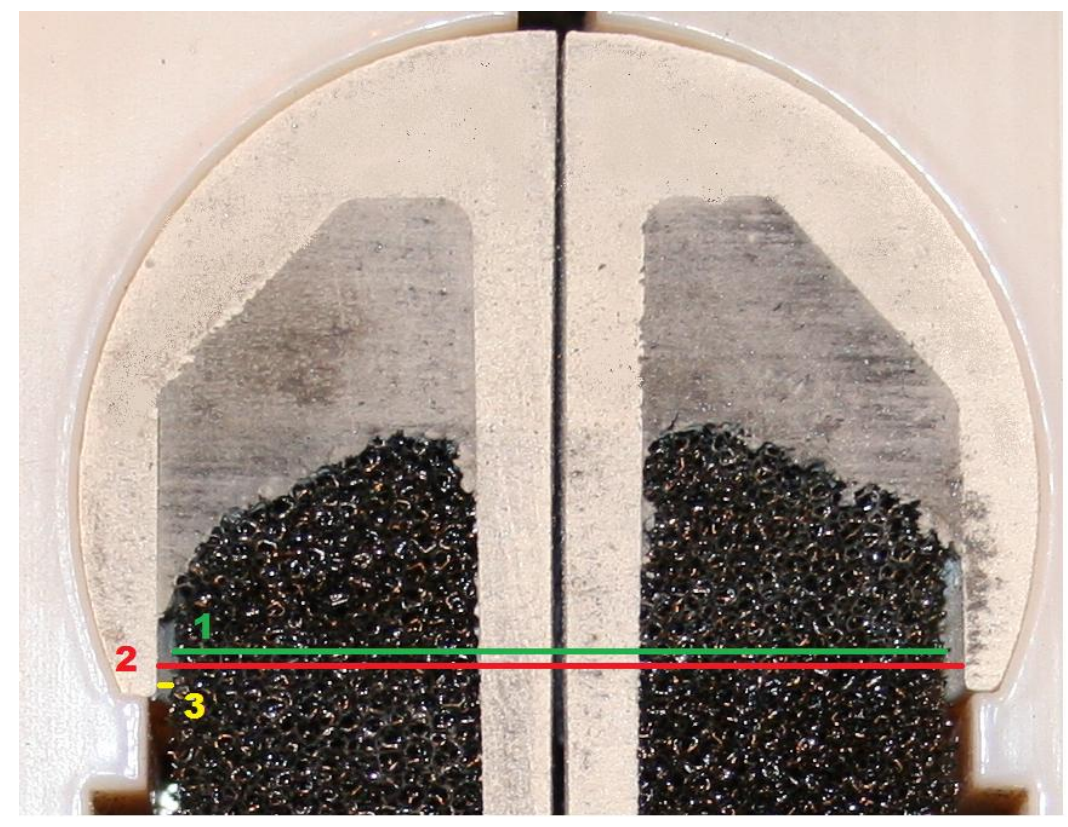

Figure 7. Mantle thickness is the result of the reamer and femoral component offset. The offset (3) equals the femoral component diameter (2) minus the reamed foam cylinder diameter (1).

During the surgery, the size of the femoral head is determined by the use of a reamer. Then the interior radius of the component is chosen to either equal the reamer radius (offset equals 0 ) or to be slightly larger than the reamer radius (offset equals up to several millimeters). This is illustrated in figure 7.

Previous research and clinical experience suggests that reamer femoral component offset will significantly affect the size of cement mantle and amount of cement penetration. Previous studies have shown that failure rates of hip resurfacing arthroplasty are directly related to cement penetration and determined by implantation techniques and prosthesis system design. However, 
it still needs to be determined how to optimize cement penetration through system design selection and the resulting cement mantle thickness. This question is directly proposed in the book $\underline{\text { Hip Resurfacing : Principles, }}$ Indications, Technique and Results (Amstutz 2008) when the author states that "How thick should the cement mantle be... nil or .5 or $1 \mathrm{~mm}$ ?" Eventually, clinical studies taken after revision surgeries will be needed. However, this study is the first to directly address the question of cement penetration and reamer femoral component offset using a laboratory model.

The problem statement for this paper is as follows: determine how optimal cement penetration is achieved in order to optimize fixation of the femoral component and therefore maintain bone viability and maximize joint longevity. In this study, it will be determined which one of three chosen offsets (difference between the outer diameter of the reamed femoral head and the inner diameter of the femoral component) and the resulting mantle thickness allow for the optimal cement penetration for adherence of the femoral component onto the femoral head. 


\section{METHODS}

\section{Solidworks Design}

Implant design was based on the dimensions taken from the Birmingham Hip Resurfacing System by Smith \& Nephew (Memphis, Tennessee). Modifications were made to the existing design to create three implants with varying diameter: $50 \mathrm{~mm}, 51 \mathrm{~mm}, 52 \mathrm{~mm}$. The dimensions were driven by the size of the reamer used during the implantation procedures to be discussed later. Solidworks, a computer aided design program, was used to create solid model formats (.prt) as seen in figure 8. These files were converted to a file type (.cgs) usable for the objet rapid prototyping machine to be used to fabricate the models. These files were set to the maximum resolution (150 DPI) that the objet machine could read.

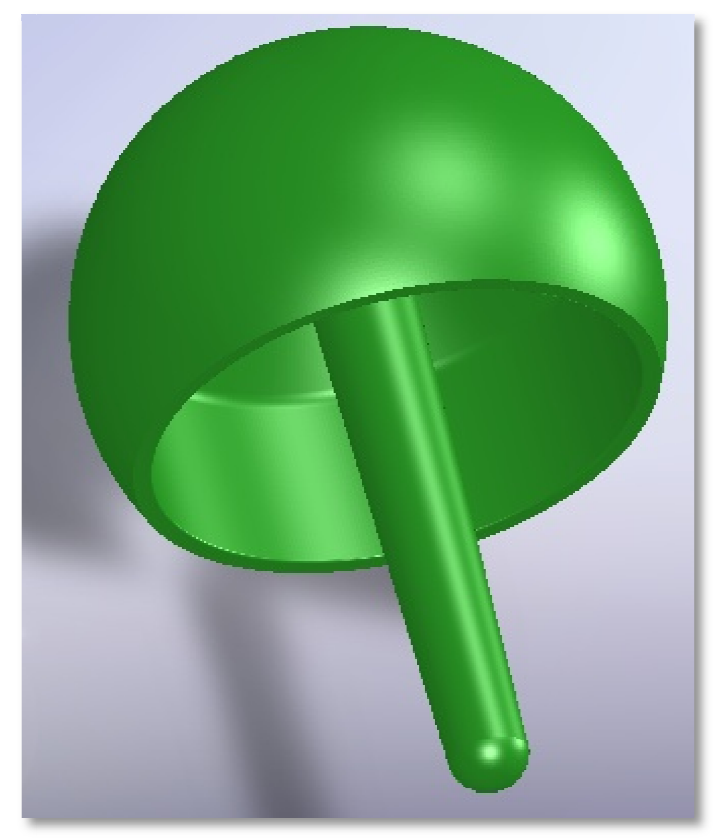

Figure 8. Solid model of the $51 \mathrm{~mm}$ hip resurfacing implant 


\section{Objet Rapid Prototyping}

Implant models were created using the Objet Eden 350V rapid prototyping system (Objet Geometries Inc., Billerica, Massachusetts) which uses UV light hardened extrusions at 16 microns thick. The Objet machine uses a method of building layers of the part on top of a support structure. Surfaces which were not in contact with the support material underwent a setting on the machine to give a glossy surface finish. To take advantage of this detail parts were oriented with the rounded dome surface down. This allows for the inside surface and stem of the femoral component, which is the surface of interest for this project, to have the best surface finish. The Object machine uses a non-disclosed polymer called VeroWhite FullCure® (Objet Geometries Inc., Billerica, Massachusetts).

Upon completion of the build, the support structure material was removed using a water and detergent blaster. The objet machine uses a support material that crumbles under the impact of a water pressure cleaner without affecting the surface of the FullCure.

\section{Silicone Mold Fabrication}

Two part molds were created using silicone called Rhodorsil V-1062 (Freeman Manufacturing and Supply Company, Avon, Ohio) from the prototypes created from the Objet machine (see figure 9). The silicone material had components of polysiloxane hydroxyl terminate silicone dioxide, sodium sulfate, and titanium dioxide. Rhodorsil is a two component silicone elastomer that cures at room temperature by a polycondensation reaction. 


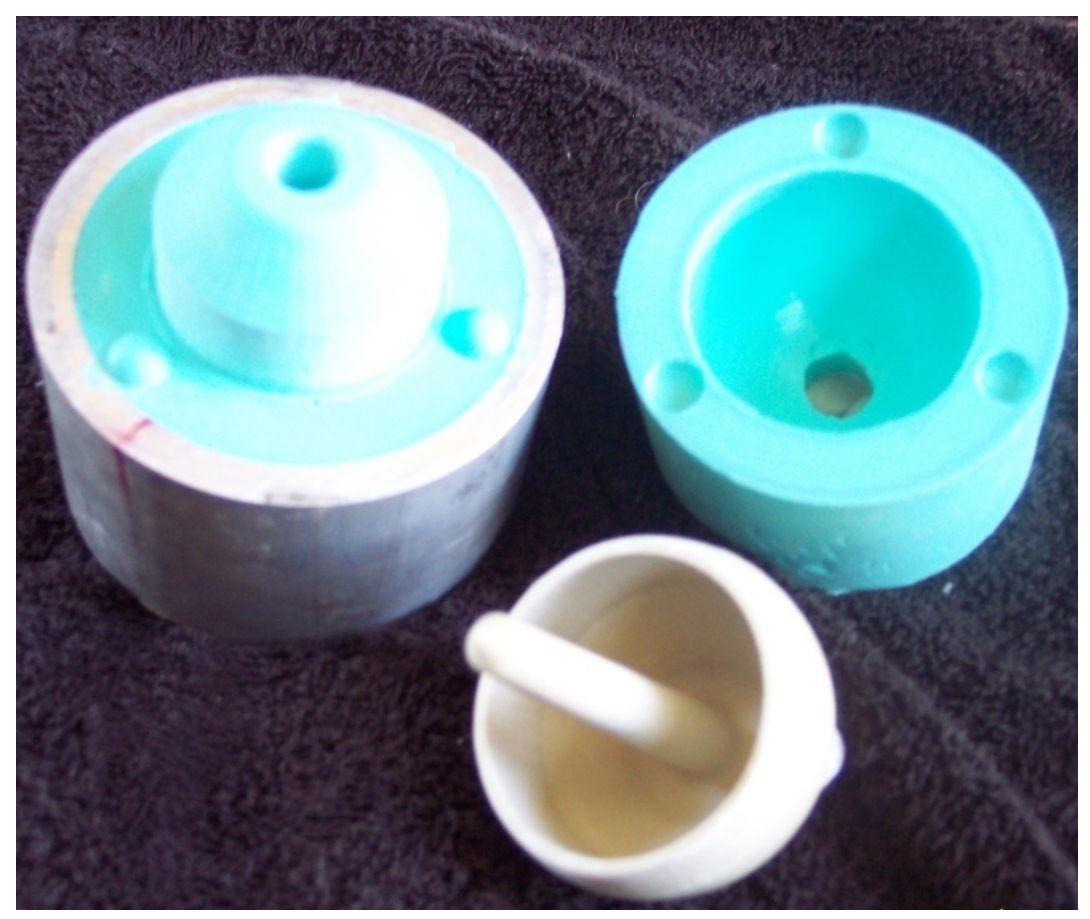

Figure 9. Two part silicone molds were used to create plastic models of femoral resurfacing components.

The process of creating the molds started with fixing the prototypes with the stem through a hole on a sheet of aluminum to let the dome side of the prototype sit on top of the aluminum sheet. The prototype and aluminum sheet were then enclosed with four inches in length of six inch-diameter aluminum pipe. A hot glue gun was used to seal the surfaces of the sheet and the edge of the pipe together. Plastic straws were glued onto the top of the implant to create pour holes on this, the top side of the mold. The two part silicone was then mixed and poured onto the top side of the mold. After hardening, the aluminum sheet was removed from the bottom of the mold and a second piece of aluminum pipe was adhered to the bottom of the top mold. Fiduciary notches were cut into the mold which orient the two parts; this was to assure reproducibility and reduce the potential for mold shifting which would result in non-uniform models of the 
femoral component. A silicone mold release material, Ease Release ${ }^{\mathrm{TM}} 800$ (Mann Formulated Products, Easton, Pennsylvania) was sprayed onto the bottom surface of the silicone and prototype before the second half of the silicone mold was poured.

\section{Plastic Casting of Models}

Femoral component models were cast using Huntsman Pro-cast $\AA^{\circledR} 20$ (Huntsman International, Hong Kong) for each implant size (50, 51, $52 \mathrm{~mm}$ ). This material was selected for compressive strength, shear strength, surface chemistry, and manufacturability. Two equal portions (50 grams each) of the resin and activator were mixed and then poured into all three cavities of the mold. Six models were made for each of the three implant sizes. After hardening, the parts were finished by smoothing out edges with P80 grade sand paper and the excess material from the pour holes removed with a belt sander. The process yielded 18 total models, one of which is seen in figure 10 .

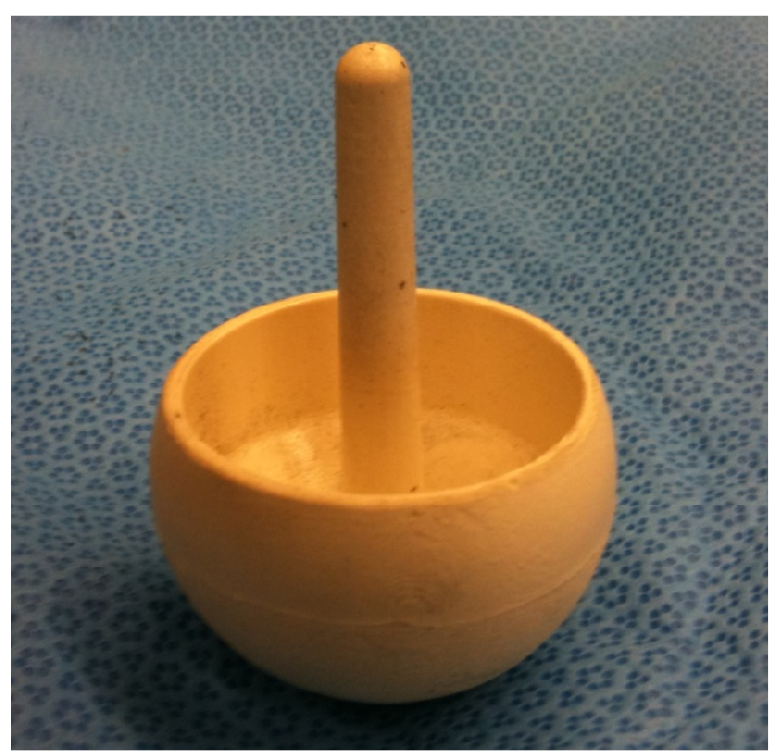

Figure 10. Plastic model of the Birmingham hip resurfacing implant 


\section{Foam Cylinders}

To model the femoral head, high-density open-cell reticulated vitreous carbon foam (Pacific Research Laboratories Inc, Vashon Washington) was used to receive the implant models. The foam bones had 30 pores per inch and $6 \%$ density was used because the density, porosity, and pore connectivity most similarly model the trabecular bone in the femoral head (Bitsch, Loidolt et al. 2008). Foam cylinders were prepared using a femoral head reamer to the shape seen in figure 11. A guide pin was placed into the femoral head and in line with the axis of what would be the femoral neck. A reamer with diameter $50 \mathrm{~mm}$ was provided by Depuy Orthopaedics (Warsaw, Indiana) for the experiment. Foam cylinders were reamed to the diameter equivalent of the 50 millimeters implant size giving a reamer-implant offset of $0.0,0.5,1.0$ millimeters.

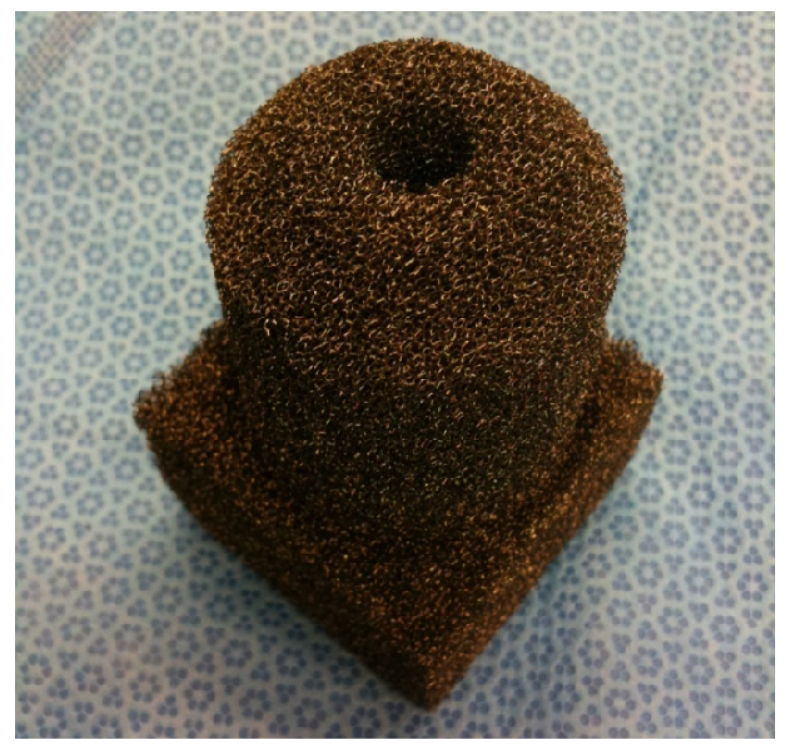

Figure 11. Carbon foam after being reamed to the shape of the prepared femoral head 


\section{Implantation Procedure}

Protocols for device model implantation onto reamed foam cylinders were developed and performed by Dr. Amir Jamali of UC Davis. Similar protocols were used and validated in a study (Bitsch, Heisel et al. 2007) previously.

The Instron 8511 servo-hydraulic testing machine (Instron, Norwood, MA) was used to implant the femoral component models onto the foam cylinders.

PMMA powder and liquid were stored in a hood at $4^{\circ} \mathrm{C}$ until immediately before they were to be used. Implants were filled to $50 \%$ of their depth (see figure 12) with PMMA powder and liquid mixture. Loading of the reamed foam bone onto the femoral component in the Instron was started at exactly 120 seconds from initial mixing of the PMMA. The implant was fixed onto the base of the Instron testing fixture and the reamed foam bone was mounted to the cross-head on the machine as seen in figure 13. The reamed foam bone was lowered into the implant until the liquid PMMA came into contact with the foam. At this point, the foam bone was fully seated into the implant at a rate of 0.5 millimeters per second. Once seated, the Instron maintained a 20-30N load on the implanted foam head for 2 minutes until the PMMA hardened. 


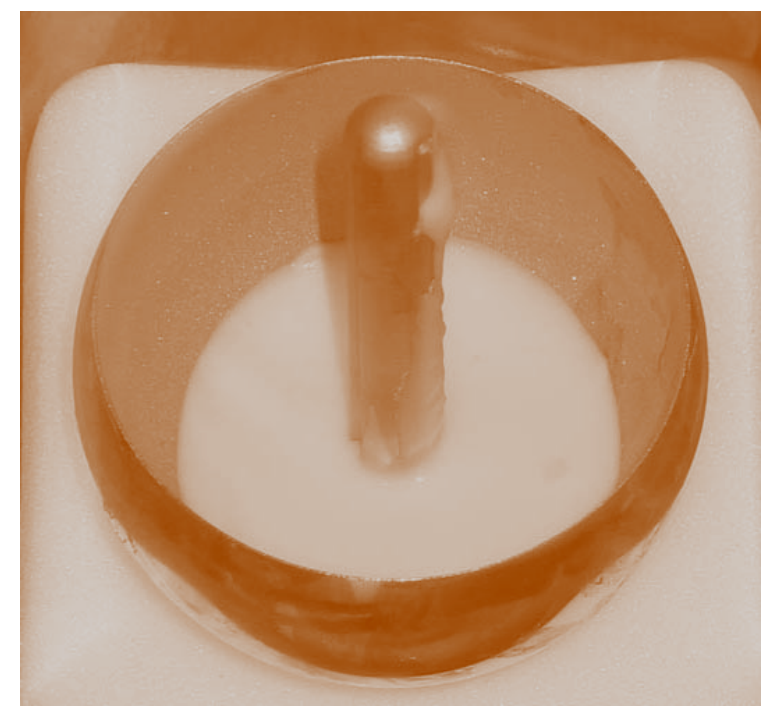

Figure 12. A demonstration of an implant model being filled with PMMA to $50 \%$ of its depth

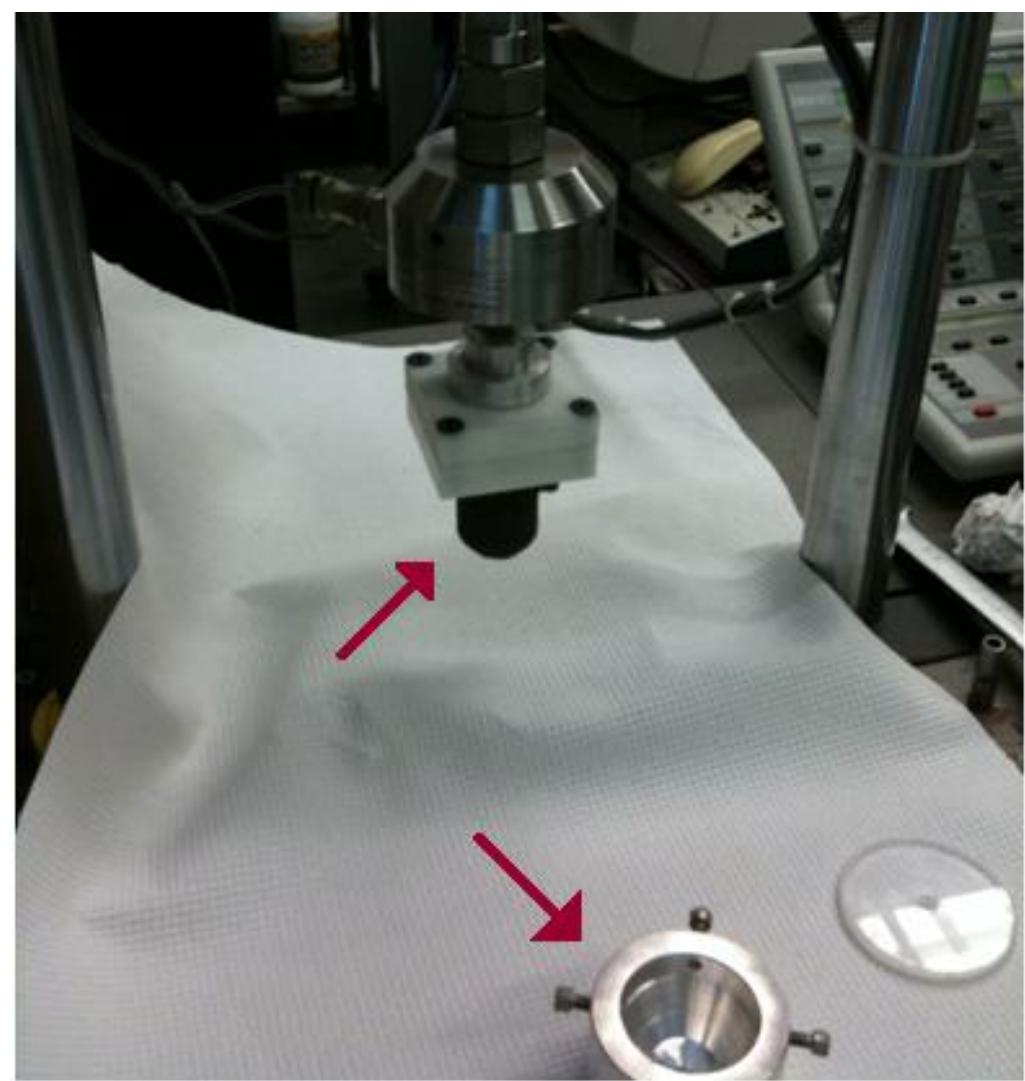

Figure 13. The Instron testing machine shown with a foam cylinder (top arrow) and the implant holding fixture (bottom arrow) used for implantation 
It is important to note that implants were filled with PMMA with the cup upside down and the foam was implanted down onto the implant. This is the only significant alteration to the clinical procedure. This was done to ensure the full volume of PMMA remained inside the seating area. The complete protocol used for implantation can be found in the Appendix C.

\section{Cross-sections}

Foam bone and implant model specimen (see figure 14) were prepared for analysis by cutting two perpendicular, longitudinal cross-sections of each unit. A holding fixture was designed using Solidworks and built on the Objet rapid prototyping machine as used before. Each unit was placed into the fixture and cut consistently into quarters. Slices were made with a 1/32 inch band saw. Three sizes of fixtures were needed for the three different sizes of implants. Photos of each cross-section were taken (see figures in Appendix A) for analysis and included a scale for reference. 


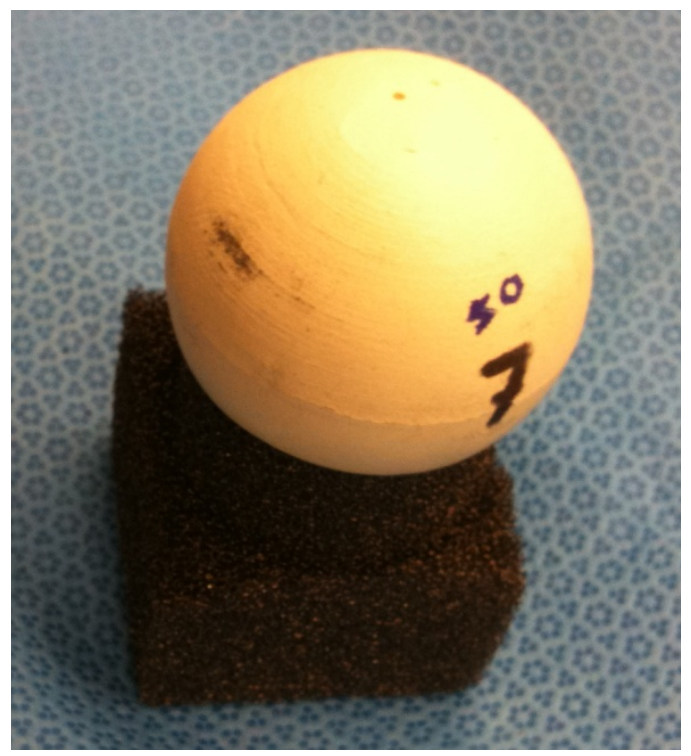

Figure 14. A implant model and foam cylinder specimen after implantation and ready for cross sections.

\section{Analysis}

Using the cross-sectional images, ImageJ (public domain, National Institutes of Health) was used to take surfaces measurements of cement penetration at multiple areas of interest on all specimens. This follows a similar method to that of a study that looked at cement-bone interface analysis after hip resurfacing arthroplasty to quantify cement penetration (Krause, Breer et al. 2009).

Specimens were analyzed according to their depth of cement penetration at three regions, according to average depth of penetration, and the area of cement penetration on both sides of the stem. Each specimen was quartered longitudinally to create eight viewable surfaces per specimen. Of the eight cut surfaces, four are unique and were labeled A, B, C, and D. 


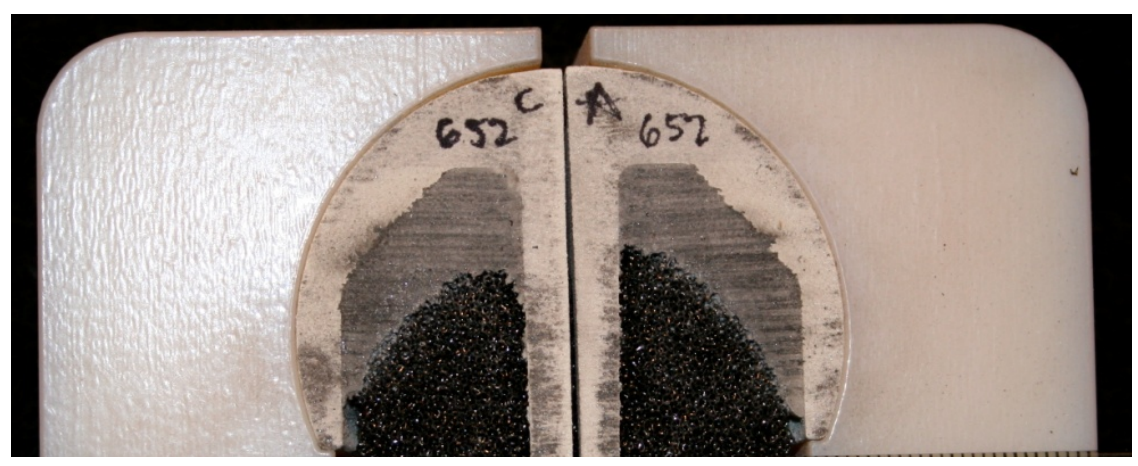

Figure 15. Cross sectional view of an implant specimen with added measurement template markings.

Each digital photograph (see figure 15) of the surfaces was processed using Adobe Photoshop (Adobe Systems Incorporated, San Jose, California) to layer a measurement template on top of the image. For each photo, a ruler in the image was used to set the scale of that image in pixels per millimeter. Measurements were taken using ImageJ at nine lengths of interest and one cross-sectional area as seen in figure 16 and explained in table 1. All values were recorded in millimeters or square millimeters. 


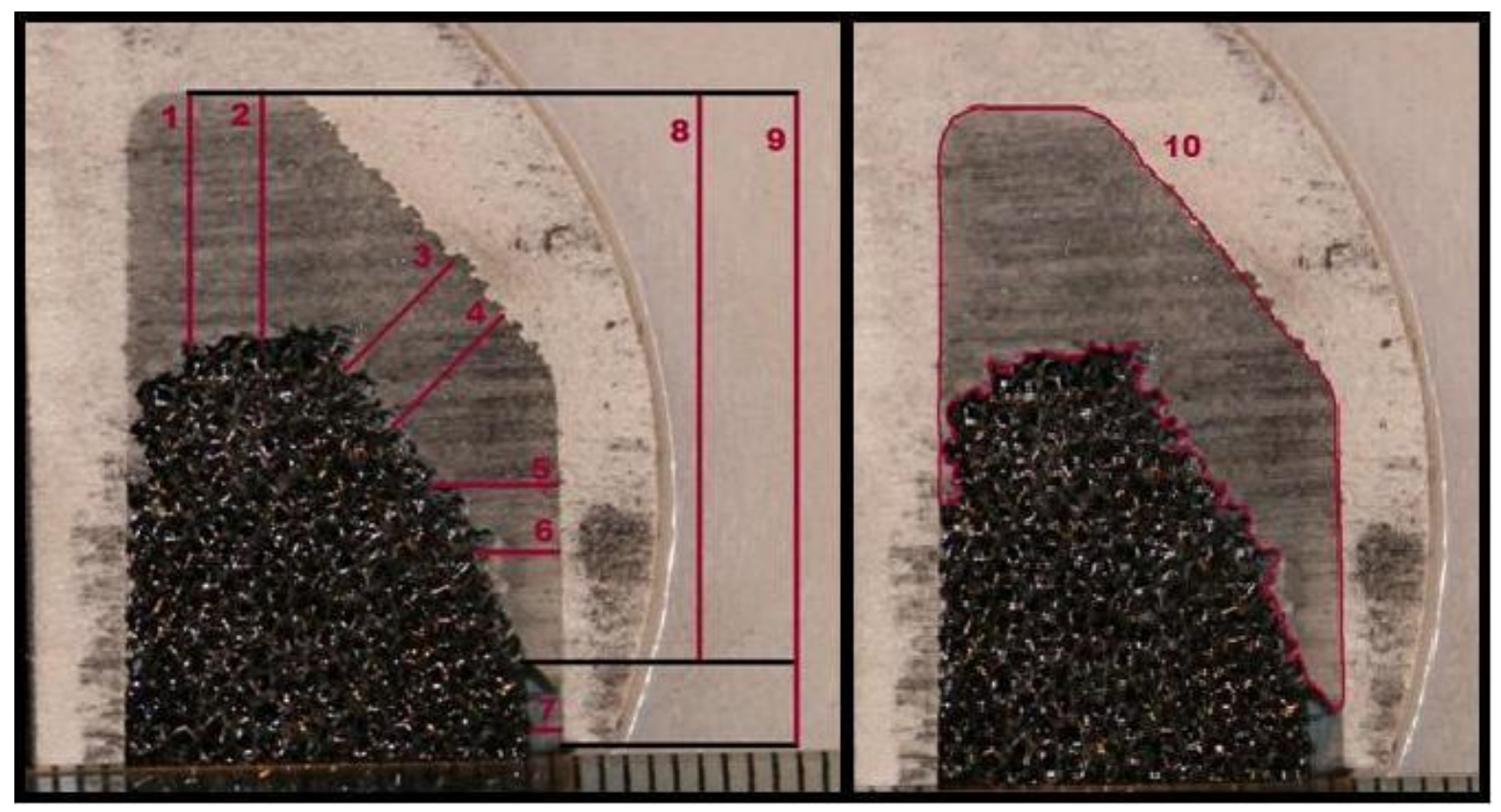

Figure 16. Cross sectional view of implant models implanted onto foam. Red markings (left) show lengths measured numbered 1 through 9 to quantify cement penetration. Red outline (right) shows cement area of penetration.

Table 1. Data collected as ten measurements taken for each unique surface.

\begin{tabular}{|c|l|}
\hline Measurement \# & \multicolumn{1}{c|}{ Description } \\
\hline 1 & Cement penetration from dome (1) \\
\hline 2 & Cement penetration from dome (2) \\
\hline 3 & Cement penetration from chamfer (superior) \\
\hline 4 & Cement penetration from chamfer (inferior) \\
\hline 5 & Cement penetration from wall (superior) \\
\hline 6 & Cement penetration from wall (inferior) \\
\hline 7 & Actual offset at wall \\
\hline 8 & Actual cement penetration height \\
\hline 9 & Maximum cement penetration height \\
\hline 10 & Cross-sectional area of penetrated cement \\
\hline
\end{tabular}

Measurements 1-6 are cement penetrations measured from the edge of the implant perpendicular to the edge of the visible cement. Measurement 7 was the observable gap from foam to implant. This measurement was used to validate the variable implant size to effectively change the reamer-femoral component off set. Measurement 8 was the vertical distance from the proximal 
dome line to the most distal region of cement penetration into foam.

Measurement 9 was the same for each size of implant and used as the control to compare the actual penetration height. Measurement 10 was the cross-sectional area of penetrated cemented. All raw data can be found in Appendix B.

Other data was calculated from these measurements and are recorded in Appendix B. Measurement $5 \mathrm{a}$ is the differences of measurement 7 subtracted from measurement 5 . Measurement $6 \mathrm{a}$ is the differences of measurement 7 subtracted from measurement 6 . Measurement 8 a was recorded as the percentage of actual penetration height (measurement 8) over the penetration height maximum (measurement 9) for that size implant. Measurement 10a indicates the cement area percentage and was measured as the area of cement penetration as seen on the cross sectional surfaces of the implants as a percentage of the total area penetration possible for that size implant.

\section{Statistical Analysis}

Statistical analysis was performed using Minitab. A general linear model was used to perform an analysis of variance and a follow up post hoc Tukey test was performed when appropriate (see Appendix D). Significance was defined as $\mathrm{p}<0.05$. Data was modeled according to the outside diameter of the implant which implies the caused offset. The analysis of variance was performed on all ten measurements listed in table 1 and the calculated measurements $5 a, 6 a, 8 a$, and 10a. 


\section{RESULTS}

Six implants were created in three sizes $(50,51$, and $52 \mathrm{~mm})$ measured at the interior diameter. Each implant was implanted onto a $50 \mathrm{~mm}$ outside diameter foam cylinder that models the trabecular bone of the femoral head to create a specimen. Each of the 18 specimens was quartered longitudinally yielding the cross sections of four unique surfaces. On each unique surface, digital photographs were used and measurements were taken as 9 unique lengths and one area. These measurements were further explained in the methods section of this paper and can be found in detail in table 1 .

Unique surface were referred to by their size, specimen, and face according to this format: (size $50,51,52)$.(specimen 1-6).(face letter A-D). All the images show the interior surfaces of the resurfacing models implanted onto foam with PMMA and can be found in Appendix A.

The complete set of data can be found in the tables in Appendix B with an accompanying table (table 27, Appendix B) to assign descriptions to each measurement.

Cement penetration on the wall was sometimes nonexistent, and a value of zero was recorded for measurements 5 or 6 . The occurrence of zero penetration was also dependent on measurement 8a. When the height percentage was less than $70 \%$, measurement 6 was zero by definition. Seventypercent represents the average distance that lies half way down from the chamfer-wall intersection. At less than $70 \%$ penetration height it was assumed that the penetration at the wall was insignificant. 
In the following data, box plots are presented for each measurement. They show the lower quartile, median, and upper quartile, in the shaded regions. The sample minimum and sample maximum are represented by the vertical error lines. Asterisks represent the sample outliers, which Minitab excludes to adjust the standard deviation. Each box plot is followed by a data table with the values of the sample size, mean, standard deviation, median, minimum, and maximum.

\section{Cement Penetration from the Dome}

Measurement 1 was measured as the depth of cement penetration from the dome's edge in the location closer to the implant's stem. The values for this data are presented in figure 17 and table 2. The mean distance for implant size 50 was $13.538 \mathrm{~mm}$. The mean distance for implant size 51 was $11.763 \mathrm{~mm}$.

The mean distance for implant size 52 was $10.170 \mathrm{~mm}$.

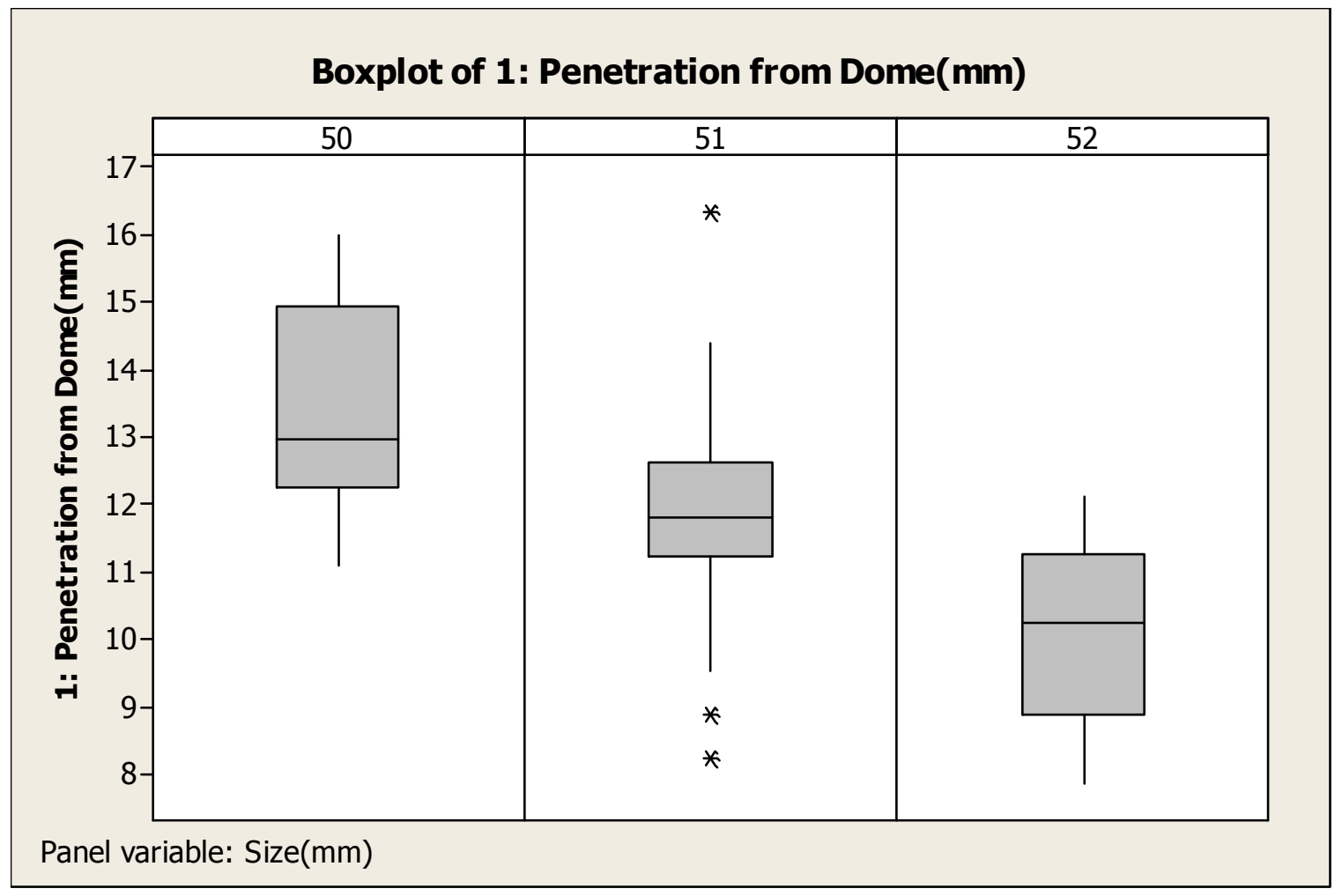


Figure 17. Boxplot comparing measurement 1 of all three implant sizes

Table 2. Data values comparing measurement 1 of all three implant sizes

\begin{tabular}{|c|c|c|c|c|c|c|}
\hline Size & $\mathbf{N}$ & Mean & StDev & Median & Minimum & Maximum \\
\hline $\mathbf{5 0}$ & 24 & 13.538 & 1.567 & 12.965 & 11.078 & 16.011 \\
\hline $\mathbf{5 1}$ & 24 & 11.763 & 1.754 & 11.822 & 8.237 & 16.358 \\
\hline $\mathbf{5 2}$ & 24 & 10.170 & 1.331 & 10.224 & 7.853 & 12.105 \\
\hline
\end{tabular}

An analysis of variance (ANOVA) was performed on the set of data to determine statistical significance (table 3). A Tukey's 95\% confidence interval test was performed to compare the means of all three populations of measurement 1. The cement penetration depth from the dome (measurement 1) was found to be significantly greater for the $50 \mathrm{~mm}$ implant compared to both the $51 \mathrm{~mm}(\mathrm{p}=0.0006)$ and $52 \mathrm{~mm}(\mathrm{p}=0.0000)$ implants. In addition, the $51 \mathrm{~mm}$ implant was found to have significantly more penetration than the $52 \mathrm{~mm}$ implant $(p=0,0021)$. Therefore, it can be concluded that implant size significantly affects the depth of penetration from the dome at measurement 1 .

Table 3. Tukey's 95\% confidence interval ANOVA test of measurement 1

\begin{tabular}{|c|c|c|}
\hline Size $(\mathbf{m m})$ & Versus Size $(\mathbf{m m})$ & P- value \\
\hline $\mathbf{5 0}$ & $\mathbf{5 1}$ & 0.0006 \\
\hline $\mathbf{5 0}$ & $\mathbf{5 2}$ & 0.0000 \\
\hline $\mathbf{5 1}$ & $\mathbf{5 2}$ & 0.0021 \\
\hline
\end{tabular}

Measurement 2 was the depth of cement penetration from the dome's edge in the location further from the implant's stem. The values for these data 
are presented in figure 18 and table 4 . The mean distance for implant size 50 was $13.342 \mathrm{~mm}$. The mean distance for implant size 51 was $11.459 \mathrm{~mm}$. The mean distance for implant size 52 was $9.849 \mathrm{~mm}$.

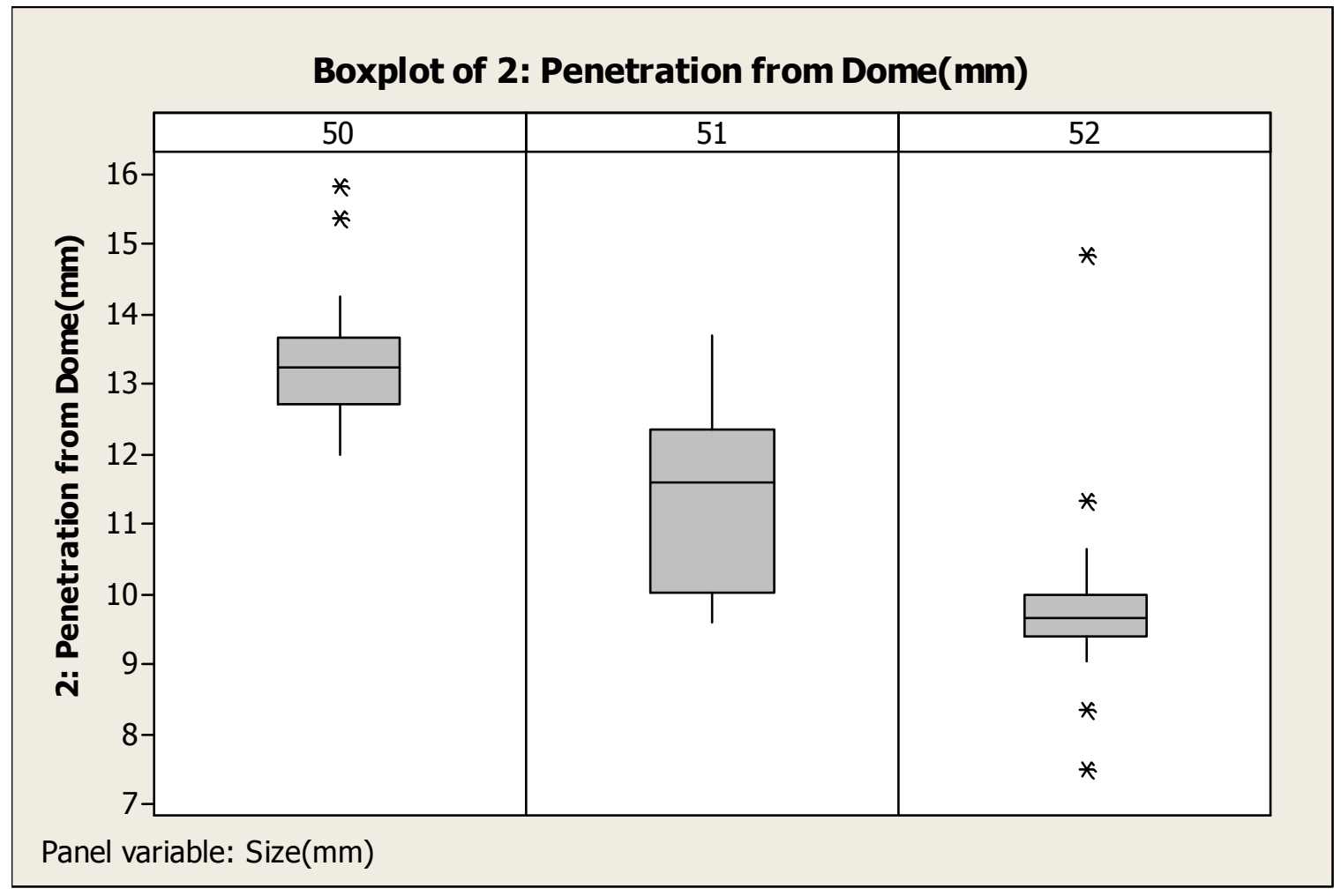

Figure 18. Boxplot comparing measurement 2 of all three implant sizes

Table 4. Data values comparing measurement 2 of all three implant sizes

\begin{tabular}{|c|c|c|c|c|c|c|}
\hline Size & $\mathbf{N}$ & Mean & StDev & Median & Minimum & Maximum \\
\hline $\mathbf{5 0}$ & 24 & 13.341 & 0.879 & 13.233 & 11.974 & 15.825 \\
\hline $\mathbf{5 1}$ & 24 & 11.458 & 1.253 & 11.605 & 9.576 & 13.681 \\
\hline $\mathbf{5 2}$ & 24 & 9.849 & 1.292 & 9.658 & 7.496 & 14.828 \\
\hline
\end{tabular}

An analysis of variance (ANOVA) was performed on the set of data for measurement 2 to determine statistical significance and is presented in table 5 . A Tukey's $95 \%$ confidence interval test was performed to compare the means of 
all three populations of measurement two. Tukey's comparison of means for implant size 50 and implant size 51, 50 and 52, and 51 and 52 all resulted in a pvalue of 0.0000 indicating that all were significantly different. The cement penetration at the dome for size 50 was significantly greater than size 51 and 52 , and size 51 was significantly greater than size 52 . Therefore, it can be concluded that implant size significantly affects the depth of penetration from the dome at measurement 2.

Table 5. Tukey's 95\% confidence interval ANOVA test of measurement 2

\begin{tabular}{|c|c|c|}
\hline Size $(\mathbf{m m})$ & Versus Size $(\mathbf{m m})$ & P- value \\
\hline $\mathbf{5 0}$ & $\mathbf{5 1}$ & 0.0000 \\
\hline $\mathbf{5 0}$ & $\mathbf{5 2}$ & 0.0000 \\
\hline $\mathbf{5 1}$ & $\mathbf{5 2}$ & 0.0000 \\
\hline
\end{tabular}

\section{Cement Penetration from the Chamfer}

Measurement 3 was measured as the depth of cement penetration from the chamfer's edge in the more proximal location. The values for this data are presented in figure 19 and table 6 . The mean distance for implant size 50 was $9.266 \mathrm{~mm}$. The mean distance for implant size 51 was $8.349 \mathrm{~mm}$. The mean distance for implant size 52 was $6.863 \mathrm{~mm}$. 


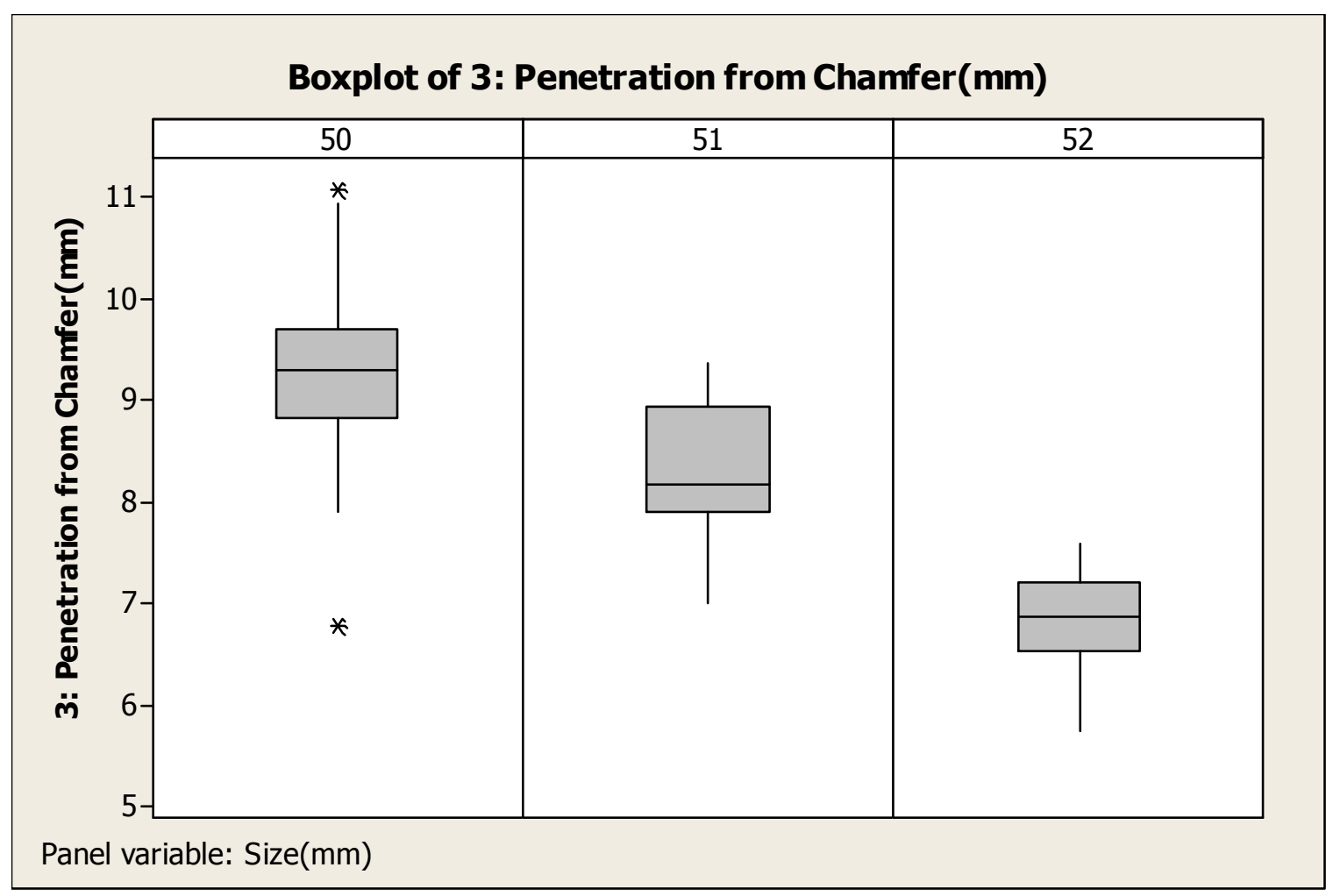

Figure 19. Boxplot comparing measurement 3 of all three implant sizes

Table 6. Data values comparing measurement 3 of all three implant sizes

\begin{tabular}{|c|c|c|c|c|c|c|}
\hline Size & $\mathbf{N}$ & Mean & StDev & Median & Minimum & Maximum \\
\hline $\mathbf{5 0}$ & $\mathbf{2 4}$ & 9.262 & 0.885 & 9.305 & 6.782 & 11.070 \\
\hline $\mathbf{5 1}$ & $\mathbf{2 4}$ & 8.349 & 0.702 & 8.167 & 7.002 & 9.367 \\
\hline $\mathbf{5 2}$ & $\mathbf{2 4}$ & 6.863 & 0.497 & 6.877 & 5.750 & 7.597 \\
\hline
\end{tabular}

An analysis of variance (ANOVA) was performed on the set of data for measurement 3 to determine statistical significance and is presented in table 7. A Tukey's 95\% confidence interval test was performed to compare the means of all three populations of measurement 3 . The cement penetration depth from the dome (measurement 3) was found to be significantly greater for the $50 \mathrm{~mm}$ implant compared to both the $51 \mathrm{~mm}(\mathrm{p}=0.0001)$ and $52 \mathrm{~mm}(\mathrm{p}=0.0000)$ 
implants. In addition, the $51 \mathrm{~mm}$ implant was found to have significantly more penetration than the $52 \mathrm{~mm}$ implant $(\mathrm{p}=0.0000)$. Therefore, it can be concluded that implant size significantly affects the depth of penetration measured from the chamfer at measurement 3.

Table 7. Tukey's $95 \%$ confidence interval ANOVA test of measurement 3

\begin{tabular}{|c|c|c|}
\hline Size $(\mathbf{m m})$ & Versus Size $(\mathbf{m m})$ & P- value \\
\hline $\mathbf{5 0}$ & $\mathbf{5 1}$ & 0.0001 \\
\hline $\mathbf{5 0}$ & $\mathbf{5 2}$ & 0.0000 \\
\hline $\mathbf{5 1}$ & $\mathbf{5 2}$ & 0.0000 \\
\hline
\end{tabular}

Measurement 4 was measured as the depth of cement penetration from the chamfer's edge in the more distal location. The values for this data are presented in figure 20 and table 8 . The mean distance for implant size 50 was $8.237 \mathrm{~mm}$. The mean distance for implant size 51 was $7.415 \mathrm{~mm}$. The mean distance for implant size 52 was $6.375 \mathrm{~mm}$. 


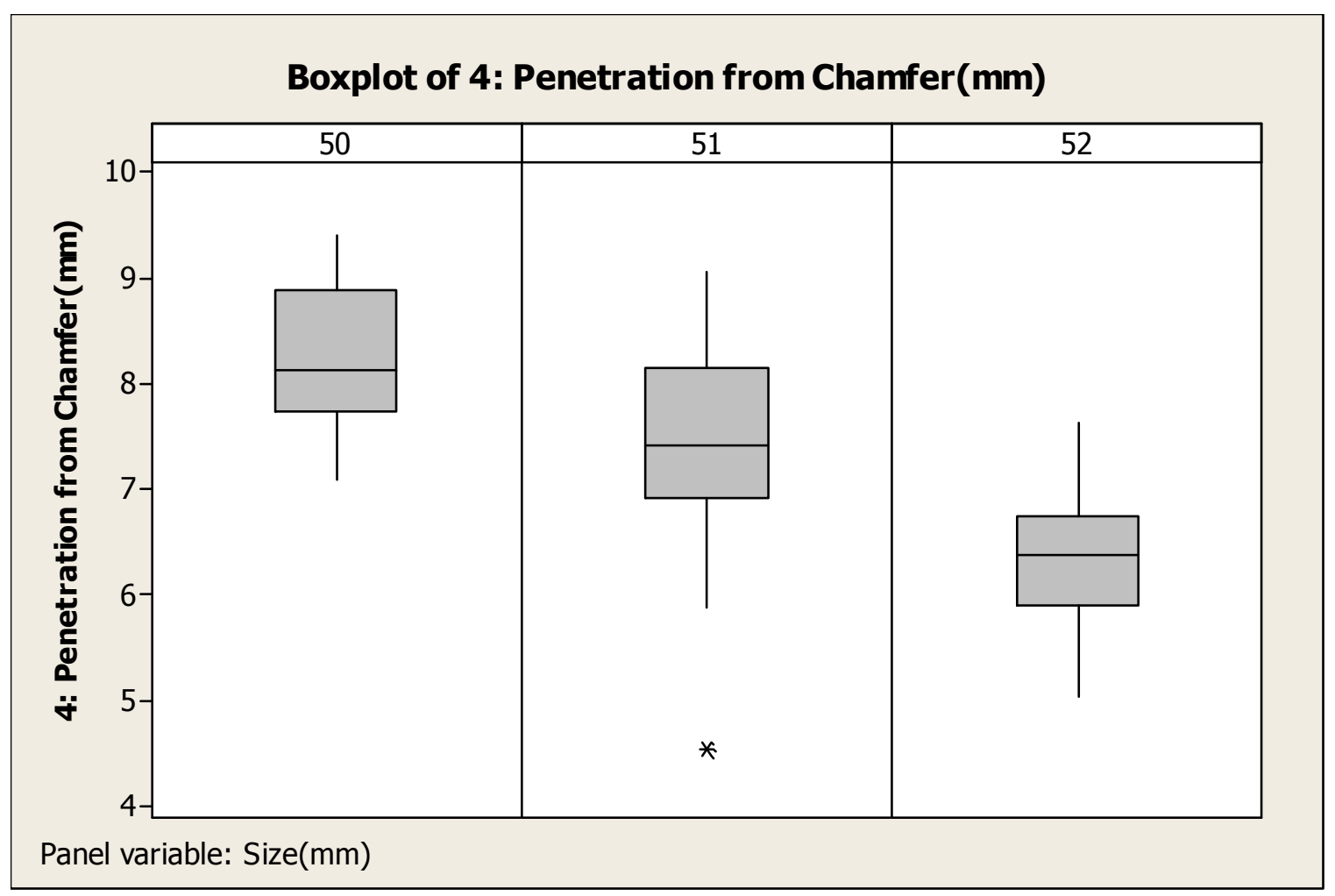

Figure 20. Boxplot comparing measurement 4 of all three implant sizes

Table 8. Data values comparing measurement 4 of all three implant sizes

\begin{tabular}{|c|c|c|c|c|c|c|}
\hline Size & $\mathbf{N}$ & Mean & StDev & Median & Minimum & Maximum \\
\hline $\mathbf{5 0}$ & $\mathbf{2 4}$ & 8.237 & 0.678 & 8.135 & 7.084 & 9.398 \\
\hline $\mathbf{5 1}$ & $\mathbf{2 4}$ & 7.415 & 1.063 & 7.428 & 4.547 & 9.062 \\
\hline $\mathbf{5 2}$ & $\mathbf{2 4}$ & 6.375 & 0.609 & 6.392 & 5.040 & 7.639 \\
\hline
\end{tabular}

An analysis of variance (ANOVA) was performed on the set of data to determine statistical significance and is presented in table 9. A Tukey's 95\% confidence interval test was performed to compare the means of all three populations of measurement 4 . The cement penetration depth from the dome (measurement 4) was found to be significantly greater for the $50 \mathrm{~mm}$ implant compared to both the $51 \mathrm{~mm}(\mathrm{p}=0.0022)$ and $52 \mathrm{~mm}(\mathrm{p}=0.0000)$ implants. In 
addition, the $51 \mathrm{~mm}$ implant was found to have significantly more penetration than the $52 \mathrm{~mm}$ implant $(p=0.0001)$. Therefore, it can be concluded that implant size significantly affects the depth of penetration from the chamfer at measurement 4 .

Table 9. Tukey's 95\% confidence interval ANOVA test of measurement 4

\begin{tabular}{|c|c|c|}
\hline Size $(\mathbf{m m})$ & Versus Size $(\mathbf{m m})$ & P- value \\
\hline $\mathbf{5 0}$ & $\mathbf{5 1}$ & 0.0022 \\
\hline $\mathbf{5 0}$ & $\mathbf{5 2}$ & 0.0000 \\
\hline $\mathbf{5 1}$ & $\mathbf{5 2}$ & 0.0001 \\
\hline
\end{tabular}

\section{Cement Penetration from the Wall}

Measurement 5 was measured as the depth of cement penetration from the wall's edge in the more superior location. The values for this data are presented in figure 21 and table 10 . The mean distance for implant size 50 was $4.737 \mathrm{~mm}$. The mean distance for implant size 51 was $5.015 \mathrm{~mm}$. The mean distance for implant size 52 was $4.629 \mathrm{~mm}$. 


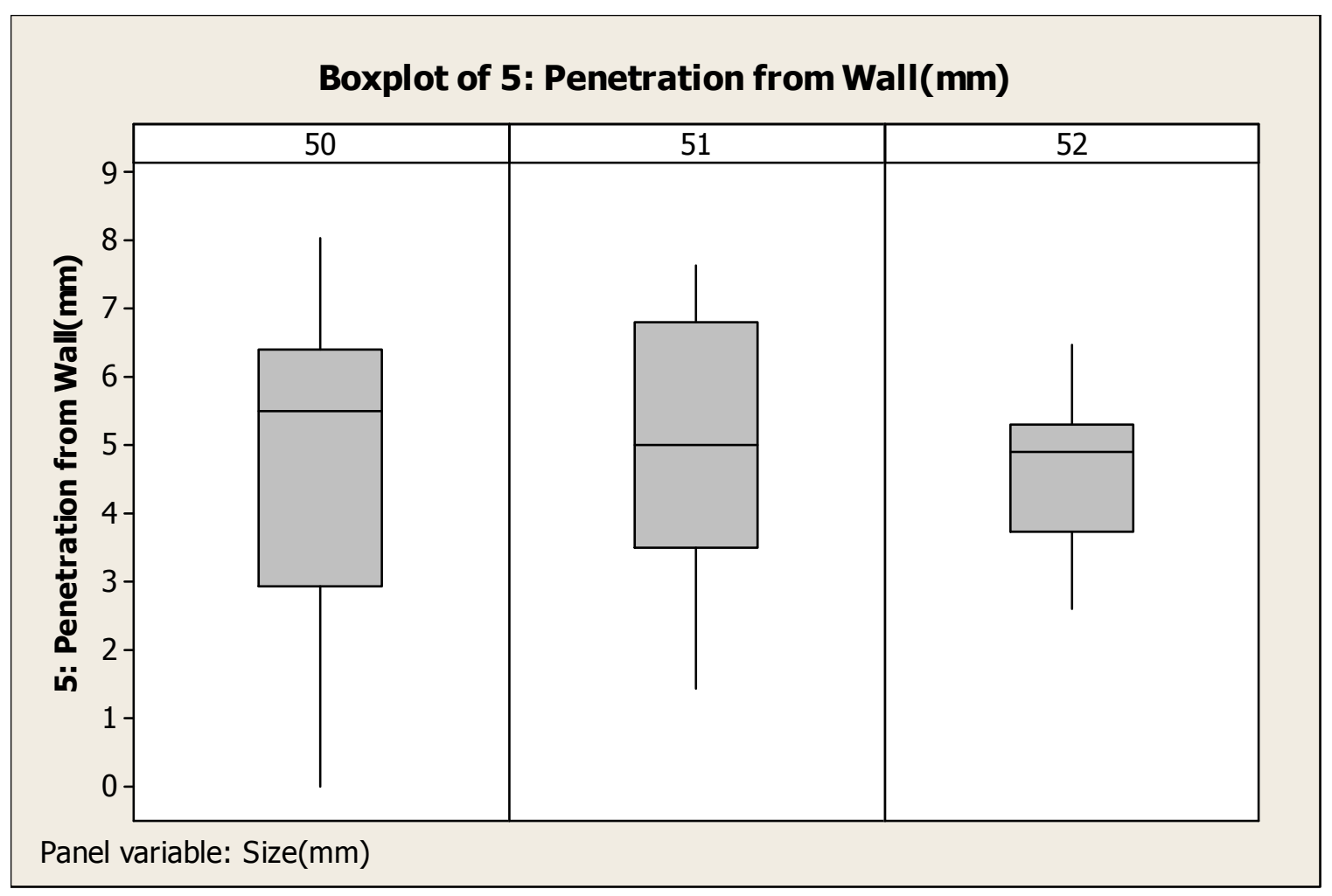

Figure 21. Boxplot comparing measurement 5 of all three implant sizes

Table 10. Data values comparing measurement 5 of all three implant sizes

\begin{tabular}{|c|c|c|c|c|c|c|}
\hline Size & $\mathbf{N}$ & Mean & StDev & Median & Minimum & Maximum \\
\hline $\mathbf{5 0}$ & 24 & 4.736 & 2.451 & 5.513 & 0.000 & 8.042 \\
\hline $\mathbf{5 1}$ & 24 & 5.015 & 1.833 & 4.994 & 1.436 & 7.635 \\
\hline $\mathbf{5 2}$ & $\mathbf{2 4}$ & 4.629 & 1.033 & 4.909 & 2.579 & 6.475 \\
\hline
\end{tabular}

An analysis of variance (ANOVA) was performed on the set of data to determine statistical significance and is presented in table 11. A Tukey's $95 \%$ confidence interval test was performed to compare the means of all three populations of measurement 5 . It was found that the cement penetration from the wall of measurement 5 was not statistically different for the $50 \mathrm{~mm}$ implant 
compared to the $51 \mathrm{~mm}$ implant $(\mathrm{p}=0.8626)$ or the $52 \mathrm{~mm}$ implant $(\mathrm{p}=0.9784)$. Also, the penetration from the wall was not significantly different between the 51 $\mathrm{mm}$ and $52 \mathrm{~mm}$ implants $(\mathrm{p}=0.7541)$. Therefore, the results of this study suggest that implant size does not significantly affect the depth of penetration at the superior portion of the wall.

Table 11. Tukey's 95\% confidence interval ANOVA test of measurement 5

\begin{tabular}{|c|c|c|}
\hline Size $(\mathbf{m m})$ & Versus Size $(\mathbf{m m})$ & P- value \\
\hline $\mathbf{5 0}$ & $\mathbf{5 1}$ & 0.8626 \\
\hline $\mathbf{5 0}$ & $\mathbf{5 2}$ & 0.9784 \\
\hline $\mathbf{5 1}$ & $\mathbf{5 2}$ & 0.7541 \\
\hline
\end{tabular}

Measurement 5a was calculated as the depth of cement penetration from the wall's edge in the more superior location (measurement 5) minus the actual implant offset (measurement 7). The value represents the depth of cement penetration into the foam structure relative to the surface of the cylinder. The values for this data are presented in figure 22 and table 12 . The mean distance for implant size 50 was $4.458 \mathrm{~mm}$. The mean distance for implant size 51 was $4.310 \mathrm{~mm}$. The mean distance for implant size 52 was $3.323 \mathrm{~mm}$. 


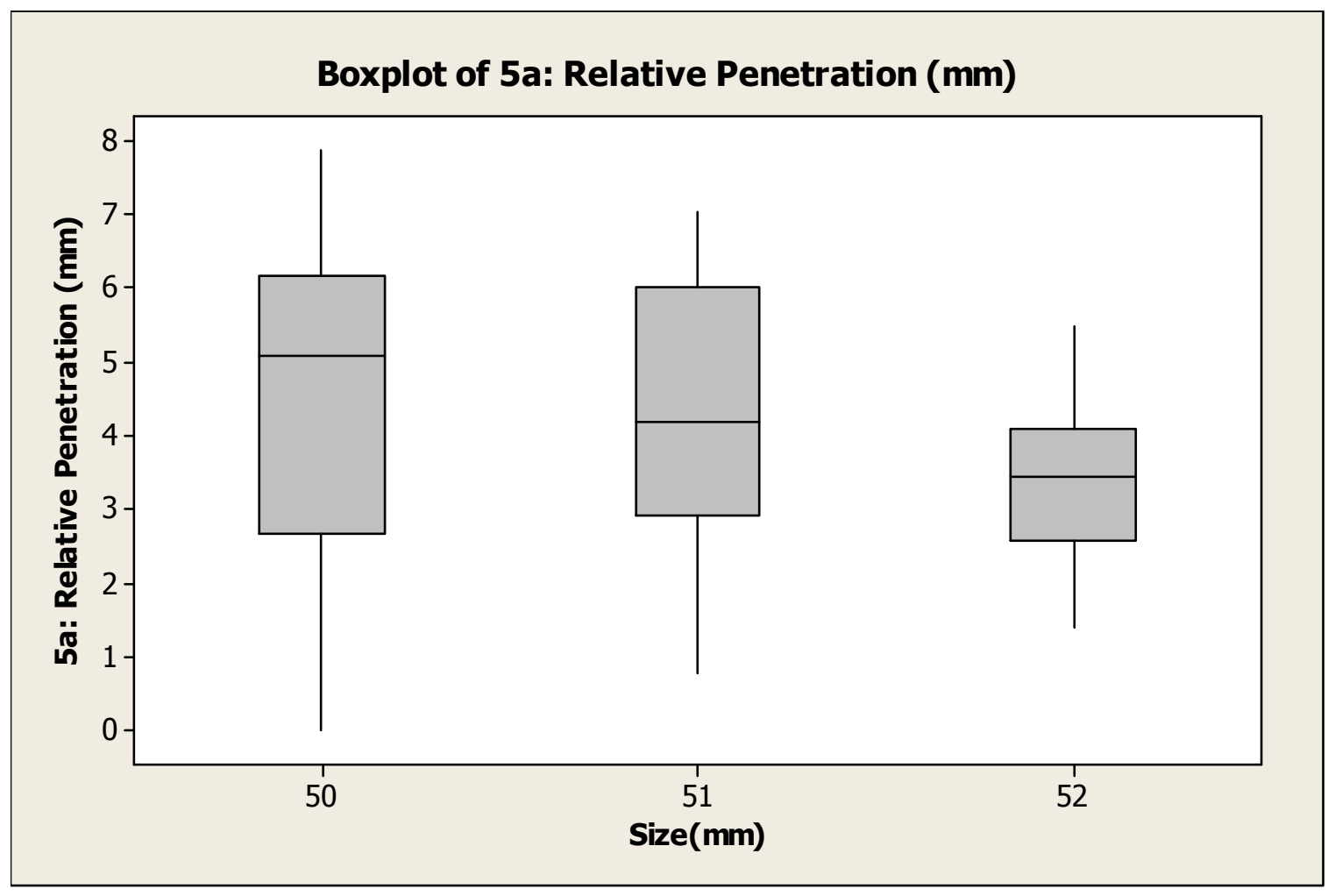

Figure 22. Boxplot comparing relative penetration (5a) of all three implant sizes

Table 12. Data values comparing relative penetration (5a) of all three implant sizes

\begin{tabular}{|c|c|c|c|c|c|c|}
\hline Size & $\mathbf{N}$ & Mean & StDev & Median & Minimum & Maximum \\
\hline $\mathbf{5 0}$ & 24 & 4.458 & 2.362 & 5.085 & 0.000 & 7.852 \\
\hline $\mathbf{5 1}$ & 24 & 4.310 & 1.819 & 4.167 & 0.777 & 7.013 \\
\hline $\mathbf{5 2}$ & $\mathbf{2 4}$ & 3.323 & 1.033 & 3.419 & 1.392 & 5.482 \\
\hline
\end{tabular}

An analysis of variance (ANOVA) was performed on the set of data to determine statistical significance and is presented in table 13. A Tukey's $95 \%$ confidence interval test was performed to compare the means of all three populations of measurement $5 \mathrm{a}$. It was found that the cement penetration from the surface of the foam cylinder was not statistically different for the $50 \mathrm{~mm}$ implant compared to the $51 \mathrm{~mm}$ implant $(\mathrm{p}=0.9576)$ or the $52 \mathrm{~mm}$ implant 
$(p=0.0858)$. Also, the penetration from the surface of the foam was not significantly different between the $51 \mathrm{~mm}$ and $52 \mathrm{~mm}$ implants $(\mathrm{p}=0.1528)$.

Therefore, the results of this study suggest that implant size does not significantly affect the depth of penetration at the superior portion of the surface of the foam cylinder.

Table 13. Tukey's 95\% confidence interval ANOVA test of relative penetration (5a)

\begin{tabular}{|c|c|c|}
\hline Size $(\mathbf{m m})$ & Versus Size $(\mathbf{m m})$ & P- value \\
\hline $\mathbf{5 0}$ & $\mathbf{5 1}$ & 0.9576 \\
\hline $\mathbf{5 0}$ & $\mathbf{5 2}$ & 0.0858 \\
\hline $\mathbf{5 1}$ & $\mathbf{5 2}$ & 0.1528 \\
\hline
\end{tabular}

Measurement 6 was measured as the depth of cement penetration from the wall's edge in the more inferior location. The values for this data are presented in figure 23 and table 14 . The mean distance for implant size 50 was $0.472 \mathrm{~mm}$. The mean distance for implant size 51 was $1.396 \mathrm{~mm}$. The mean distance for implant size 52 was $2.871 \mathrm{~mm}$. 


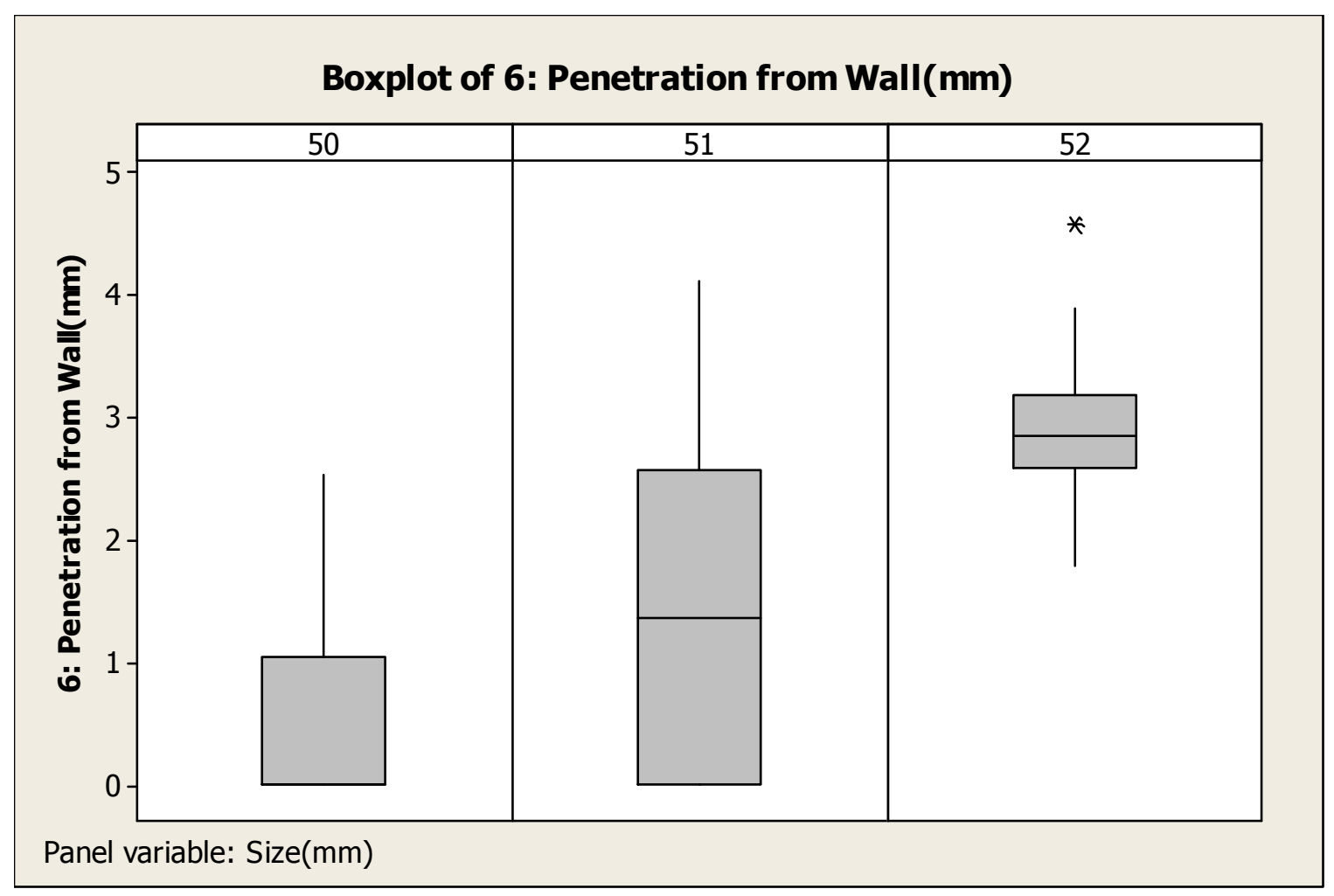

Figure 23. Boxplot comparing measurement 6 of all three implant sizes

Table 14. Data values comparing measurement 6 of all three implant sizes

\begin{tabular}{|c|c|c|c|c|c|c|}
\hline Size & $\mathbf{N}$ & Mean & StDev & Median & Minimum & Maximum \\
\hline $\mathbf{5 0}$ & 24 & 0.427 & 0.705 & 0.000 & 0.000 & 2.540 \\
\hline $\mathbf{5 1}$ & 24 & 1.395 & 1.343 & 1.359 & 0.000 & 4.128 \\
\hline $\mathbf{5 2}$ & 24 & 2.870 & 0.648 & 2.846 & 1.788 & 4.576 \\
\hline
\end{tabular}

An analysis of variance (ANOVA) was performed on the set of data for measurement 6 to determine statistical significance and is presented in table 15 . A Tukey's 95\% confidence interval test was performed to compare the means of all three populations of measurement 6 . The cement penetration depth from the dome (measurement 6) was found to be significantly less for the $50 \mathrm{~mm}$ implant 
compared to both the $51 \mathrm{~mm}(\mathrm{p}=0.0022)$ and $52 \mathrm{~mm}(\mathrm{p}=0.0000)$ implants. In addition, the $51 \mathrm{~mm}$ implant was found to have significantly less penetration than the $52 \mathrm{~mm}$ implant $(\mathrm{p}=0.0000)$. Therefore, it can be concluded that implant size significantly affects the depth of penetration measured from the inferior location of the implant wall.

Table 15. Tukey's 95\% confidence interval ANOVA test of measurement 6

\begin{tabular}{|c|c|c|}
\hline Size $(\mathbf{m m})$ & Versus Size $(\mathbf{m m})$ & P- value \\
\hline $\mathbf{5 0}$ & $\mathbf{5 1}$ & 0.0022 \\
\hline $\mathbf{5 0}$ & $\mathbf{5 2}$ & 0.0000 \\
\hline $\mathbf{5 1}$ & $\mathbf{5 2}$ & 0.0000 \\
\hline
\end{tabular}

Measurement 6a was calculated as the depth of cement penetration from the wall's edge in the more inferior location (measurement 6) minus the actual implant offset (measurement 7). The value represents the depth of cement penetration into the foam structure relative to the surface of the cylinder. The values for this data are presented in figure 24 and table 16 . The mean distance for implant size 50 was $0.294 \mathrm{~mm}$. The mean distance for implant size 51 was $0.939 \mathrm{~mm}$. The mean distance for implant size 52 was $1.564 \mathrm{~mm}$. 


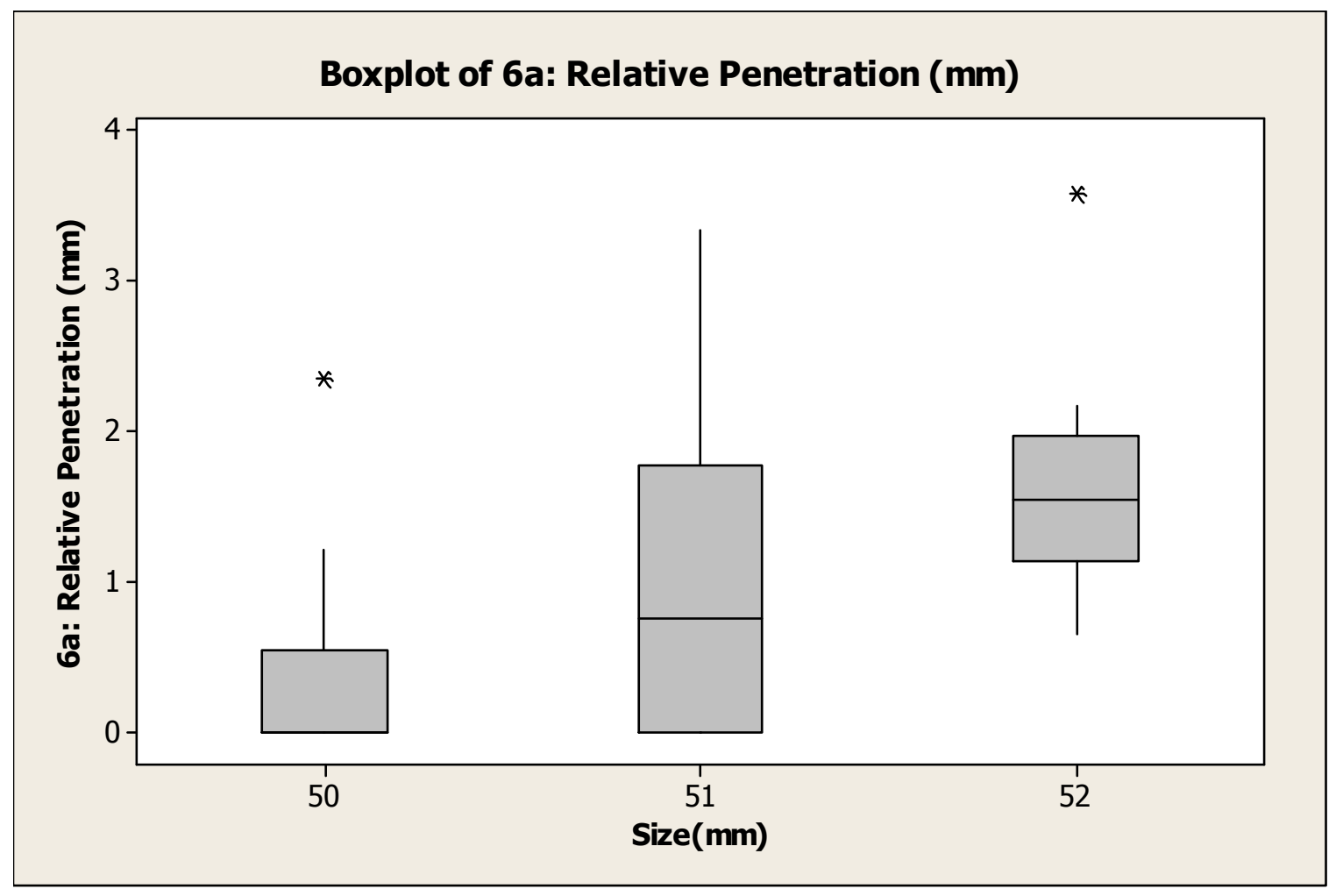

Figure 24. Boxplot comparing relative penetration (6a) of all three implant sizes

Table 16. Data values comparing relative penetration (6a) of all three implant sizes

\begin{tabular}{|c|c|c|c|c|c|c|}
\hline Size & $\mathbf{N}$ & Mean & StDev & Median & Minimum & Maximum \\
\hline $\mathbf{5 0}$ & 24 & 0.294 & 0.563 & 0.000 & 0.000 & 2.350 \\
\hline $\mathbf{5 1}$ & 24 & 0.939 & 0.985 & 0.761 & 0.000 & 3.347 \\
\hline $\mathbf{5 2}$ & 24 & 1.564 & 0.631 & 1.545 & 0.645 & 3.583 \\
\hline
\end{tabular}

An analysis of variance (ANOVA) was performed on the set of data to determine statistical significance and is presented in table 17. A Tukey's $95 \%$ confidence interval test was performed to compare the means of all three populations of measurement $6 \mathrm{a}$. It was found that the cement penetration from 
the surface of the foam cylinder was significantly less for the $50 \mathrm{~mm}$ implant compared to both the $51 \mathrm{~mm}(\mathrm{p}=0.0110)$ and $52 \mathrm{~mm}(\mathrm{p}=0.0000)$ implants. In addition, the $51 \mathrm{~mm}$ implant was found to have significantly less penetration than the $52 \mathrm{~mm}$ implant $(\mathrm{p}=0.0141)$. Therefore, it can be concluded that implant size significantly affects the depth of cement penetration from the inferior portion of the surface on the foam cylinder.

Table 17. Tukey's $95 \%$ confidence interval ANOVA test of relative penetration (6a)

\begin{tabular}{|c|c|c|}
\hline Size $(\mathbf{m m})$ & Versus Size $(\mathbf{m m})$ & P- value \\
\hline $\mathbf{5 0}$ & $\mathbf{5 1}$ & 0.0110 \\
\hline $\mathbf{5 0}$ & $\mathbf{5 2}$ & 0.0000 \\
\hline $\mathbf{5 1}$ & $\mathbf{5 2}$ & 0.0141 \\
\hline
\end{tabular}

\section{Measured Offset}

Measurement 7 was measured as the actual offset between the implant and the foam cylinder. It was expected that the offsets for the $50 \mathrm{~mm}, 51 \mathrm{~mm}$, and $52 \mathrm{~mm}$ implants would be $0.0 \mathrm{~mm}, 0.5 \mathrm{~mm}$, and $1.0 \mathrm{~mm}$ respectively. The values for this data are presented in figure 25 and table 18. The mean distance for implant size 50 was $0.319 \mathrm{~mm}$. The mean distance for implant size 51 was $0.706 \mathrm{~mm}$. The mean distance for implant size 52 was $1.307 \mathrm{~mm}$. 


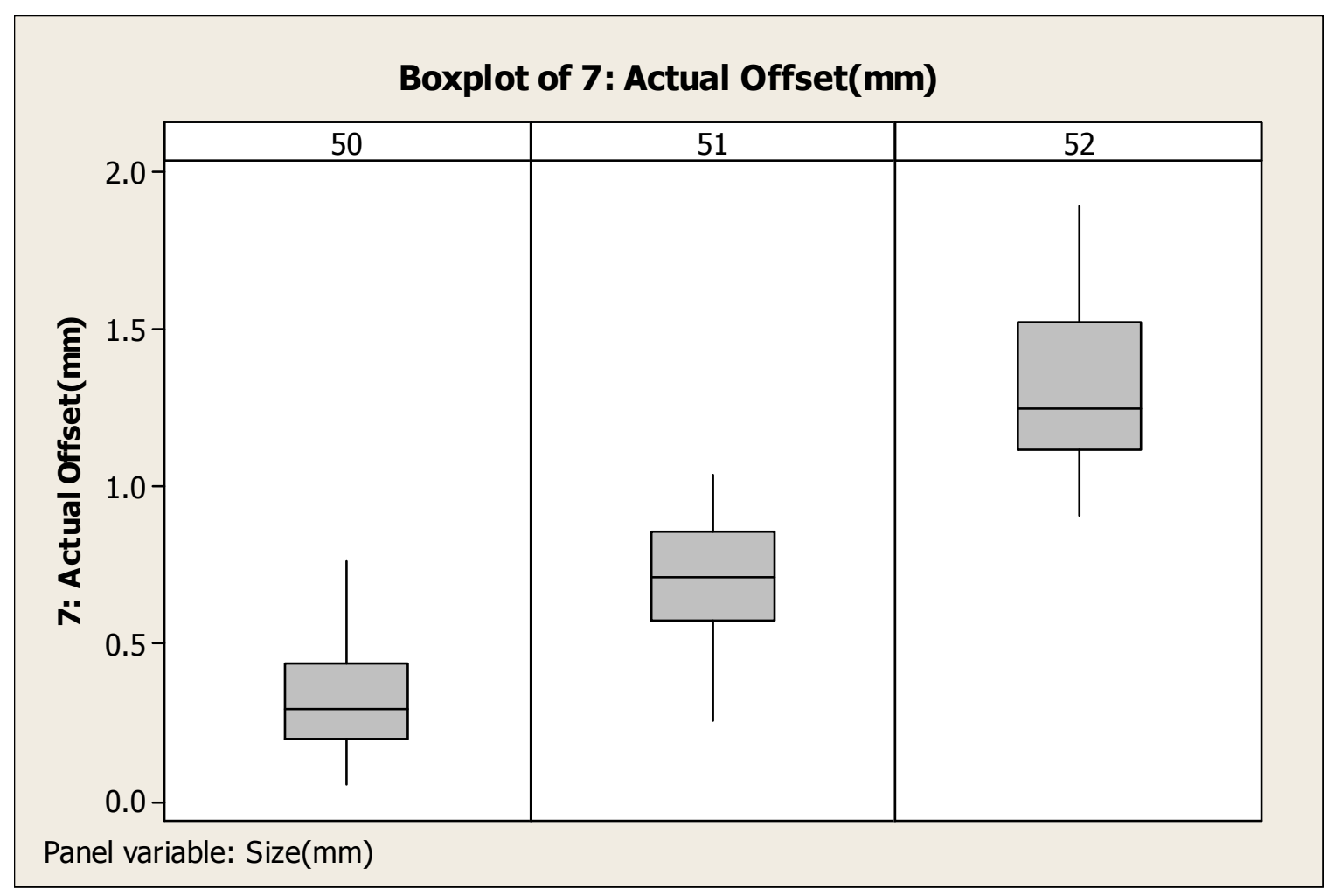

Figure 25. Boxplot comparing measurement 7 of all three implant sizes

Table 18. Data values comparing measurement 7 of all three implant sizes

\begin{tabular}{|c|c|c|c|c|c|c|}
\hline Size & $\mathbf{N}$ & Mean & StDev & Median & Minimum & Maximum \\
\hline $\mathbf{5 0}$ & 24 & 0.318 & 0.1846 & 0.287 & 0.053 & 0.765 \\
\hline $\mathbf{5 1}$ & 24 & 0.705 & 0.1916 & 0.712 & 0.256 & 1.041 \\
\hline $\mathbf{5 2}$ & 24 & 1.306 & 0.2684 & 1.250 & 0.912 & 1.900 \\
\hline
\end{tabular}

An analysis of variance (ANOVA) was performed on the set of data for measurement 7 to determine statistical significance and is presented in table 19 . A Tukey's 95\% confidence interval test was performed to compare the means of all three populations of measurement 7 . It was found that actual offset between the implant and the foam cylinder was significantly smaller for the $50 \mathrm{~mm}$ implant 
compared to both the $51 \mathrm{~mm}(\mathrm{p}=0.0000)$ and $52 \mathrm{~mm}(\mathrm{p}=0.0000)$ implants. In addition, the $51 \mathrm{~mm}$ implant was found to have significantly smaller actual offset than the $52 \mathrm{~mm}$ implant $(p=0.0000)$. Therefore, it can be concluded that implant size significantly affects the actual offset of the implant to the foam cylinder.

This conclusion primarily serves to confirm the methods of this study. The data shows that the plastic femoral component models and reamed foam cylinders effectively model the dimensions and mechanical environment of a hip resurfacing implant.

Table 19. Tukey's $95 \%$ confidence interval ANOVA test of measurement 7

\begin{tabular}{|c|c|c|}
\hline Size $(\mathbf{m m})$ & Versus Size $(\mathbf{m m})$ & P- value \\
\hline $\mathbf{5 0}$ & $\mathbf{5 1}$ & 0.0000 \\
\hline $\mathbf{5 0}$ & $\mathbf{5 2}$ & 0.0000 \\
\hline $\mathbf{5 1}$ & $\mathbf{5 2}$ & 0.0000 \\
\hline
\end{tabular}

\section{Cement Penetration Height}

Measurement 8 was measured as the height of cement penetration from the dome's edge to furthest point down the implant where cement penetrated into the foam. The values for this data are presented in figure 26 and table 20 . The mean cement height for implant size 50 was $18.381 \mathrm{~mm}$. The mean cement height for implant size 51 was $19.529 \mathrm{~mm}$. The mean cement height for implant size 52 was $22.528 \mathrm{~mm}$. 


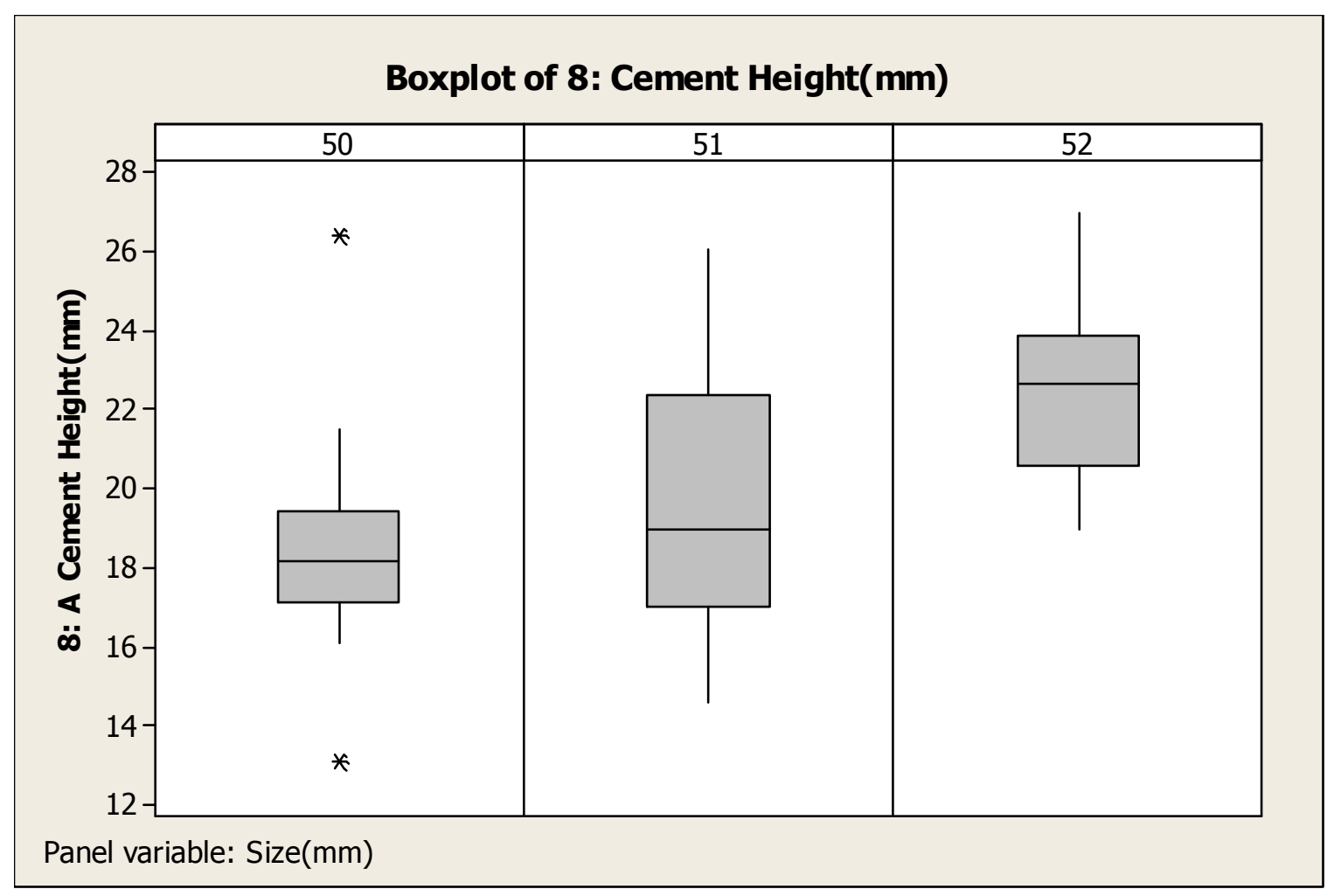

Figure 26. Boxplot comparing measurement 8 of all three implant sizes

Table 20. Data values comparing measurement 8 of all three implant sizes

\begin{tabular}{|c|c|c|c|c|c|c|}
\hline Size & $\mathbf{N}$ & Mean & StDev & Median & Minimum & Maximum \\
\hline $\mathbf{5 0}$ & 24 & 18.380 & 2.424 & 18.165 & 13.125 & 26.416 \\
\hline $\mathbf{5 1}$ & 24 & 19.529 & 3.141 & 18.970 & 14.588 & 26.100 \\
\hline $\mathbf{5 2}$ & 24 & 22.528 & 2.085 & 22.669 & 18.967 & 26.978 \\
\hline
\end{tabular}

An analysis of variance (ANOVA) was performed on the set of data to determine statistical significance and is presented in table 21 . A Tukey's $95 \%$ confidence interval test was performed to compare the means of all three populations of measurement 8 . It was found that the height of cement penetration was significantly smaller for the $50 \mathrm{~mm}$ implant compared to the 52 
$\mathrm{mm}(\mathrm{p}=0.0000)$ implants but was not significantly smaller than the $51 \mathrm{~mm}$ implant $(\mathrm{p}=0.2800)$. In addition, the $51 \mathrm{~mm}$ implant was found to have significantly smaller actual height of cement penetration than the $52 \mathrm{~mm}$ implant $(p=0.0004)$. Therefore, it can be concluded that the $52 \mathrm{~mm}$ implant size significantly affects the cement height compared to both the $50 \mathrm{~mm}$ and $51 \mathrm{~mm}$ sizes

Table 21. Tukey's 95\% confidence interval ANOVA test of measurement 8

\begin{tabular}{|c|c|c|}
\hline Size $(\mathrm{mm})$ & Versus Size $(\mathbf{m m})$ & P- value \\
\hline 50 & 51 & 0.2800 \\
\hline 50 & 52 & 0.0000 \\
\hline 51 & 52 & 0.0004 \\
\hline
\end{tabular}

Cement height percentage (measurement 8a) was measured as the height of cement penetration from the dome's edge to the furthest point down the implant where cement was penetrating into the foam (measurement 8) as a percentage of the height of the implant (measurement 9). The values for this data are presented in figure 27 and table 22 . The mean cement height percentage for implant size 50 was $68.7 \%$. The mean cement height for implant size 51 was $73.3 \%$. The cement height for implant size 52 was $85.6 \%$. 


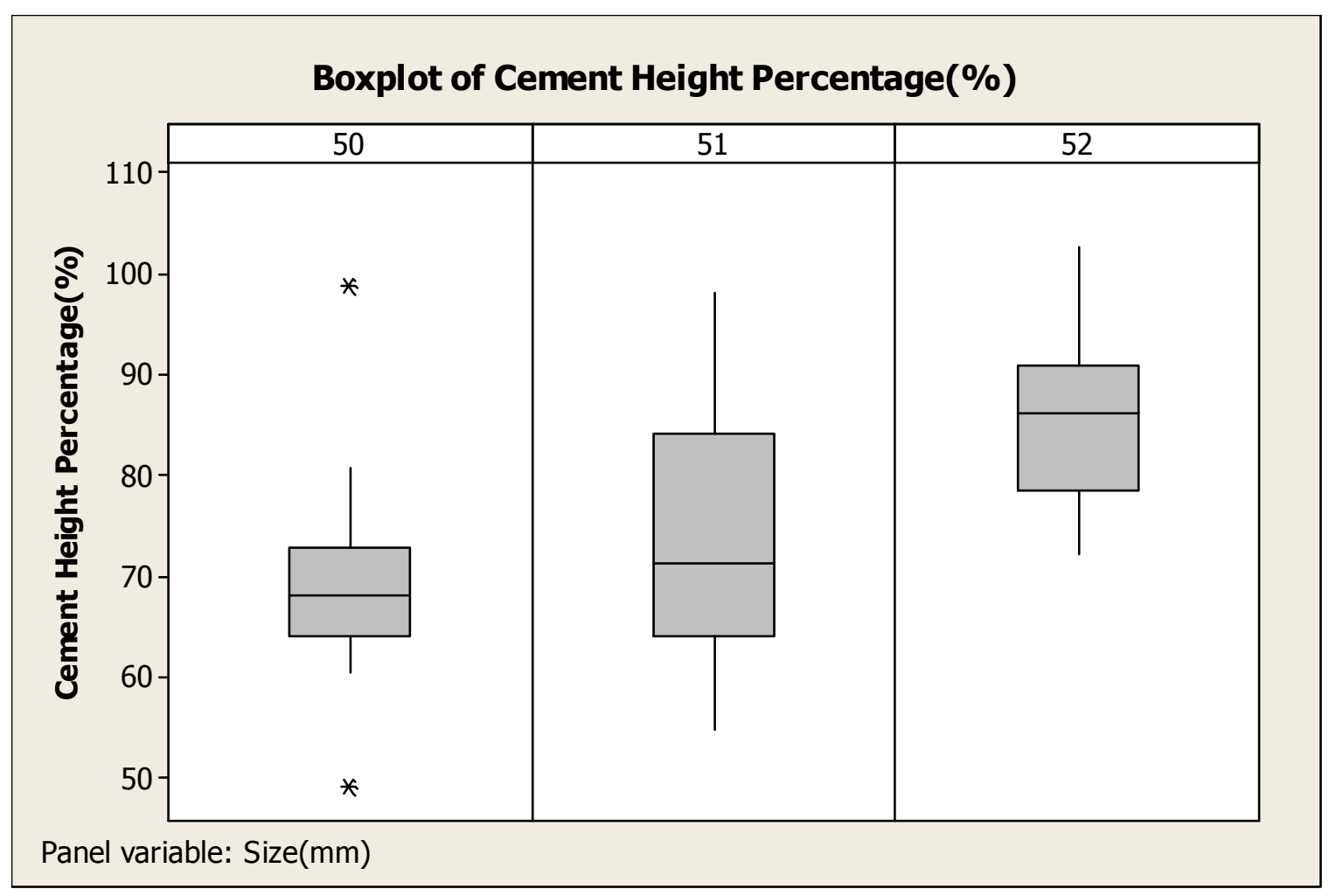

Figure 27. Boxplot comparing of cement height percentage (8a) of all three implant sizes

Table 22. Data values comparing cement height percentage (8a) of all three implant sizes

\begin{tabular}{|c|c|c|c|c|c|c|}
\hline Size & $\mathbf{N}$ & Mean & StDev & Median & Minimum & Maximum \\
\hline $\mathbf{5 0}$ & 24 & 0.687 & 0.090 & 0.679 & 0.491 & 0.988 \\
\hline $\mathbf{5 1}$ & 24 & 0.733 & 0.118 & 0.712 & 0.548 & 0.980 \\
\hline $\mathbf{5 2}$ & 24 & 0.856 & 0.079 & 0.861 & 0.721 & 1.025 \\
\hline
\end{tabular}

An analysis of variance (ANOVA) was performed on the set of data to determine statistical significance and is presented in table 23. A Tukey's 95\% confidence interval test was performed to compare the means of all three populations of measurement 8a. It was found that the height of cement penetration percentage was significantly smaller for the $50 \mathrm{~mm}$ implant compared 
to the $52 \mathrm{~mm}(p=0.0000)$ implants but was not significantly smaller than the 51 $\mathrm{mm}$ implant $(\mathrm{p}=0.2376)$. In addition, the $51 \mathrm{~mm}$ implant was found to have significantly smaller cement height percentage than the $52 \mathrm{~mm}$ implant $(\mathrm{p}=0.0001)$. Therefore, it can be concluded that the $52 \mathrm{~mm}$ implant size significantly affects the cement height percentage compared to both the $50 \mathrm{~mm}$ and $51 \mathrm{~mm}$ sizes.

Table 23. Tukey's $95 \%$ confidence interval ANOVA test of cement height percentage (8a)

\begin{tabular}{|c|c|c|}
\hline Size $(\mathbf{m m})$ & Versus Size $(\mathbf{m m})$ & P- value \\
\hline $\mathbf{5 0}$ & $\mathbf{5 1}$ & 0.2376 \\
\hline $\mathbf{5 0}$ & $\mathbf{5 2}$ & 0.0000 \\
\hline $\mathbf{5 1}$ & $\mathbf{5 2}$ & 0.0001 \\
\hline
\end{tabular}

\section{Area of Cement Penetration}

Measurement 10 was measured as the area of cement penetration as seen on the cross sectional surfaces of the implants. The values for this data are presented in figure 28 and table 24 . The mean area for implant size 50 was $191.029 \mathrm{~mm}^{2}$. The mean area for implant size 51 was $182.455 \mathrm{~mm}^{2}$. The area for implant size 52 was $178.968 \mathrm{~mm}^{2}$. 


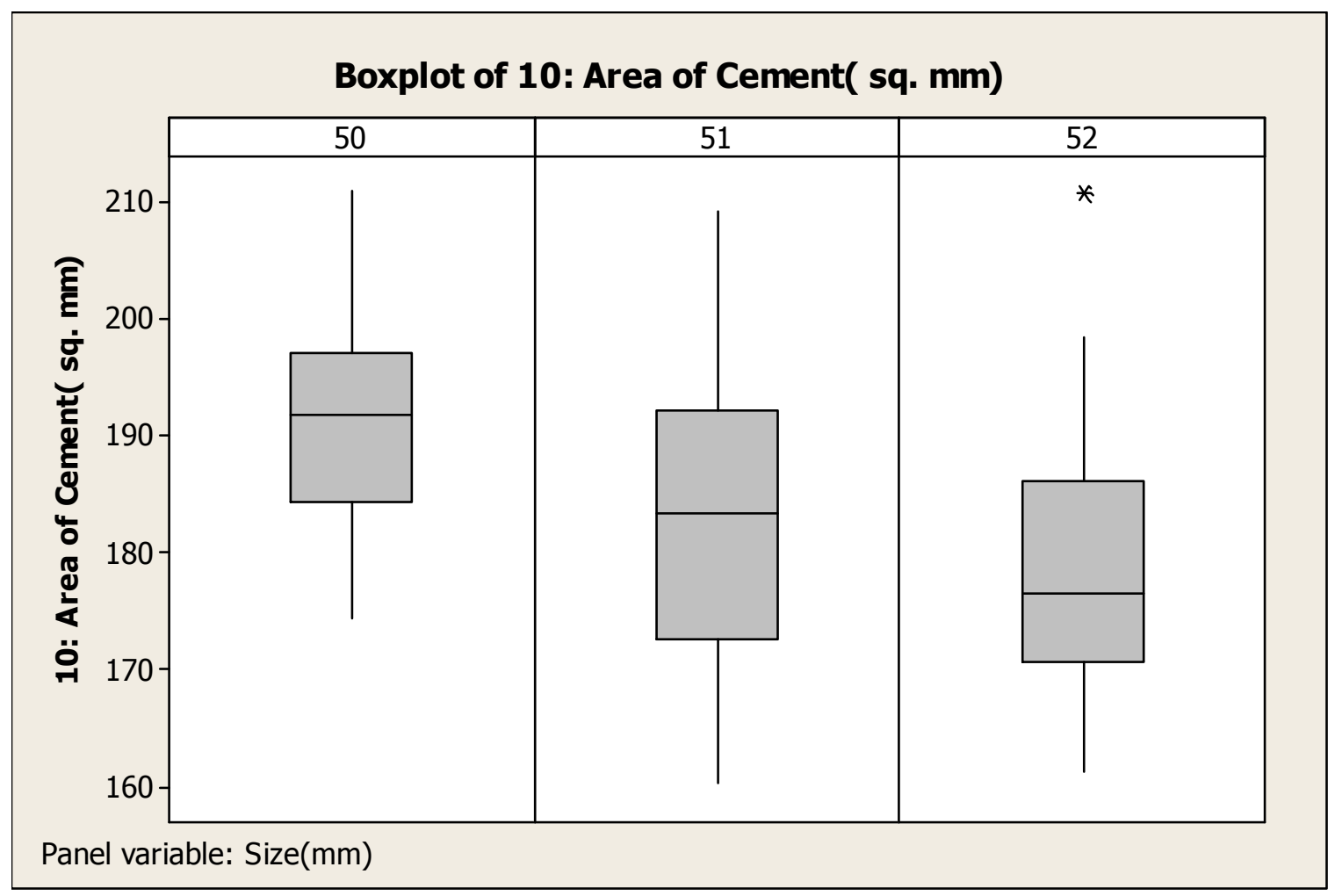

Figure 28. Boxplot comparing measurement 10 of all three implant sizes

Table 24. Data values comparing measurement 10 of all three implant sizes

\begin{tabular}{|c|c|c|c|c|c|c|}
\hline Size & $\mathbf{N}$ & Mean & StDev & Median & Minimum & Maximum \\
\hline $\mathbf{5 0}$ & 24 & 191.029 & 8.856 & 191.666 & 174.367 & 210.903 \\
\hline $\mathbf{5 1}$ & 24 & 182.455 & 13.601 & 183.313 & 160.123 & 209.182 \\
\hline $\mathbf{5 2}$ & 24 & 178.968 & 12.819 & 176.551 & 161.222 & 210.681 \\
\hline
\end{tabular}

An analysis of variance (ANOVA) was performed on the set of data to determine statistical significance and is presented in 25 . A Tukey's $95 \%$ confidence interval test was performed to compare the means of all three populations of measurement 10. It was found that the area of cement penetration was significantly larger for the $50 \mathrm{~mm}$ implant compared to the 51 
$\mathrm{mm}$ implant $(p=0.0501)$ and significantly larger than the $52 \mathrm{~mm}$ implant $(p=0.0024)$. However, the $51 \mathrm{~mm}$ implant was not found to have significantly different area of penetration than the $52 \mathrm{~mm}$ implant $(\mathrm{p}=0.5721)$. Therefore, it can be concluded that the $50 \mathrm{~mm}$ implant size significantly affects the cement area compared to both the $51 \mathrm{~mm}$ and $52 \mathrm{~mm}$ sizes

Table 25. Tukey's 95\% confidence interval ANOVA test of measurement 10

\begin{tabular}{|c|c|c|}
\hline Size $(\mathbf{m m})$ & Versus Size $(\mathbf{m m})$ & P- value \\
\hline $\mathbf{5 0}$ & $\mathbf{5 1}$ & 0.0401 \\
\hline $\mathbf{5 0}$ & $\mathbf{5 2}$ & 0.0024 \\
\hline $\mathbf{5 1}$ & $\mathbf{5 2}$ & 0.5721 \\
\hline
\end{tabular}

Cement area percentage (recorded as 10a) was measured as the area of cement penetration as seen on the cross sectional surfaces of the implants as a percentage of the total area penetration possible for that size implant. The values for this data are presented in figure 29 and table 22 . The mean percentage for implant size 50 was $50.538 \%$. The mean area percentage for implant size 51 was $46.783 \%$. The mean area percentage for implant size 52 was $44.630 \%$. 


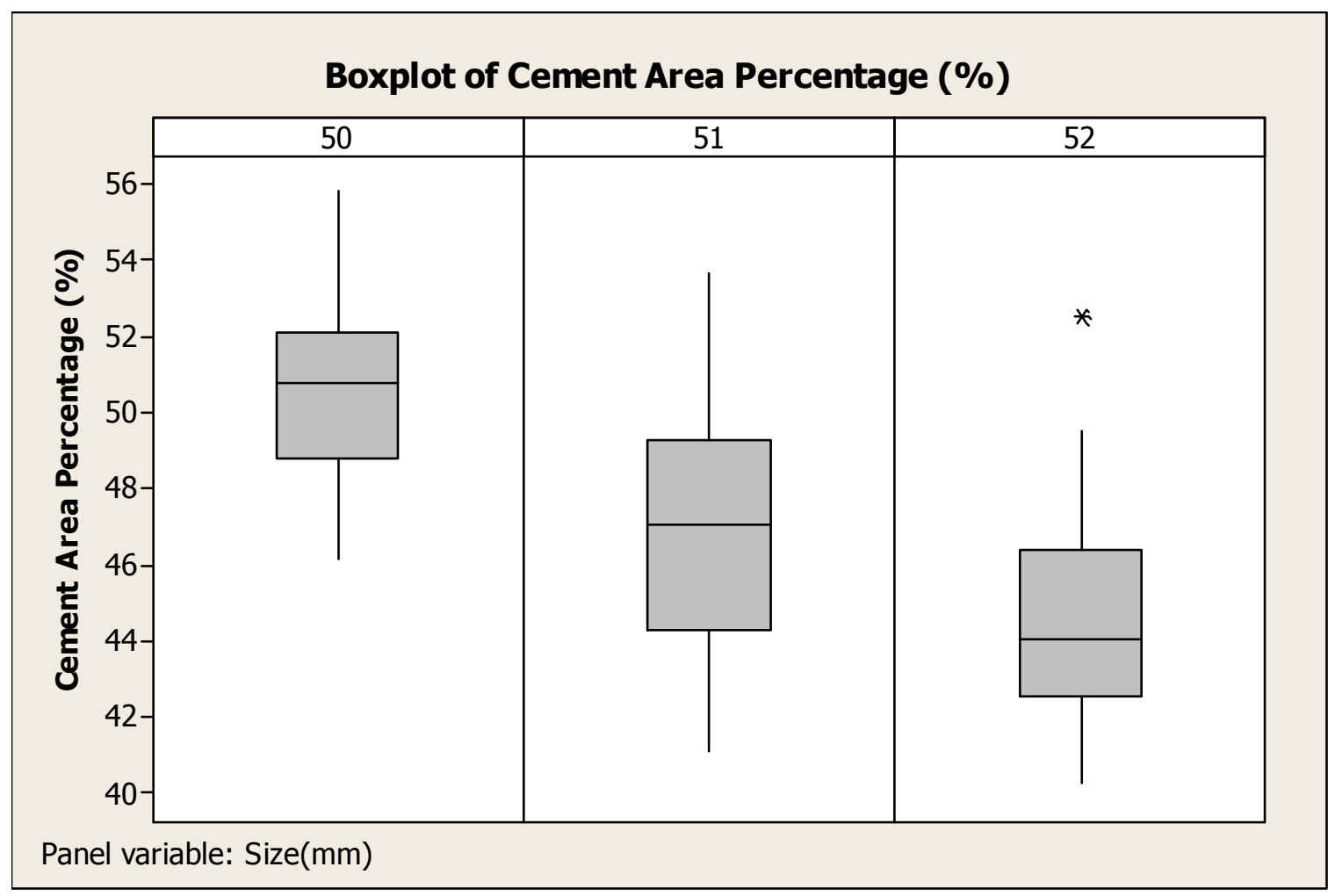

Figure 29. Boxplot comparing cement area percentage (10a) of all three implant sizes

Table 26. Data values comparing cement area percentage (10a) of all three implant sizes

\begin{tabular}{|c|c|c|c|c|c|c|}
\hline Size & $\mathbf{N}$ & Mean & StDev & Median & Minimum & Maximum \\
\hline $\mathbf{5 0}$ & $\mathbf{2 4}$ & 50.538 & 2.347 & 50.750 & 46.100 & 55.800 \\
\hline $\mathbf{5 1}$ & $\mathbf{2 4}$ & 46.783 & 3.487 & 47.003 & 41.057 & 53.636 \\
\hline $\mathbf{5 2}$ & $\mathbf{2 4}$ & 44.630 & 3.197 & 44.028 & 40.205 & 52.539 \\
\hline
\end{tabular}

An analysis of variance (ANOVA) was performed on the set of data for measurement 10a to determine statistical significance and is presented in table 27. A Tukey's $95 \%$ confidence interval test was performed to compare the means of all three populations of cement penetration area percentage. It was found that cement area percentage was significantly larger for the $50 \mathrm{~mm}$ implant 
compared to both the $51 \mathrm{~mm}(\mathrm{p}=0.0002)$ and $52 \mathrm{~mm}(\mathrm{p}=0.0000)$ implants. In addition, the $51 \mathrm{~mm}$ implant was found to have significantly smaller cement area percentage than the $52 \mathrm{~mm}$ implant $(p=0.0443)$. Therefore, it can be concluded that implant size significantly affects the cement penetration area percentage. This data is significant because it accounts for the changes in implant size as opposed to the raw data in the previous comparison of total cement area.

Table 27. Tukey's 95\% confidence interval ANOVA test of cement area percentage (10a)

\begin{tabular}{|c|c|c|}
\hline Size $(\mathbf{m m})$ & Versus Size $(\mathbf{m m})$ & P- value \\
\hline $\mathbf{5 0}$ & $\mathbf{5 1}$ & 0.0002 \\
\hline $\mathbf{5 0}$ & $\mathbf{5 2}$ & 0.0000 \\
\hline $\mathbf{5 1}$ & $\mathbf{5 2}$ & 0.0443 \\
\hline
\end{tabular}




\section{DISCUSSION}

There was evidence to conclude that the reamer-femoral component off set significantly affects the size of the cement mantle, the area of cement penetration, and the depth of cement penetration at several locations.

The experiment was set up to compare the three different sizes of reamerfemoral component offset $(0.0,0.5$, and $1.0 \mathrm{~mm})$. Measuring the offset gives a direct indication of the potential size of the mantle thickness at the walls. Our data shows that the offsets are significantly different, but not at exactly the values expected. There is variance in the data and the actual means of the offset are $0.3,0.7$, and $1.3 \mathrm{~mm}$ as opposed to $0.0,0.5$, and 1.0 . Variations in the manufacturing process may have resulted in implants with inexact dimensions. Also, the foam material used for bone models is very brittle, and treatment with the reamer and handling them may have caused the decreased size of the cylinders. Nevertheless, ANOVA tests showed that the values are statistically different. As a result, we can conclude that the change in offset is the driving variable for the results in this study.

The depth of penetration from the dome and from the chamfer showed a significant decrease when the offset was increased. The method used in this study was inclined to localize the majority of cement penetration at the dome and chamfer because no cement was digitally applied to the foam. This resulted in consistent over penetration at these locations because they were the areas where the cement first came into contact with the foam. In trials with the smallest actual offset (mean of $0.3 \mathrm{~mm}$ ), penetration depths were the greatest (mean 
always greater than $8.2 \mathrm{~mm}$ ). As the offset was increased, the penetration in these areas significantly decreased. The mean penetration was lowest for these regions at the chamfer with the $1.3 \mathrm{~mm}$ offset with a value of $6.3 \mathrm{~mm}$. Although this value is still significantly higher than the accepted range of effective penetration at 2-5 mm (Krause, Krug et al. 1982), it shows a trend of improvement from the smaller offset trials. This study shows that increasing the offset to $1.3 \mathrm{~mm}$ reduces over penetration in the dome and chamfer regions.

The depth of cement penetration from the wall and the height of penetration percentage needed to be considered together in order to make significant conclusions. Cement penetration height was only considered effective when it was greater than $70 \%$ of the total cement height for that size implant. This value was determined by comparing the length of the wall to the total height; halfway down the wall occurred at $70 \%$ of the total height. This value allows for a more meaningful discussion of the cement penetration. The first penetration from the wall measurement was taken from the portion of the wall that was superior to the point of $70 \%$ height of penetration. And as expected, there was no evidence that offset size affected the penetration depth in this area because it is considered ineffective. However, in the measurement of cement penetration from the wall in the portion that did contribute to cement height greater than $70 \%$, the offset showed statistically significant effects on penetration.

It was found that in the group with mean offset of $0.3 \mathrm{~mm}$, mean cement height percentage was $68.7 \%$ and 9 of the 24 specimen had cement penetration that exceeded $70 \%$ of the height. In the group with mean offset of $0.7 \mathrm{~mm}$, mean 
cement height percentage was $73.3 \%$ and 13 of the 24 specimen had cement penetration that exceed $70 \%$ of the height. In the last group with mean offset of $1.3 \mathrm{~mm}$, mean cement height percentage was $85.6 \%$ and all 24 of the 24 specimen had cement penetration that exceed $70 \%$ of the height. The evidence suggests that an increased size of offset is effective at increasing the height of cement penetration into a region that will most effectively fixate the implant onto the femoral head.

This study showed great success in achieving complete seating of all 18 implants. Other studies have shown incomplete seating of the femoral component to be a cause of early failure. Also, other studies (Bitsch, Heisel et al. 2007) have developed methods of modeling the resurfacing implantation technique but were unable to prevent incomplete seating. This study offers an experimental modeling of the implantation method that completely seats all implants. It is still open for debate which model would be more useful in further research. Previously used methods that see incomplete seating may find more translatable conclusions because their methods have similar shortcomings as the clinical methods. Or, this model may be more useful in laboratory research because it achieves implants that are fully seated consistently. In any case, this study established a new method for modeling the implantation technique that yields fully seated implants.

The area of penetration percentage was shown to be an appropriate adjustment to the total area of penetration. For total penetration, statistical comparisons showed that the area of penetration percentage is a good indicator 
of the character of the penetration. A decrease in cement penetration and a decrease in cement penetration depth at the chamfer and dome coinciding with the increase in offset suggest that an increase in offset encourages penetration increase localized at the walls. This study showed a trend of over penetration at the dome and chamfer while under penetration to ideal penetration at the wall.

Clinically, a more even distribution of cement penetration is achieved with varying cementation techniques. Most notably, balanced cement penetration occurred when the femoral cup was filled with cement to half volume or less and cement was digitally applied to the femoral head (Bitsch, Loidolt et al. 2008). This study did not make use of digitally applying cement to the femoral head, but instead focused on just cup filling. This was done to isolate the offset at the driving variable to increase cement penetration at the walls. One possible improvement on this study would be to use a femoral cup filled to a quarter volume. This would likely reduce the incidence of over penetration from the dome (measurement 1 and 2) and the chamfer (measurement 3 and 4). However, we would expect that this method would significantly reduce the cement mantle height (measurement 8) and therefore reduce the population size of implants with significant cement penetration from the wall (measurement 5 and 6). This would produce results that make it more difficult to extrapolate the significance of mantle thickness and component offset. Clinically, we would suggest using the manual application of cement onto the femoral head, as established in other studies, along with using increased component offset as 
established in this study. Further studies should be conducted investigating the complementary affects of using these techniques simultaneously.

Previously a study (Campbell, Beaule et al. 2006) of 98 failed resurfacing implants concluded that neck fractures could be caused by improperly seating of the femoral component and by excessive implantation forces to the implant by the surgeon. Both of these scenarios were found to be exacerbated by components with no cement mantle. This study determined that implantation procedures can be designed so that all implants are fully seated on to the femoral head. Further this study showed that consistently fully seated components can be achieved while also allowing a cement mantle to be formed. This study showed that this can be achieved by increasing the reamer femoral component offset to approximately $1.3 \mathrm{~mm}$.

Another study (Breusch, Lukoschek et al. 2001) concluded that the specimens that failed from femoral loosening had significantly higher amounts of cement than those that failed by other modes. It was suggested that thermal necrosis results in bone tissue loss and replacement by fibrous membranes, which causes component loosening. This study confirms that larger areas of cement contribute to over penetration which leads to thermal necrosis and joint loosening. Further, this study showed that an effective method of decreasing cement area and the incidence of over penetration is to increase the component offset. This in turn will decrease the incidence of destructive thermal necrosis and increase joint longevity. 
From the findings of other previous studies (Krause, Krug et al. 1982), it was been determined that optimal cement penetration into cancellous bone is $2-5$ $\mathrm{mm}$. Furthermore, it has been determined that penetration depths over $5 \mathrm{~mm}$ cause thermal necrosis of the bone (Huiskes 1980; Sih, Connelly et al. 1980). Cement penetration was a major factor in controlling optimal implant seating which will ultimately lead to optimized implant longevity. This study addresses the importance on limiting cement penetration to $2-5 \mathrm{~mm}$ while achieving complete implant seating. We have determined that increasing implant offset to $1.3 \mathrm{~mm}$ significantly contributes to achieving these goals.

Future versions of this model should include changes to materials. This model focused on modeling the geometries of femoral components and femoral head trabecular bone. However, it did not consider the chemistries, tribology, or surface interactions of the materials used. Clinically, PMMA interacts with the dynamic, living tissue of the femoral head and with the surface of cobalt chromium on the implant. These material changes could affect the outcomes of this study and should be pursued. The material chosen for this study had to adequately model the material used clinically as well as withstand the implantation impacting protocols and heat resistance of the activated PMMA. Also, the material was chosen because it would later need to be cut into cross sections for further analysis. In future studies, Implants should be obtained from manufacturers to be used in a future study. Also, the implants should be implanted onto a fresh frozen human cadaver femoral head. 
This study has established methods for effectively modeling the implantation of the femoral component in a hip resurfacing implant. To summarize, this study has:

- Established a method for duplicating femoral implants from existing designs and adding design modifications.

- Established methods for manufacturing resurfacing implants on a small scale to be used for laboratory experiments.

- Established a laboratory model of a cement fixation technique that completely seats all implants and yields cement penetration profiles similar to the clinical outcomes.

- Determined that hip resurfacing implant systems with a $1 \mathrm{~mm}$ offset minimize over penetration of cement from the dome.

- Determined hip resurfacing implant systems with a $1 \mathrm{~mm}$ offset maximize the height of cement penetration up the length of the wall.

- Determined that hip resurfacing implant systems with a $1 \mathrm{~mm}$ offset allow for effective cement penetration from the wall of $2-5 \mathrm{~mm}$ when filling the femoral cup with cement to half volume. 


\section{BIBLIOGRAPHY}

(2009). "Smith \& Nephew Products." Smith \& Nephew Corporate.

Agarwal, S. (2004). "Osteolysis - basic science incidence and diagnosis." Current Orthopaedics 18(3): 220-231.

Amstutz, A., P. Campbell, et al. (1991). "Modes of failure of surface replacements." Hip Arthroplasty Amstutz HC (ed).

Amstutz, H. C. (2008). Hip resurfacing : principles, indications, technique and results. Philadelphia, PA, Saunders/Elsevier.

Amstutz, H. C. (2008). "Present state of metal-on-metal hybrid hip resurfacing." $\underline{J}$ Surg Orthop Adv 17(1): 12-6.

Amstutz, H. C., P. E. Beaule, et al. (2004). "Metal-on-metal hybrid surface arthroplasty: two to six-year follow-up study." J Bone Joint Surg Am 86A(1): 28-39.

Amstutz, H. C., P. Campbell, et al. (1996). "Metal on metal total hip replacement workshop consensus document." Clin Orthop Relat Res(329 Suppl): S297-303.

Amstutz, H. C., P. A. Campbell, et al. (2004). "Fracture of the neck of the femur after surface arthroplasty of the hip." J Bone Joint Surg Am 86-A(9): 18747.

Amstutz, H. C., M. J. Le Duff, et al. (2007). "The effects of technique changes on aseptic loosening of the femoral component in hip resurfacing. Results of 600 Conserve Plus with a 3 to 9 year follow-up." J Arthroplasty 22(4): 4819.

Anissian, H. L., A. Stark, et al. (1999). "Metal-on-metal bearing in hip prosthesis generates 100 -fold less wear debris than metal-on-polyethylene." Acta Orthop Scand 70(6): 578-82.

Bal, B. S., D. Haltom, et al. (2006). "Early complications of primary total hip replacement performed with a two-incision minimally invasive technique. Surgical technique." J Bone Joint Surg Am 88 Suppl 1 Pt 2: 221-33.

Bilezikian, J. P., L. G. Raisz, et al. (2008). Principles of bone biology. Amsterdam ; Boston, Academic Press.

Bitsch, R. G., C. Heisel, et al. (2007). "Femoral cementing technique for hip resurfacing arthroplasty." J Orthop Res 25(4): 423-31.

Bitsch, R. G., T. Loidolt, et al. (2008). "Cementing techniques for hip resurfacing arthroplasty: development of a laboratory model." $\underline{\mathrm{J} \text { Bone Joint Surg Am }}$ 90 Suppl 3: 102-10.

Breusch, S. J., M. Lukoschek, et al. (2001). "Dependency of cement mantle thickness on femoral stem design and centralizer." $\underline{J}$ Arthroplasty 16(5): 648-57.

Campbell, P., P. E. Beaule, et al. (2006). "A study of implant failure in metal-onmetal surface arthroplasties." Clin Orthop Relat Res 453: 35-46.

Campbell, P., K. Takamura, et al. (2009). "Cement technique changes improved hip resurfacing longevity - implant retrieval findings." Bull NYU Hosp Jt Dis 67(2): 146-53. 
Daniel, J., P. B. Pynsent, et al. (2004). "Metal-on-metal resurfacing of the hip in patients under the age of 55 years with osteoarthritis." J Bone Joint Surg $\mathrm{Br}$ 86(2): 177-84.

Daniel, J., H. Ziaee, et al. (2009). "Six-year results of a prospective study of metal ion levels in young patients with metal-on-metal hip resurfacings." $\underline{\mathrm{J}}$ Bone Joint Surg Br 91(2): 176-9.

Firkins, P. J., J. L. Tipper, et al. (2001). "Quantitative analysis of wear and wear debris from metal-on-metal hip prostheses tested in a physiological hip joint simulator." Biomed Mater Eng 11(2): 143-57.

Harris, W. H., J. C. McCarthy, Jr., et al. (1982). "Femoral component loosening using contemporary techniques of femoral cement fixation." $\underline{\mathrm{J} \text { Bone Joint }}$ Surg Am 64(7): 1063-7.

Heisel, C., M. Silva, et al. (2004). "Bearing surface options for total hip replacement in young patients." Instr Course Lect 53: 49-65.

Huiskes, R. (1980). "Some fundamental aspects of human joint replacement. Analyses of stresses and heat conduction in bone-prosthesis structures." Acta Orthop Scand Suppl 185: 1-208.

Hungerford, M. W., M. A. Mont, et al. (1998). "Surface replacement hemiarthroplasty for the treatment of osteonecrosis of the femoral head." $\underline{\mathrm{J}}$ Bone Joint Surg Am 80(11): 1656-64.

Isaac, G. H., T. Siebel, et al. (2006). "Development rationale for an articular surface replacement: a science-based evolution." Proc Inst Mech Eng $\mathrm{H}$ 220(2): 253-68.

Jamali, D. A. (2008). "Hipandknee.net."

Krause, M., S. Breer, et al. (2009). "Cement-bone interface analysis of 118 failure cases after hip resurfacing arthroplasty: interface demineralization is significantly correlated to time in situ, cement penetration, and sex." Transactions of the 55th Annual Meeting of the Orthopaedic Research Society 34: 203.

Krause, W. R., W. Krug, et al. (1982). "Strength of the cement-bone interface." Clin Orthop Relat Res(163): 290-9.

Little, C. P., A. L. Ruiz, et al. (2005). "Osteonecrosis in retrieved femoral heads after failed resurfacing arthroplasty of the hip." $\underline{\mathrm{J} \text { Bone Joint Surg } \mathrm{Br}} \mathbf{8 7 ( 3 )}$ : 320-3.

Martin, R. B., D. B. Burr, et al. (1998). "Skeletal Tissue Mechanics." XIV: 392.

Morlock, M. M., N. Bishop, et al. (2006). "Biomechanical, morphological, and histological analysis of early failures in hip resurfacing arthroplasty." Proc Inst Mech Eng $\mathrm{H}$ 220(2): 333-44.

Mulroy, R. D., Jr. and W. H. Harris (1990). "The effect of improved cementing techniques on component loosening in total hip replacement. An 11-year radiographic review." J Bone Joint Surg Br 72(5): 757-60.

Rieker, C. B., R. Schon, et al. (2005). "Influence of the clearance on in-vitro tribology of large diameter metal-on-metal articulations pertaining to resurfacing hip implants." Orthop Clin North Am 36(2): 135-42, vii. 
Schmalzried, T. P., V. A. Fowble, et al. (1996). "Metal on metal surface replacement of the hip. Technique, fixation, and early results." Clin Orthop Relat Res(329 Suppl): S106-14.

Schmalzried, T. P., M. Silva, et al. (2005). "Optimizing patient selection and outcomes with total hip resurfacing." Clin Orthop Relat Res 441: 200-4.

Shimmin, A. J. and D. Back (2005). "Femoral neck fractures following Birmingham hip resurfacing: a national review of 50 cases." J Bone Joint Surg $\operatorname{Br} 87(4): 463-4$.

Sih, G. C., G. M. Connelly, et al. (1980). "The effect of thickness and pressure on the curing of PMMA bone cement for the total hip joint replacement." $\underline{J}$ Biomech 13(4): 347-52.

Silva, M., K. H. Lee, et al. (2004). "The biomechanical results of total hip resurfacing arthroplasty." J Bone Joint Surg Am 86-A(1): 40-6.

Surin, V. (2007). "Facts About Total Joints."

Ziaee, H., J. Daniel, et al. (2007). "Transplacental transfer of cobalt and chromium in patients with metal-on-metal hip arthroplasty: a controlled study." J Bone Joint Surg Br 89(3): 301-5.

Zustin, J., M. Amling, et al. (2009). "Intraosseous lymphocytic infiltrates after hip resurfacing arthroplasty : a histopathological study on 181 retrieved femoral remnants." Virchows Arch 454(5): 581-8. 


\section{APPENDIX A}

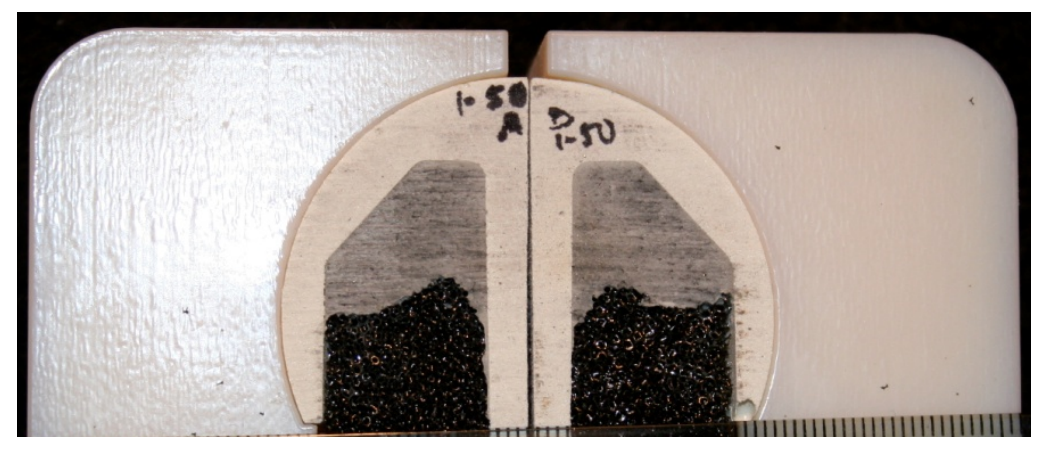

Figure 30. 50.1.A and 50.1.D

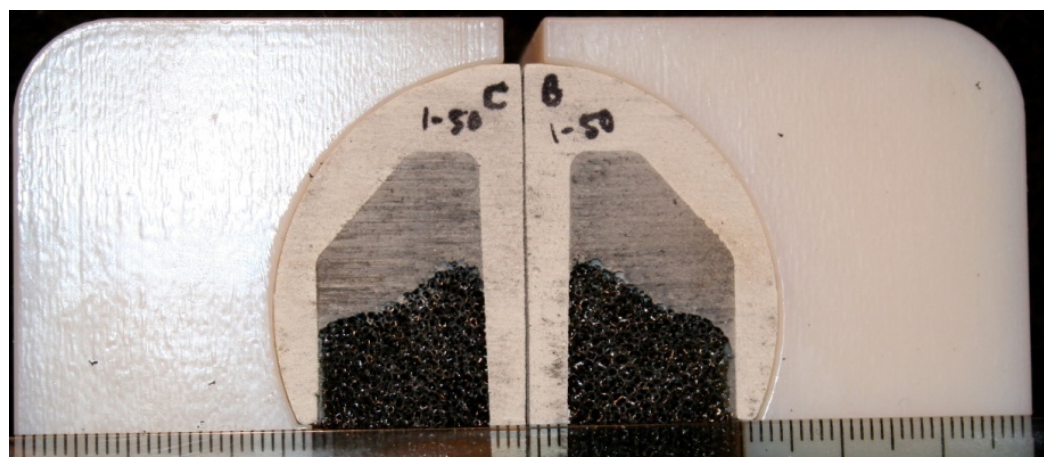

Figure 31. 50.1.C and 50.1.B

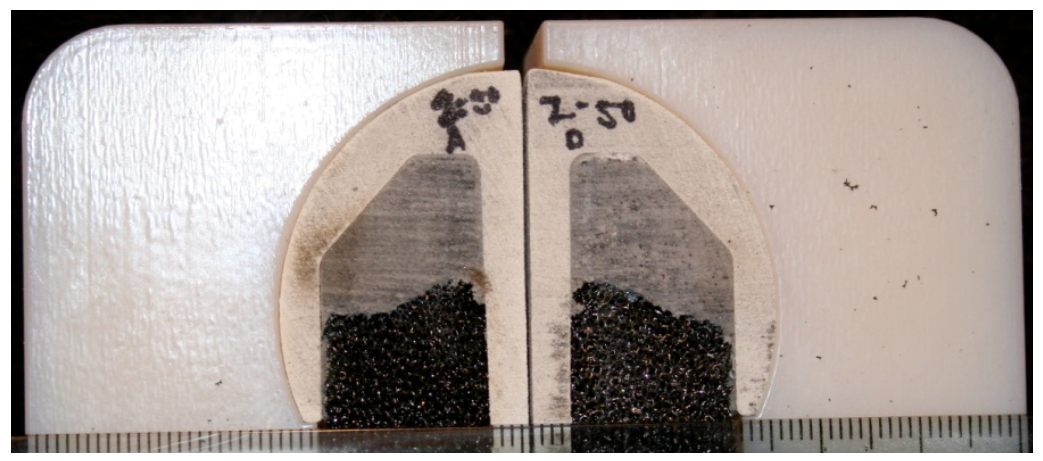

Figure 32. 50.2.A and 50.2.D 


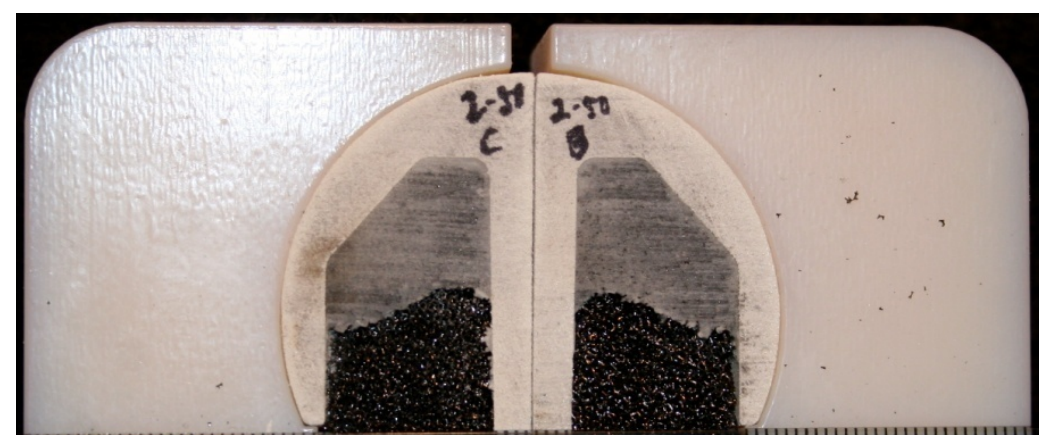

Figure 33. 50.2.C and 50.2.B

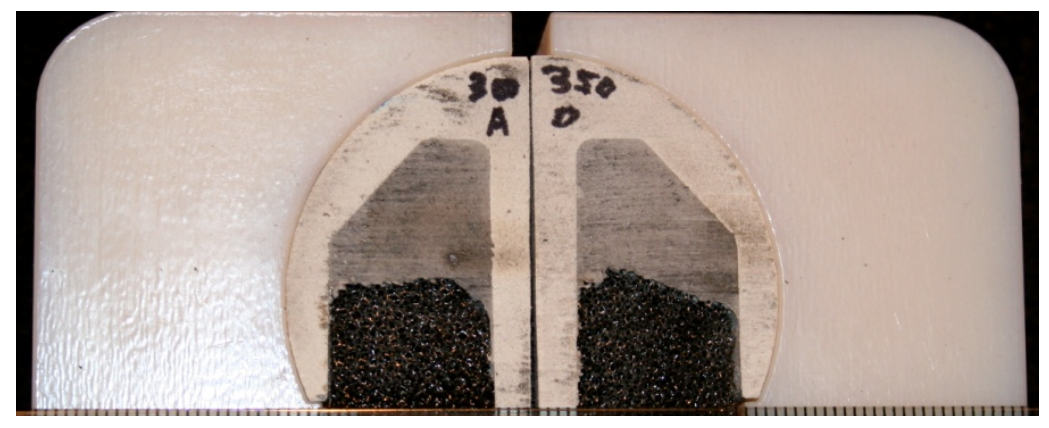

Figure 34. 50.3.C and 50.3.D

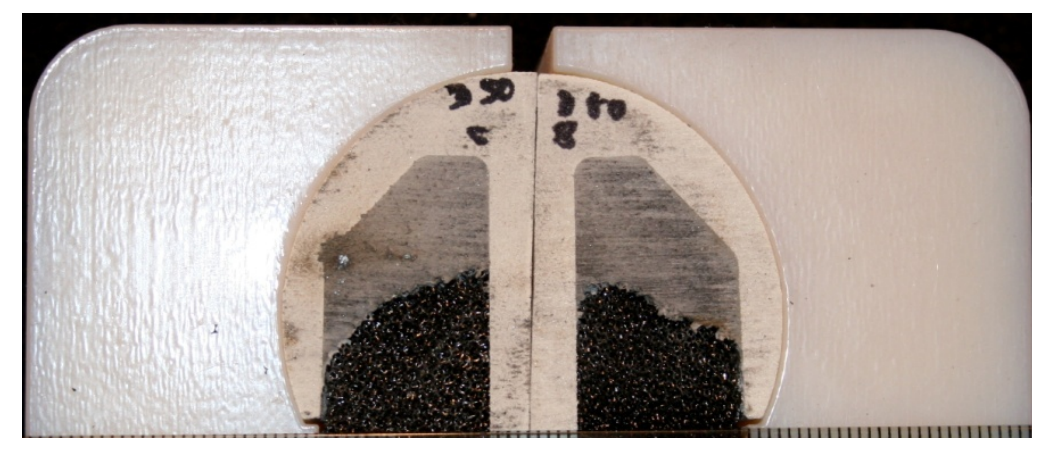

Figure 35. 50.3.C and 50.4.B 


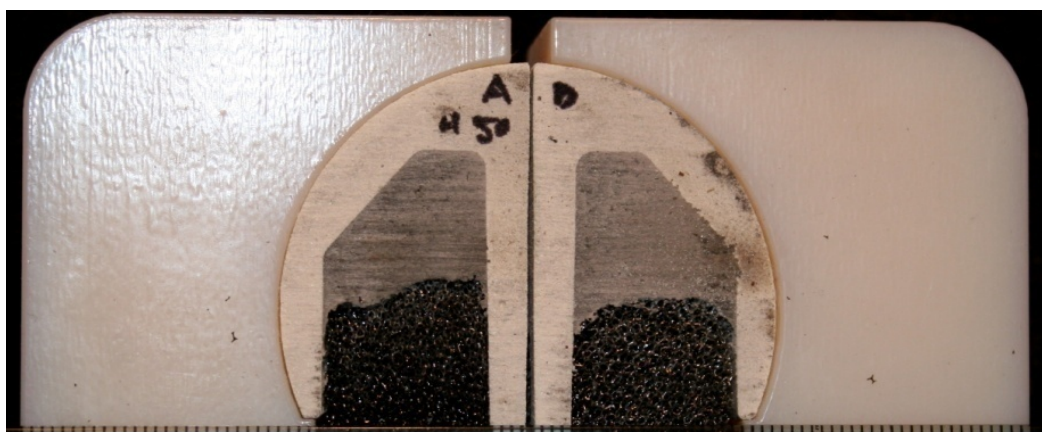

Figure 36. 50.4.A and 50.5.D

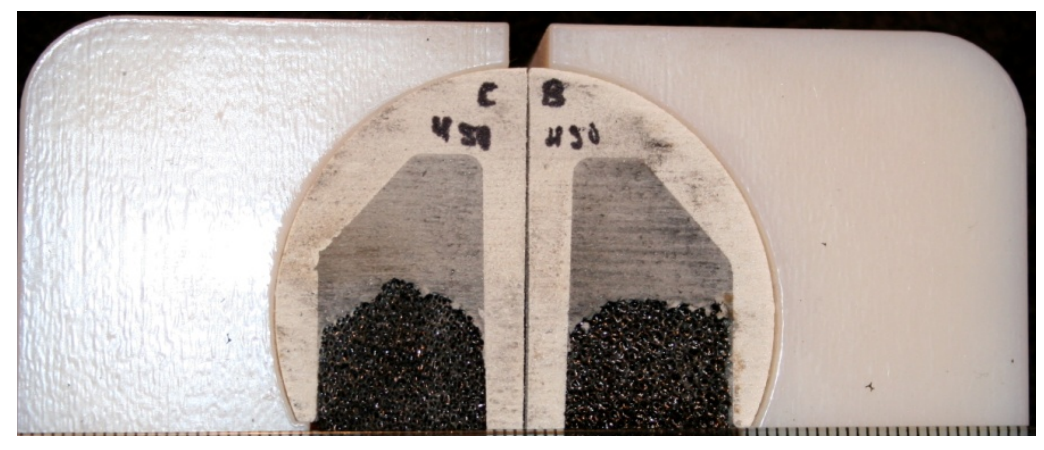

Figure 37. 50.4.C and 50.4.B

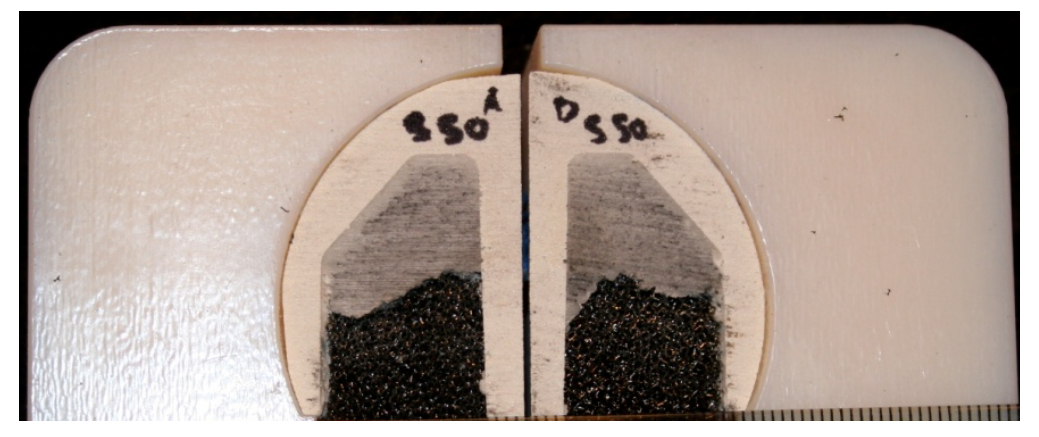

Figure 38. 50.5.A and 50.5.D 


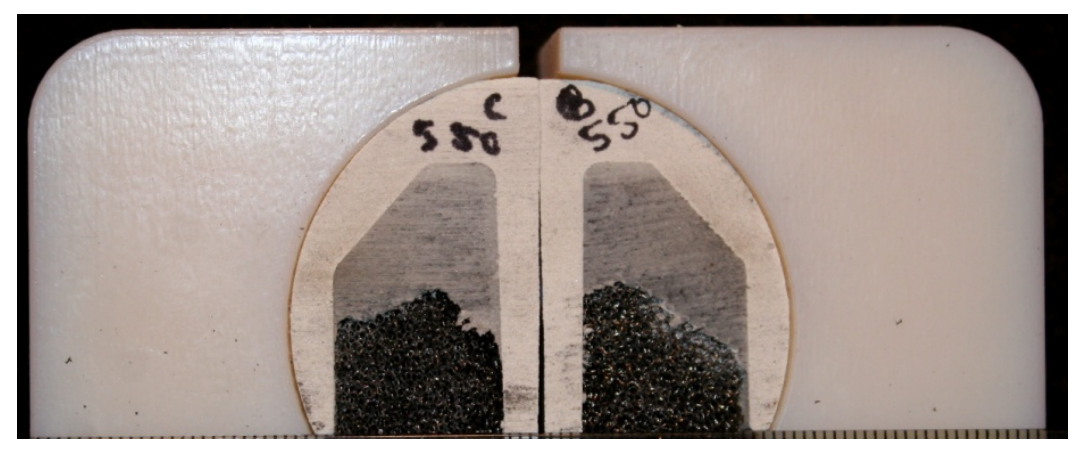

Figure 39. 50.5.C and 50.5.B

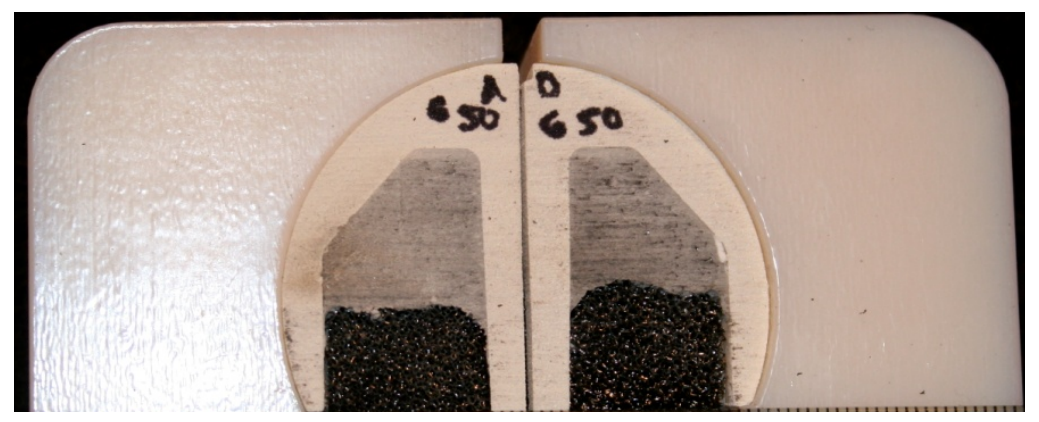

Figure 40. 50.6.A and 50.6.D

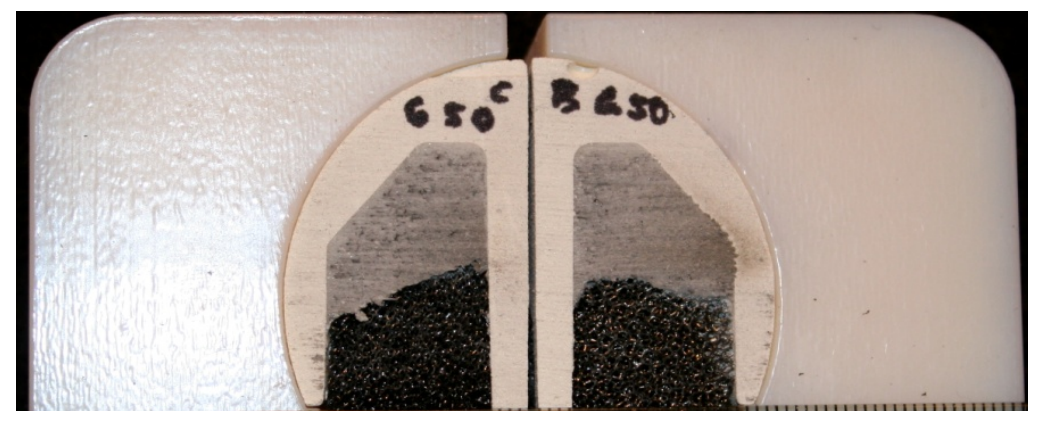

Figure 41. 50.6.C and 50.6.B 


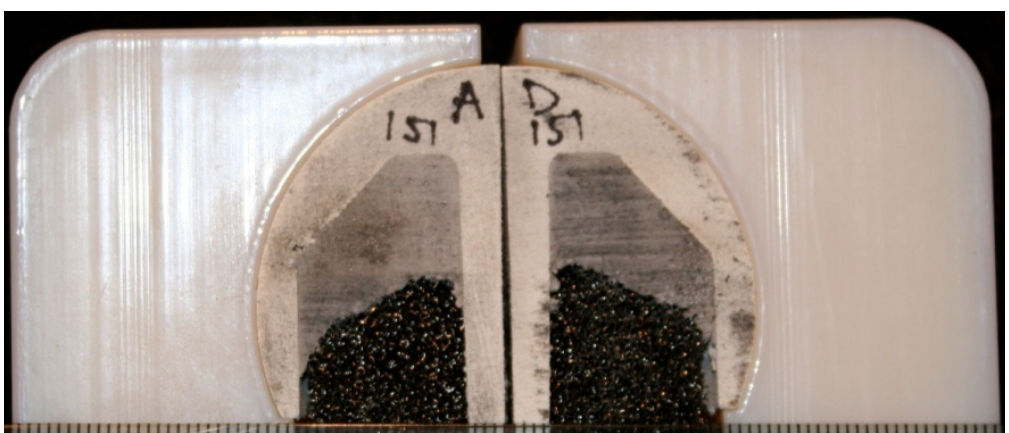

Figure 42. 51.1.A and 51.1.D

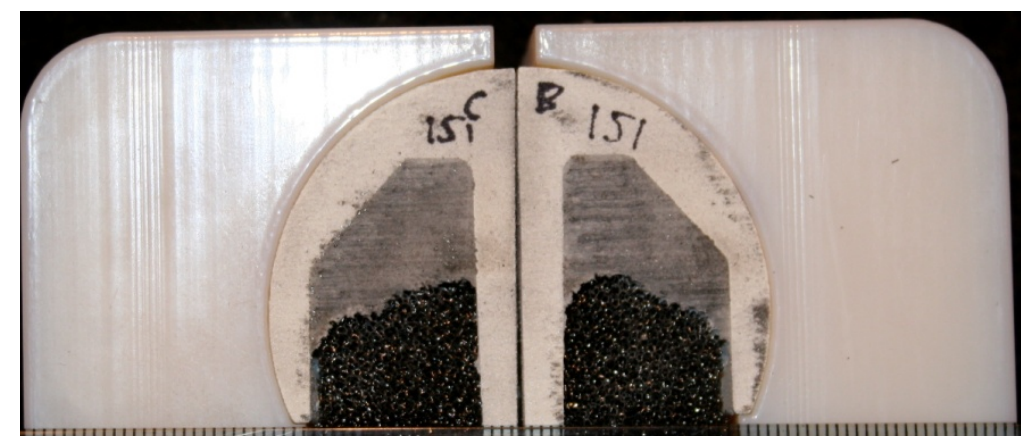

Figure 43. 51.1.C and 51.1.B

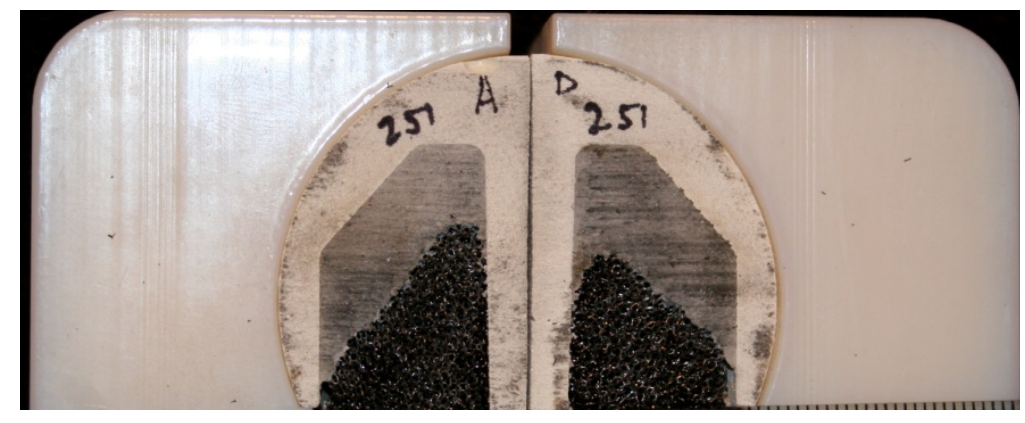

Figure 44. 51.2.A and 51.2.D 


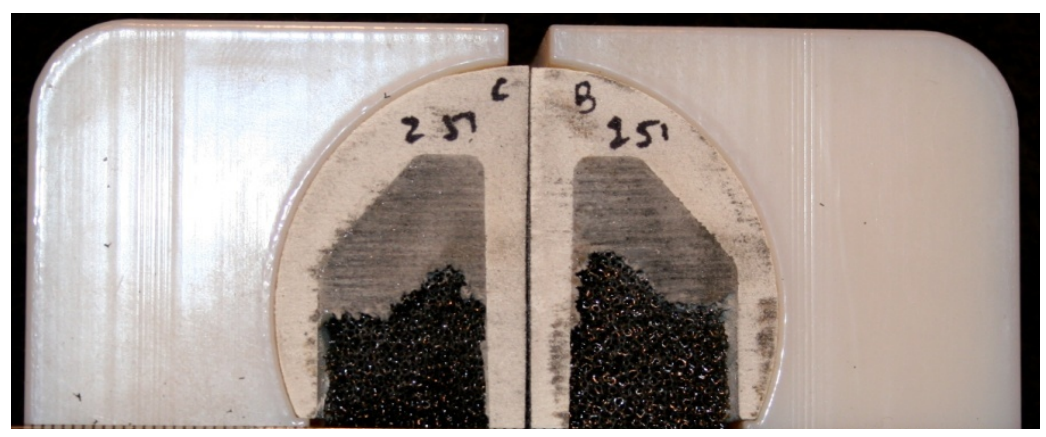

Figure 45. 51.2.C and 51.2.B

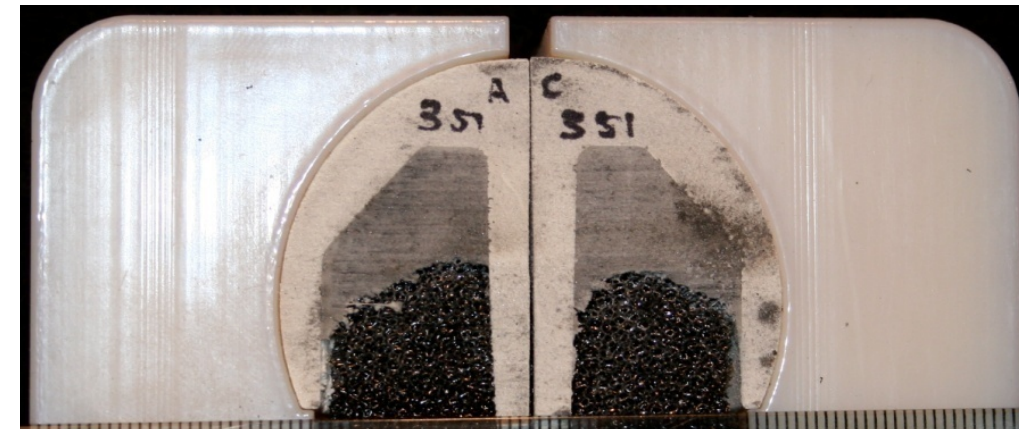

Figure 46. 51.3.A and 51.3.C

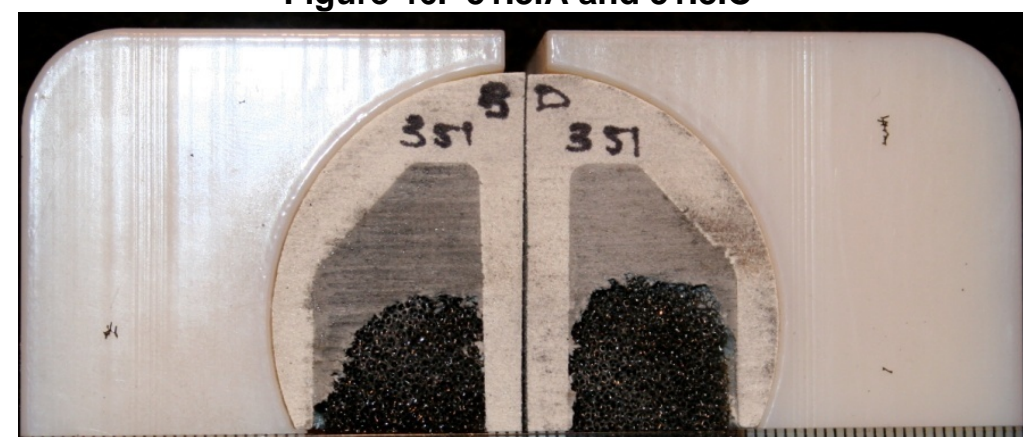

Figure 47. 51.3.B and 51.3.D 


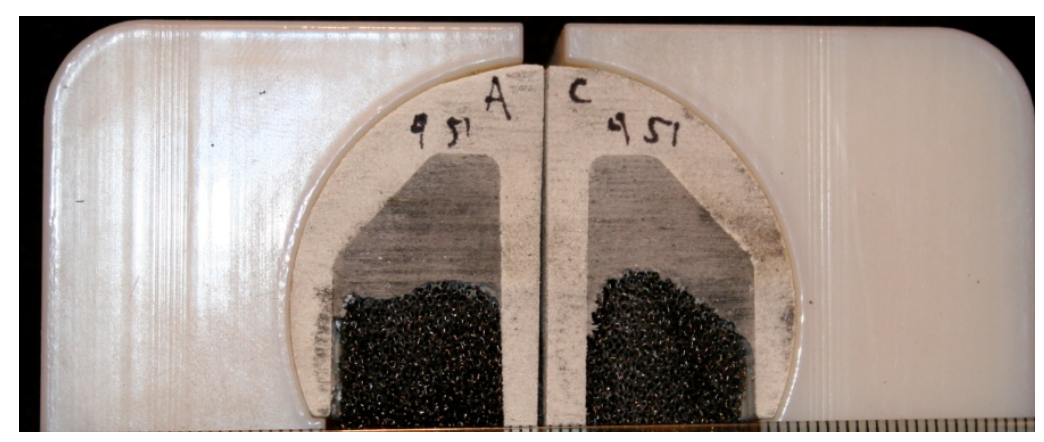

Figure 48. 51.4.A and 51.4.C

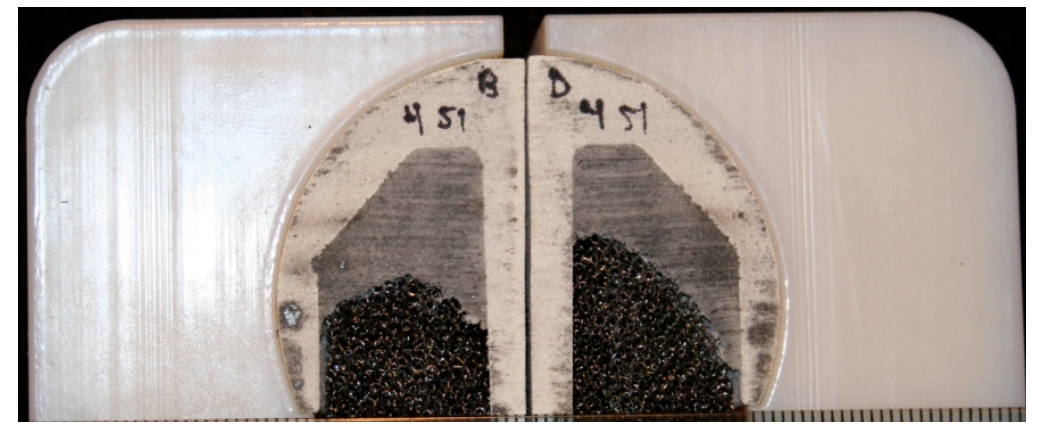

Figure 49. 51.4.B and 51.4.D

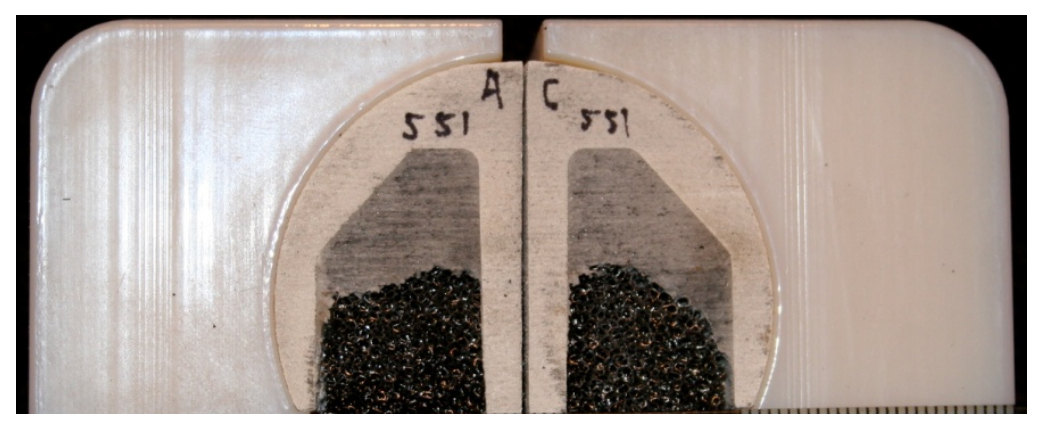

Figure 50. 51.5.A and 51.5.C 


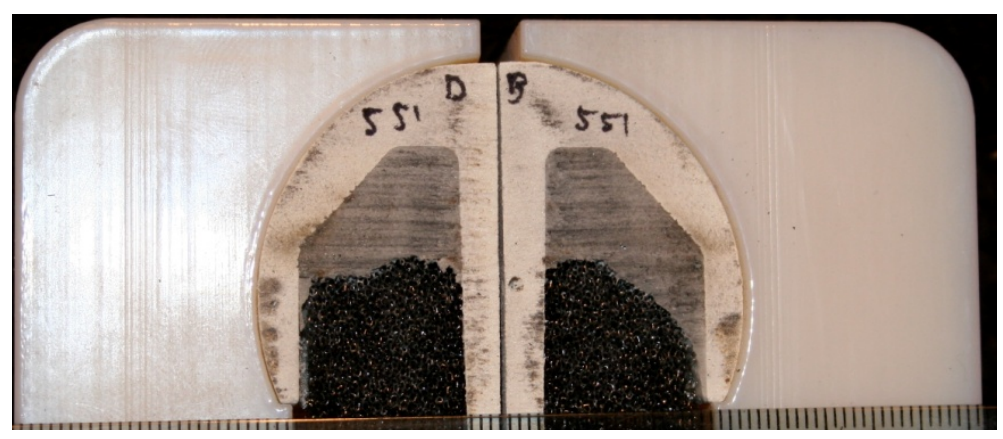

Figure 51. 51.5.D and 51.5.B

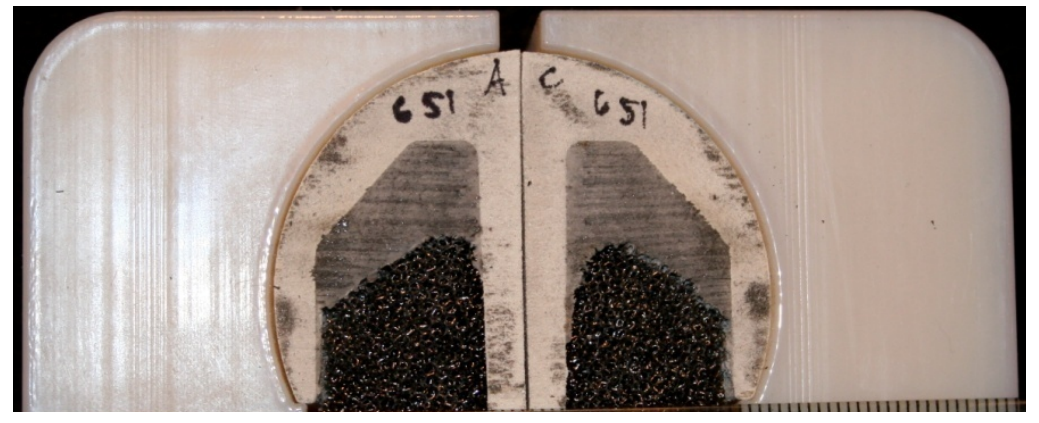

Figure 52. 51.6.A and 51.6.C

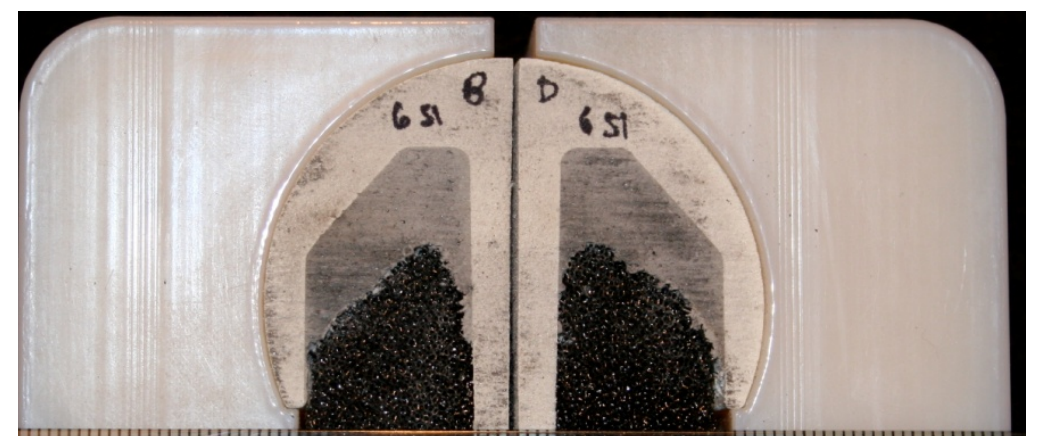

Figure 53. 51.6.B and 51.6.C 


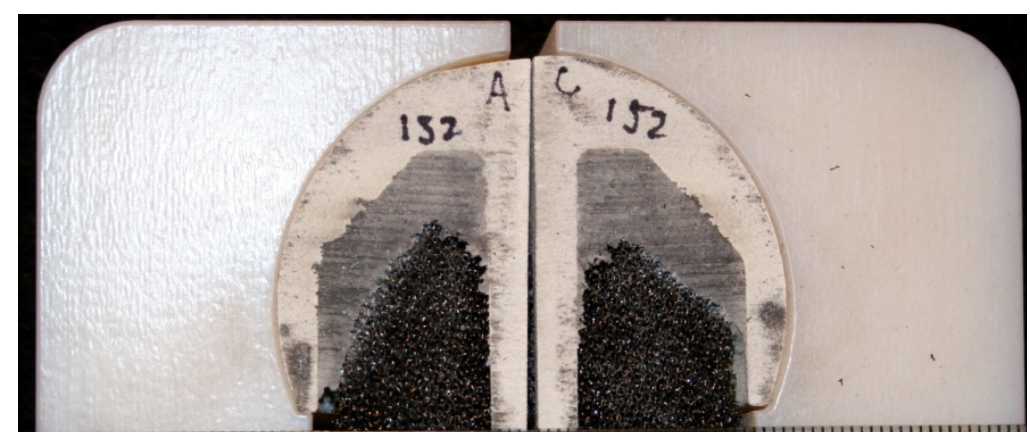

Figure 54. 52.1.A and 52.1.C

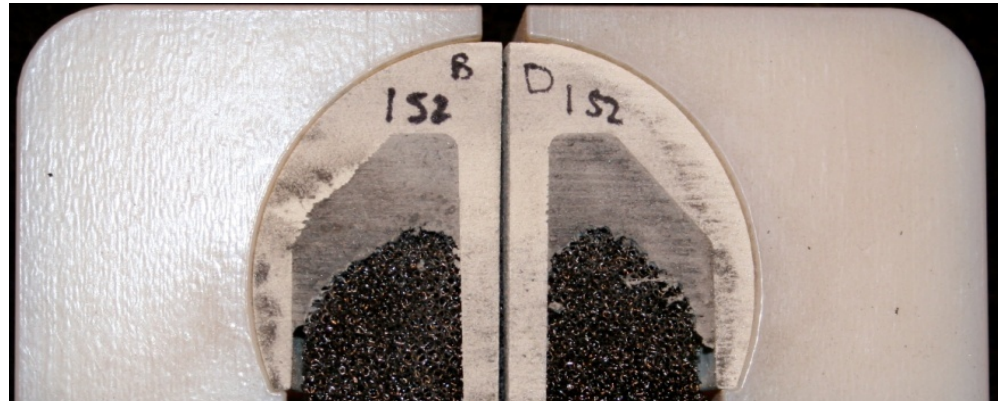

Figure 55. 52.1.B and 52.1.D

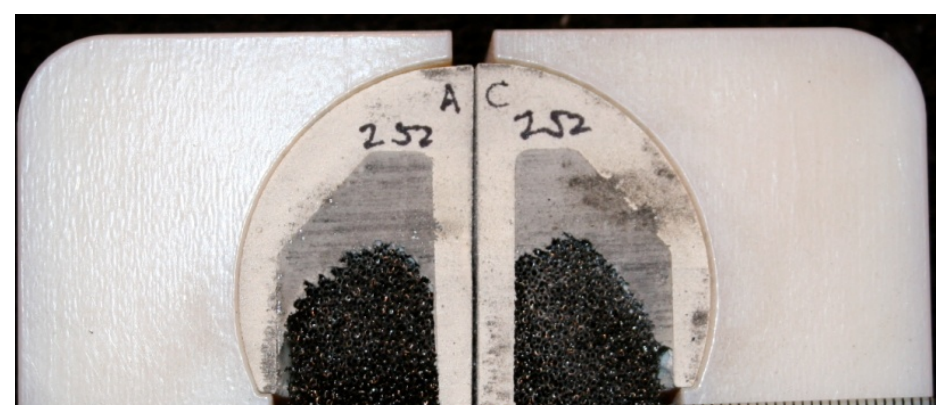

Figure 56. 52.2.A and 52.2.C 


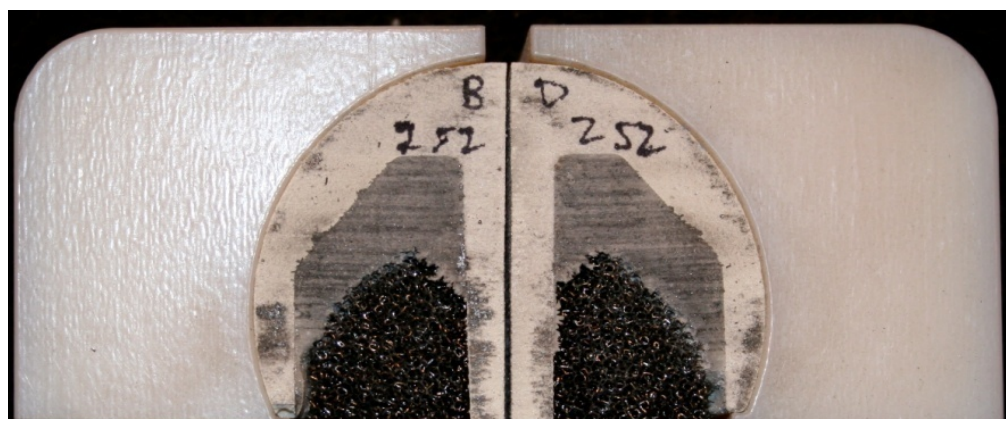

Figure 57. 52.2.B and 52.2.D

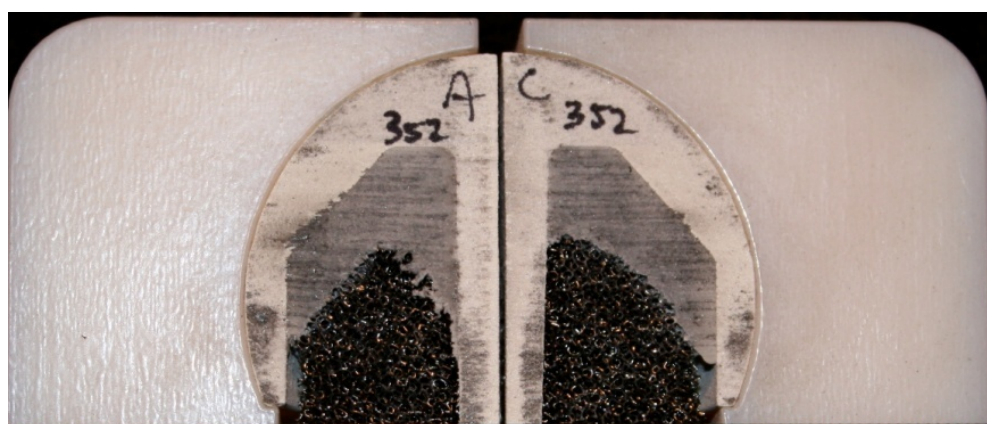

Figure 58. 52.3.A and 52.3.C

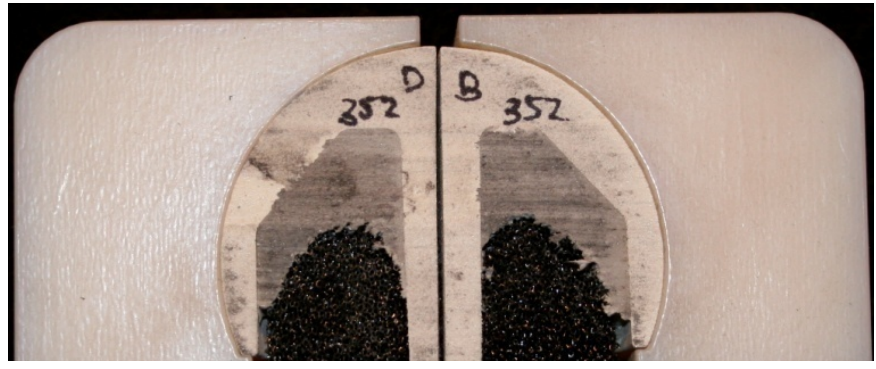

Figure 59. 52.3.D and 52.3.B 


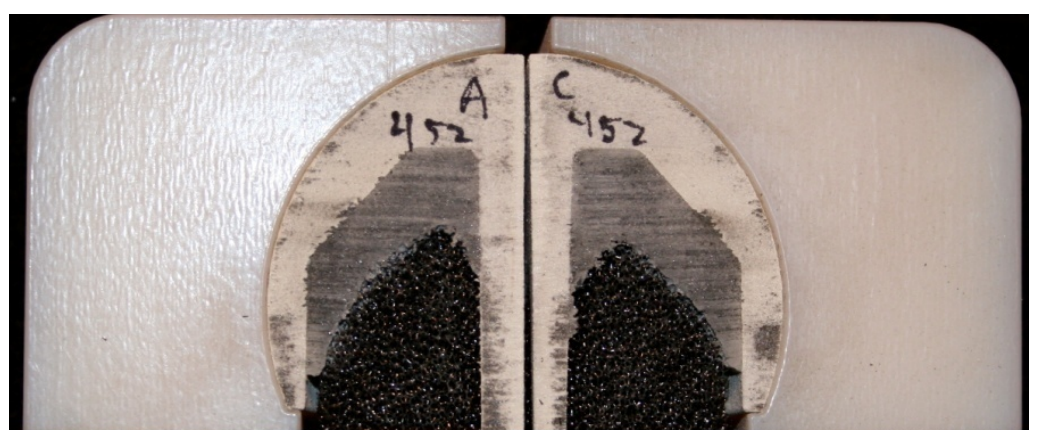

Figure 60. 52.4.A and 52.4.C

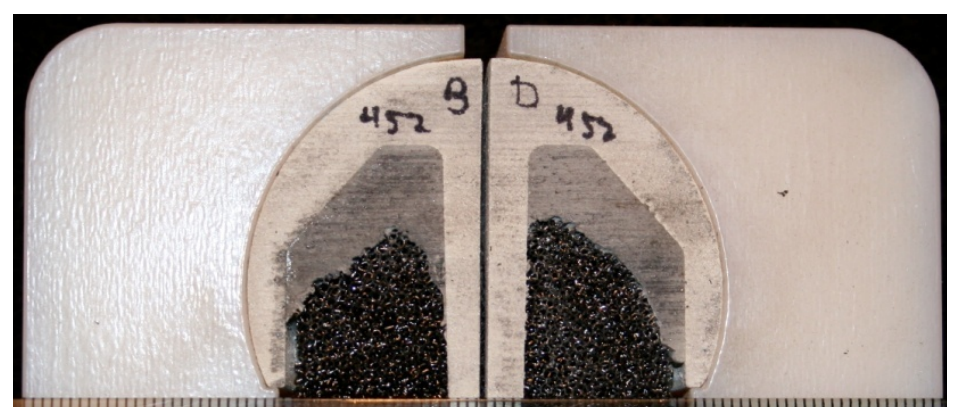

Figure 61. 52.4.B and 52.4.D

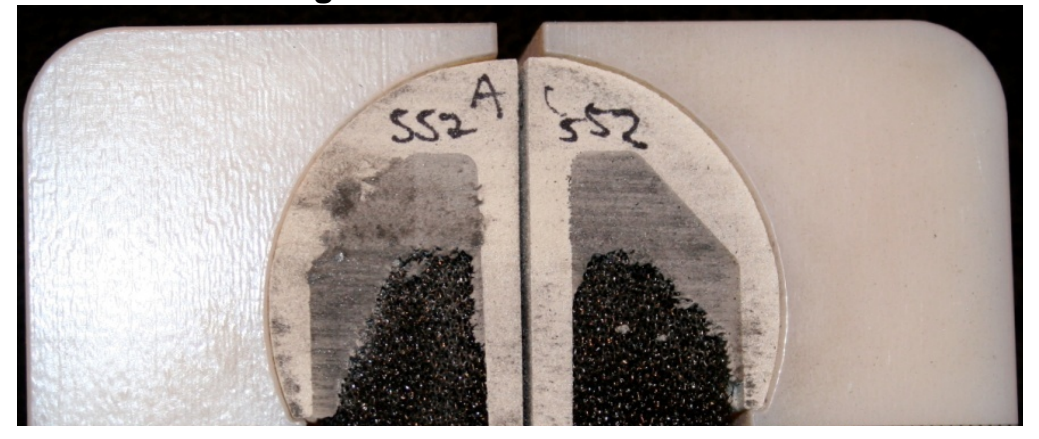

Figure 62. 52.5.A and 52.5.C 


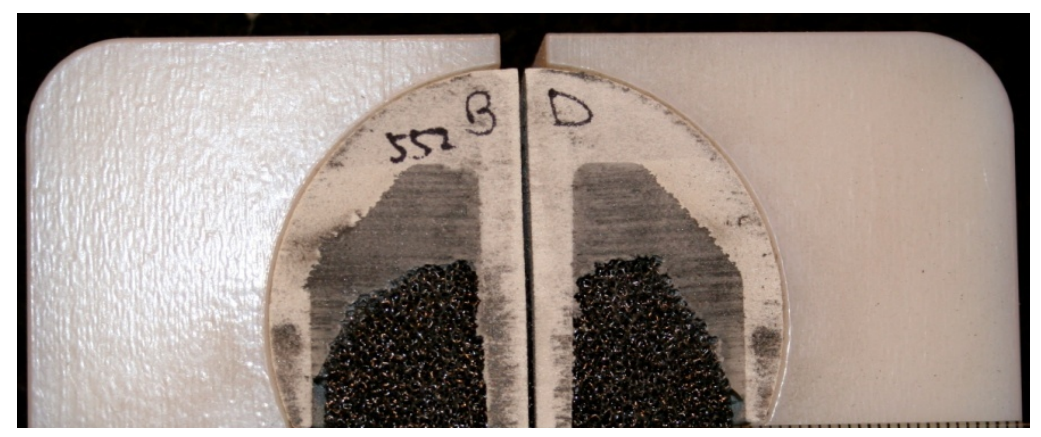

Figure 63. 52.5.B and 52.5.D

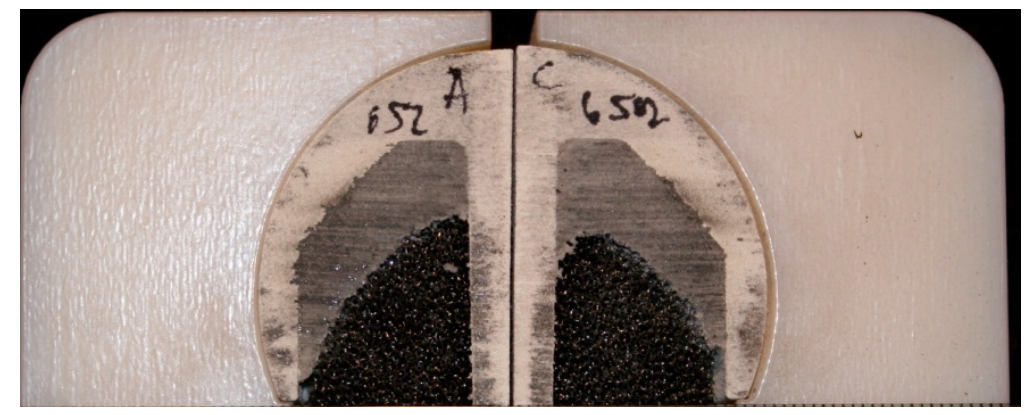

Figure 64. 52.6.A and 52.6.C

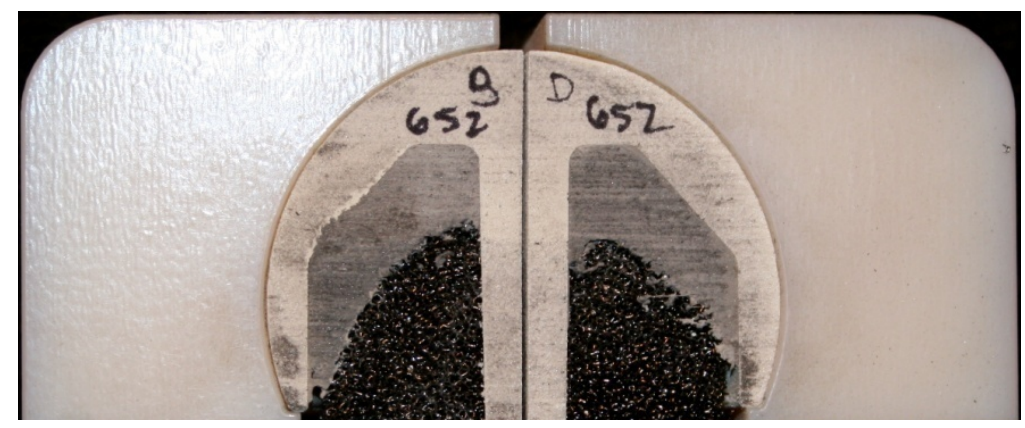

Figure 65. 52.6.B and 52.6.D 


\section{APPENDIX B}

\section{Complete Data Set}

Table 28. Measured distances and areas of the $50 \mathrm{~mm}$ implant series.

\begin{tabular}{|c|c|c|c|c|c|c|c|c|c|c|c|c|c|c|c|c|}
\hline jize & Spec & Face & 1 & 2 & 3 & 4 & 5 & 6 & 7 & 8 & 9 & 10 & $5 a$ & $6 a$ & $8 a$ & $10 a$ \\
\hline 50 & 1 & A & 13.21 & 11.97 & 9.14 & 7.84 & 0.78 & 0.00 & 0.15 & 16.11 & 26.72 & 186.16 & 0.63 & 0.00 & 60.29 & 49.20 \\
\hline 0 & 1 & B & 11.08 & 13.08 & 9.37 & 8.95 & 5.92 & 1.11 & 0.50 & 19.81 & 26.72 & 185.70 & 5.43 & 0.61 & 74.15 & 49.10 \\
\hline 50 & 1 & C & 11.48 & 12.50 & 9.20 & 8.90 & 6.33 & 0.00 & 0.36 & 17.58 & 26.72 & 183.95 & 5.97 & 0.00 & 65.80 & 48.70 \\
\hline 50 & 1 & D & 14.21 & 12.87 & 9.47 & 7.66 & 0.00 & 0.00 & 0.39 & 13.13 & 26.72 & 182.66 & 0.00 & 0.00 & 49.12 & 48.30 \\
\hline 0 & 2 & A & 12.88 & 13.35 & 10.94 & 8.96 & 4.70 & 0.00 & 0.13 & 17.96 & 26.72 & 193.28 & 4.58 & 0.00 & 67.22 & 51.10 \\
\hline & 2 & B & 12.79 & 13.47 & 9.35 & 8.87 & 5.59 & 1.16 & 0.27 & 18.85 & 26.72 & 203.89 & 5.32 & 0.89 & 70.55 & 53.90 \\
\hline 0 & 2 & C & 12.45 & 12.99 & 9.79 & 8.87 & 6.44 & 0.00 & 0.23 & 18.30 & 26.72 & 197.01 & 6.21 & 0.00 & 68.49 & 52.10 \\
\hline 0 & 2 & D & 12.50 & 13.26 & 9.74 & 8.96 & 6.02 & 1.10 & 0.35 & 19.55 & 26.72 & 200.79 & 5.66 & 0.75 & 73.14 & 53.10 \\
\hline 50 & 3 & A & 14.83 & 13.94 & 9.06 & 7.86 & 1.73 & 0.00 & 0.21 & 16.70 & 26.72 & 197.48 & 1.52 & 0.00 & 62.48 & 52.20 \\
\hline 50 & 3 & B & 13.04 & 13.21 & 9.60 & 9.38 & 8.04 & 2.54 & 0.19 & 19.13 & 26.72 & 202.10 & 7.85 & 2.35 & 71.60 & 53.50 \\
\hline 50 & 3 & C & 11.54 & 12.47 & 8.66 & 7.72 & 5.62 & 1.61 & 0.39 & 21.54 & 26.72 & 191.99 & 5.23 & 1.22 & 80.63 & 50.80 \\
\hline 50 & 3 & D & 14.55 & 13.33 & 8.98 & 8.06 & 5.20 & 0.00 & 0.45 & 18.49 & 26.72 & 196.02 & 4.75 & 0.00 & 69.18 & 51.90 \\
\hline & 4 & A & 15.79 & 15.36 & 10.13 & 8.13 & 2.61 & 0.00 & 0.31 & 18.03 & 26.72 & 180.29 & 2.30 & 0.00 & 67.48 & 47.70 \\
\hline 50 & 4 & B & 15.67 & 14.26 & 9.27 & 7.55 & 4.48 & 0.00 & 0.30 & 16.24 & 26.72 & 191.87 & 4.18 & 0.00 & 60.76 & 50.80 \\
\hline 50 & 4 & C & 15.00 & 14.03 & 6.78 & 7.08 & 3.84 & 0.43 & 0.05 & 19.55 & 26.72 & 194.99 & 3.79 & 0.37 & 73.17 & 51.60 \\
\hline 50 & 4 & D & 12.89 & 13.07 & 8.57 & 7.90 & 5.72 & 0.00 & 0.22 & 18.55 & 26.72 & 196.83 & 5.50 & 0.00 & 69.43 & 52.10 \\
\hline 50 & 5 & A & 12.18 & 12.79 & 9.10 & 8.14 & 5.43 & 0.87 & 0.69 & 26.42 & 26.72 & 177.31 & 4.75 & 0.19 & 98.86 & 46.90 \\
\hline & 5 & B & 12.01 & 12.51 & 8.55 & 8.34 & 7.58 & 1.43 & 0.77 & 20.77 & 26.72 & 191.46 & 6.82 & 0.67 & 77.74 & 50.70 \\
\hline 0 & 5 & C & 16.01 & 12.68 & 7.91 & 7.27 & 5.00 & 0.00 & 0.06 & 17.44 & 26.72 & 190.34 & 4.94 & 0.00 & 65.28 & 50.40 \\
\hline 50 & 5 & D & 14.47 & 12.70 & 8.78 & 7.09 & 1.02 & 0.00 & 0.28 & 17.18 & 26.72 & 174.37 & 0.74 & 0.00 & 64.28 & 46.10 \\
\hline 50 & 6 & A & 15.97 & 15.83 & 11.07 & 9.40 & 0.00 & 0.00 & 0.56 & 16.80 & 26.72 & 210.90 & 0.00 & 0.00 & 62.86 & 55.80 \\
\hline 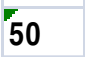 & 6 & B & 12.88 & 13.35 & 10.13 & 8.33 & 6.76 & 0.00 & 0.09 & 17.15 & 26.72 & 185.16 & 6.67 & 0.00 & 64.17 & 49.00 \\
\hline 50 & 6 & C & 12.06 & 13.49 & 9.42 & 8.32 & 7.44 & 0.00 & 0.27 & 18.77 & 26.72 & 187.11 & 7.16 & 0.00 & 70.23 & 49.50 \\
\hline \multirow[t]{5}{*}{50} & 6 & D & 15.44 & 13.71 & 9.42 & 8.13 & 7.44 & 0.00 & 0.45 & 17.10 & 26.72 & 183.05 & 4.78 & 0.00 & 63.99 & 48.40 \\
\hline & & $\mathrm{N}$ & 24 & 24 & 24 & 24 & 24 & 24 & 24 & 24 & 24 & 24 & 24 & 24 & 24 & 24 \\
\hline & & Mean & 13.54 & 13.34 & 9.27 & 8.24 & & 0.43 & 0.32 & 18.38 & 26.72 & 191.03 & 4.37 & 0.29 & 68.79 & 50.54 \\
\hline & & $\sigma$ & 1.57 & 0.88 & 0.89 & 0.68 & 2.45 & 0.71 & 0.18 & 2.42 & 0.00 & 8.86 & 2.30 & 0.56 & 9.07 & 2.35 \\
\hline & & SE & 0.32 & 0.18 & 0.18 & 0.14 & 0.50 & 0.14 & 0.04 & 0.49 & 0.00 & 1.81 & 0.47 & 0.11 & 1.85 & 0.48 \\
\hline
\end{tabular}


Table 29. Measured distances and areas of the $51 \mathrm{~mm}$ implant series.

\begin{tabular}{|c|c|c|c|c|c|c|c|c|c|c|c|c|c|c|c|c|}
\hline ee & ec & Face & 1 & 2 & 3 & 4 & 5 & 6 & 7 & 8 & 9 & 10 & $5 a$ & $6 a$ & $8 a$ & \\
\hline 51 & 1 & A & 12.64 & 12.38 & 9.37 & 9.06 & 6.85 & 2.56 & 0.69 & 22.53 & 26.61 & 188.84 & 6.16 & 1.87 & 84.69 & 0.48 \\
\hline 1 & 1 & B & 49 & 11.89 & 8.93 & 8.04 & 3 & 2.56 & 0.87 & 18.67 & 26.61 & 184.76 & 4.16 & 1.69 & .16 & 47 \\
\hline 1 & 1 & & 73 & 07 & & 8.41 & 4 & 1.88 & 87 & 3 & 26.61 & .22 & 6.96 & 1.21 & 39 & 46 \\
\hline 1 & 1 & D & .51 & 12.09 & 5 & 7.36 & 0 & 1.31 & 0.87 & 19.52 & 26.61 & 3.94 & 3.02 & 0.44 & 36 & 47 \\
\hline 1 & a & 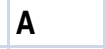 & 8.24 & 58 & 8.09 & 8.69 & 6.99 & 2.85 & 0.96 & .42 & 26.61 & .13 & 6.03 & 1.89 & 77 & 50 \\
\hline 1 & 2 & 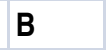 & 0 & 3 & 8.12 & 8.06 & & 0.00 & 0.82 & 9 & 26.61 & .58 & 6.02 & 0 & & \\
\hline 1 & 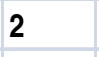 & C & 1.78 & 11.89 & 8.92 & 8.84 & 7.45 & 0.00 & 0.43 & 17.17 & 26.61 & 192.50 & 7.01 & 0.00 & 53 & 0.49 \\
\hline 1 & 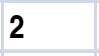 & D & 1.24 & 11.73 & 9.10 & 8.38 & 6.37 & 2.27 & 0.86 & 23.14 & 26.61 & 202.48 & 5.52 & 1.41 & 86.96 & 0.52 \\
\hline & 3 & 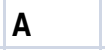 & & & & 5 & & 1.41 & & 7 & 26.61 & 63 & 6 & 8 & & \\
\hline 51 & 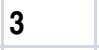 & B & 3.59 & 13.66 & 8.92 & 7.73 & 6.50 & 3.06 & 0.90 & 24.63 & 26.61 & 209.18 & 5.60 & 2.15 & .56 & 0.54 \\
\hline 1 & . & C & .39 & 12.42 & 35 & 7.23 & 3.28 & 0.00 & 0.62 & 17.05 & 26.61 & 190.43 & 2.66 & 0.00 & .07 & 0.49 \\
\hline & 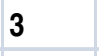 & - & 63 & 51 & & 4.55 & 2.04 & 0.00 & 0.49 & 16.36 & 26.61 & .37 & 1.55 & 0.00 & & 0. \\
\hline 1 & 4 & A & 2.72 & 12.47 & 9.36 & 7.31 & 1.44 & 0.00 & 0.66 & 16.21 & 26.61 & 173.28 & 0.78 & 0.00 & 60.92 & 0.44 \\
\hline 1 & 1. & 5 & & & & 6.67 & & 1.31 & c & 1 & 26.61 & 85 & 1 & . & ( & 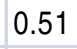 \\
\hline 1 & 4 & 0 & .42 & 11.54 & 4 & 6.98 & 4.34 & 0.00 & 0.83 & 18.17 & 26.61 & .51 & 3.51 & 0.00 & 28 & 0.46 \\
\hline 51 & 4 & D & 87 & 5 & 7.29 & 6.91 & 4.96 & 2.58 & 0.79 & 22.39 & 26.61 & 172.30 & 4.17 & 1.79 & .15 & 0.44 \\
\hline 54 & - & A & & & & 8.15 & & 0.00 & & & 26.61 & 92 & 7 & 0.00 & & \\
\hline 51 & 5 & $B$ & .37 & 11.56 & 8.09 & 8.13 & 6.82 & 2.95 & 0.64 & 26.10 & 26.61 & 195.43 & 6.17 & 2.30 & 98.09 & 0.50 \\
\hline 1 & $\mathrm{~J}$ & 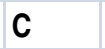 & 87 & 11.65 & 1 & 7.79 & 6.75 & 4.13 & 0.78 & 20.60 & 26.61 & 185.72 & 5.97 & 3.35 & 77.41 & 0.48 \\
\hline 1 & - & - & & 16 & & 7.50 & & 0.00 & & & 26.61 & 160.80 & 1.28 & 0 & & \\
\hline 51 & 6 & A & & 0 & 7.15 & 6.07 & 3.37 & 0.00 & 0.26 & 16.90 & 26.61 & 160.12 & 3.12 & 0.00 & .52 & 0.41 \\
\hline- & 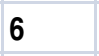 & - & & & & 7.00 & & 1.85 & & 20.44 & 26.61 & .84 & 4.35 & 1.16 & 82 & c \\
\hline 51 & 0 & C & .23 & 29 & 7.00 & 5.89 & 1 & 0.00 & 66 & 17.81 & 26.61 & 182.69 & 2.85 & 0.00 & 94 & 0.47 \\
\hline \multirow[t]{5}{*}{51} & 6 & D & & & & 5.99 & & 2.78 & 1.04 & 22.38 & 26.61 & 170.39 & 2.73 & 1.74 & 84.11 & 0.44 \\
\hline & & $\mathrm{N}$ & & & 44 & & 24 & 4 & 24 & & 24 & 24 & 24 & 24 & 24 & 4 \\
\hline & & Me & & & & & & & 0.7 & 19. & 26. & 182 & 4.31 & 0.94 & 73.39 & 0.47 \\
\hline & & $\sigma$ & 1.75 & & 0.70 & 1. & & 1.34 & 0.19 & & 0.00 & & 82 & 99 & 1.80 & 03 \\
\hline & & SE & 0.36 & 26 & 0.14 & 22 & 0.37 & 0.27 & 0.04 & 0.64 & 0.00 & 2.78 & 0.37 & 0.20 & 2.41 & 0.01 \\
\hline
\end{tabular}


Table 30. Measured distances and areas of the $52 \mathrm{~mm}$ implant series.

\begin{tabular}{|c|c|c|c|c|c|c|c|c|c|c|c|c|c|c|c|c|}
\hline ze & Spec & ce & & & & 1 & 5 & 6 & 7 & 8 & 9 & 10 & $5 a$ & $6 a$ & $3 a$ & a \\
\hline 2 & 1 & A & 96 & 7.50 & 5.75 & 6.04 & 4.66 & 2.89 & 1.53 & 24.83 & 26.30 & 174.33 & 3.13 & 1.36 & 94.41 & .47 \\
\hline & 1 & & .04 & 9.69 & 7.50 & 6.24 & 3.67 & 99 & 1.19 & 50 & 26.30 & & 2.47 & 79 & .92 & \\
\hline & 1 & 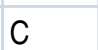 & 51 & 9.20 & 7.21 & 6.69 & 4.21 & 1.87 & 0.91 & 20.49 & 26.30 & 4.68 & 3.30 & 0.96 & 7.90 & .56 \\
\hline & 1 & & .09 & 9.61 & 6.51 & 5.87 & 3.35 & 2.18 & 1.41 & .14 & 26.30 & .20 & 1.94 & 78 & .18 & 6 \\
\hline & 2 & & .75 & 10.65 & 6.86 & 5.04 & 3.20 & 94 & 1.17 & .01 & 26.30 & & 2.03 & 77 & .87 & .6 \\
\hline & 2 & B & 11 & 9.85 & 6.87 & 5.59 & 2.92 & 2.61 & 1.52 & 97 & 26.30 & .85 & 1.39 & 1.08 & 72.11 & .8 \\
\hline & 2 & & .33 & 10.24 & 7.41 & 6.55 & 5.25 & 3.32 & 1.26 & .37 & 26.30 & .08 & 4.00 & 2.06 & 88.87 & .40 \\
\hline & 2 & D & .25 & 9.96 & 7.16 & 39 & 5.27 & 2.80 & 1.17 & 22.64 & 26.30 & & 4.10 & 33 & 08 & .5 \\
\hline & 3 & $A$ & .83 & 14.83 & 5.96 & 5.90 & 3.87 & 2.71 & 1.02 & 19.87 & 26.30 & .71 & 2.85 & 1.69 & 75.55 & 46.3 \\
\hline & 3 & & .01 & 11.34 & 6.62 & 6.17 & 4.38 & 3.21 & 1.04 & 21.20 & 26.30 & & 3.35 & 17 & .60 & 37 \\
\hline & 3 & & 58 & 9.83 & 7.50 & 75 & 5.01 & 2.77 & 1.25 & 23.66 & 30 & & 3.76 & 33 & & 1.3 \\
\hline & 3 & D & .01 & 10.56 & 7.10 & 6.35 & 6.02 & 3.84 & 1.86 & 22.60 & 26.30 & .46 & 4.17 & 1.98 & 94 & 3.4 \\
\hline & 4 & A & 5 & 8.34 & 49 & 6.02 & 4.94 & 3.09 & 1.72 & .24 & 30 & & 3.22 & . & & \\
\hline & 4 & & .28 & 9.70 & 6.59 & 5.86 & 2.58 & 79 & 1.14 & .66 & 30 & & 1.44 & 5 & 76 & 4 \\
\hline & 4 & $C$ & .05 & 9.41 & 7.15 & 6.65 & 4.88 & 3.06 & 1.26 & 22.70 & 26.30 & .10 & 3.62 & 1.79 & 86.29 & 45.41 \\
\hline & 4 & & 35 & 9.03 & 6.96 & 13 & 5.30 & 31 & 1.32 & 25 & 30 & & 3.99 & & 40 & 4 \\
\hline & 5 & & 89 & 63 & 26 & 5 & 6.48 & 8 & 0.99 & 98 & 30 & & 5.48 & 88 & .6 & 52.5 \\
\hline & 5 & B & 36 & 9.42 & 7.01 & 5.58 & 3.41 & 2.20 & 1.53 & 19.88 & 26.30 & 38 & 1.88 & 0.66 & 75.60 & 40.9 \\
\hline & 5 & & 56 & 10.01 & 6.74 & & & & & 41 & & & & & & \\
\hline & 5 & D & .40 & 9.39 & 6.23 & 4 & 5.32 & 2.98 & 1.04 & .97 & 30 & 1 & 4.28 & 94 & 5 & .50 \\
\hline & 6 & & & 9.35 & 52 & 7.64 & 5.87 & 2.92 & 1.54 & 24.49 & 26.30 & & 4.33 & 1.37 & 93.13 & 45.0 \\
\hline & 6 & & & 9.56 & 85 & & 5.39 & & 1.90 & 39 & & & 3.49 & 00 & & .13 \\
\hline & 6 & C & & 9.60 & 6.88 & 6.73 & 5.02 & 2.70 & 1.20 & 21.26 & 26.30 & 25 & 3.82 & 1.50 & 80.85 & 44.2 \\
\hline & 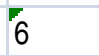 & & & & 30 & & 56 & 59 & 1.27 & .15 & 30 & 01 & 3.29 & 1.32 & 3.03 & 43.1 \\
\hline & & $\mathbf{N}$ & & 24 & 24 & 24 & 24 & 24 & 24 & 24 & 24 & & 24 & 4 & 24 & 24 \\
\hline & & & & & 6.86 & & & & & 22.53 & 26.30 & & 3.32 & 56 & 5.65 & 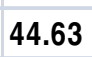 \\
\hline & & $\boldsymbol{\sigma}$ & & 1. & 0.50 & 0.61 & 1.03 & 0.65 & 0.27 & & 0.00 & & 1.03 & c & & .20 \\
\hline & & D & 0.21 & 0.26 & 0.10 & 0.12 & 0.21 & 0.13 & 0.05 & 0.43 & 0.00 & 2.6 & 0.21 & 0.13 & 1.62 & .65 \\
\hline
\end{tabular}


Table 31. Results collected as eleven values for each unique surface.

\begin{tabular}{|l|l|}
\hline Measurement \# & \multicolumn{1}{|c|}{ Description } \\
\hline 1 & Cement penetration from dome (1) \\
\hline 2 & Cement penetration from dome (2) \\
\hline 3 & Cement penetration from chamfer (superior) \\
\hline 4 & Cement penetration from chamfer (inferior) \\
\hline 5 & Cement penetration from wall (inferior) \\
\hline 6 & Actual offset at wall \\
\hline 7 & Actual cement penetration height \\
\hline 8 & Maximum cement penetration height \\
\hline 9 & Cross-sectional area of penetrated cement \\
\hline 10 & $\begin{array}{l}\text { depth of cement penetration from the wall's edge in } \\
\text { the more superior location (measurement 5) minus } \\
\text { the actual implant offset (measurement 7) }\end{array}$ \\
\hline $5 a$ & $\begin{array}{l}\text { depth of cement penetration from the wall's edge in } \\
\text { the more inferior location (measurement 6) minus } \\
\text { the actual implant offset (measurement 7) }\end{array}$ \\
\hline $6 \mathrm{a}$ & $\begin{array}{l}\text { height of cement penetration from the dome's edge } \\
\text { to furthest point down the implant where cement } \\
\text { was penetrating into the foam as a percentage of } \\
\text { the height of the implant }\end{array}$ \\
\hline $8 \mathrm{a}$ & $\begin{array}{l}\text { Ratio of cross sectional area of penetrated cement } \\
\text { (measurement 10) over to total area available to } \\
\text { that size implant }\end{array}$ \\
\hline $10 \mathrm{a}$ &
\end{tabular}




\title{
APPENDIX C
}

\section{Hip Resurfacing Implantation Actual Protocol}

\author{
Resurfacing Foam Study
}

Instron 8511 servo-hydraulic testing machine

Instron Norwood, MA

Setup limits for load and displacement

(use Function stop reset to re enable limits)

limit action should be UNLOAD

if limit is tripped you must turn it off then back on to continue

move down and find the bottom zero position

set the load limit to $-100 \mathrm{~N}$

\section{CAREFULLY USE THE SET POINT BUTTON}

Set the new setpoint to the bottom out number - (insert value here)

Load protect kept coming on and holding the load at $4 \mathrm{~N}$ after hitting the limit Store pmma powder and liquid in cold room until IMMEDIATELY before you are ready to use them

Press the foam into the head and use scotch tape to mark the bottom of the head position on the foam

Place the construct in the instron and gently insert the foam into the loading fixture while holding the head in place

LOOSEN all of the screws in the head fixture and lower the construct into the fixture and preload to $-15 n$ and mark instron position on paper Tighten the screws in opposing pairs 
Raise up the foam to clear the head and remove the head and fixture to the hood Place funnel into the head and fill with pmma powder from the cold room Pour the liquid into the funnel and start the timer for 2 minutes Mix with a wooden cotton swab end and remove the funnel when it is clear of the mixture

Stir in the powder until the timer goes off at 2 minutes Quickly load the fixture with the head into the instron and lower the ram until the liquid comes into contact with the foam (load will start to increase and then use the slow positioning button to lower the ram to the initial bottom position) Slow positioning button moves ram $.5 \mathrm{~mm} /$ second Leave 20-30 newtons load on the head and wait for 2 minutes Hold the foam down and raise the ram to clear the block Loosen the screws and remove the construct 


\section{APPENDIX D}

\section{Minitab statistical analysis report}

\section{General Linear Model: Cement penetration from dome 1 versus SIZE}

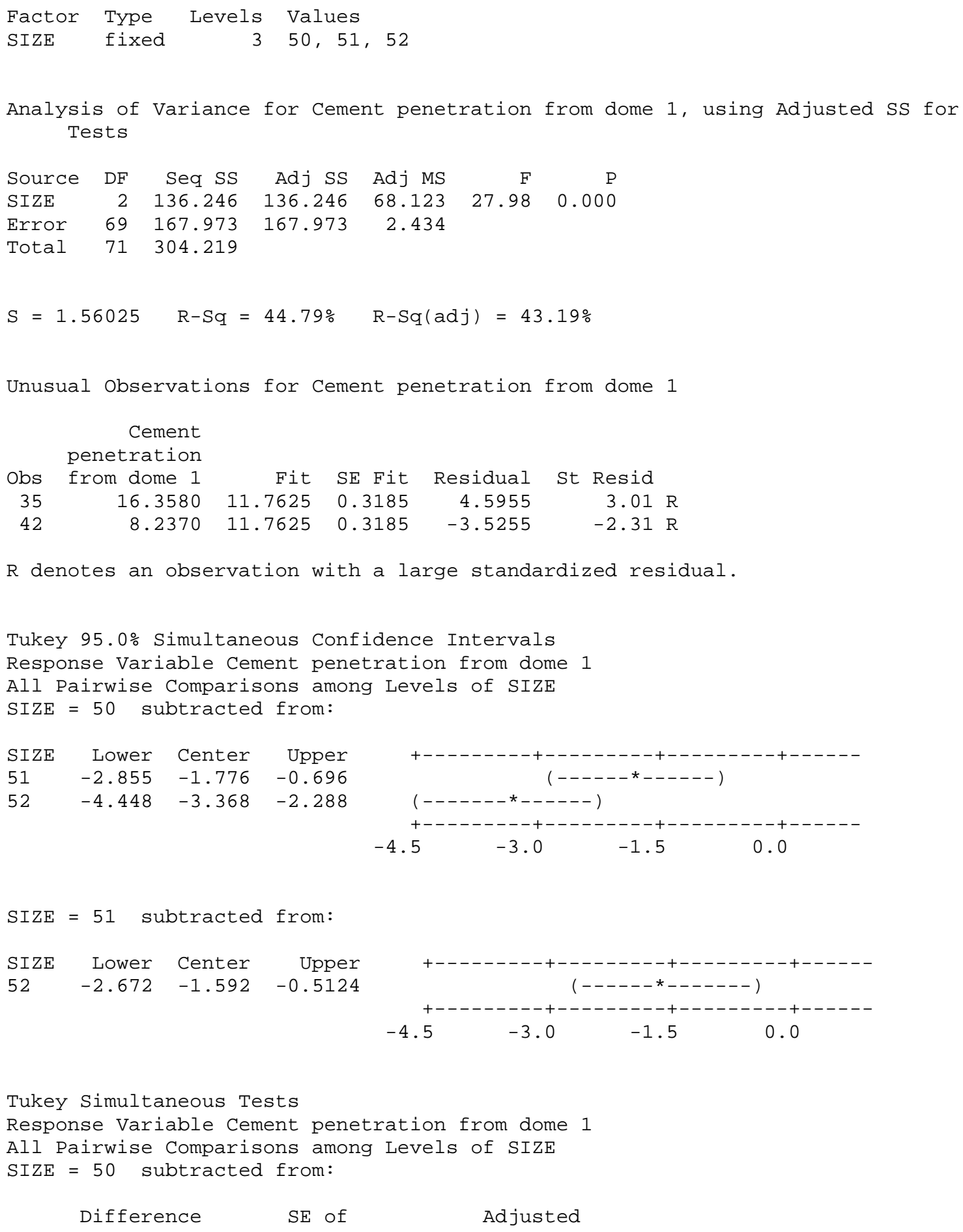

Tukey Simultaneous Tests

Response Variable Cement penetration from dome 1

All Pairwise Comparisons among Levels of SIZE

$\mathrm{SIZE}=50$ subtracted from:
Difference
SE of
Adjusted 


\begin{tabular}{|c|c|c|c|c|}
\hline SIZE & of Means & Difference & T-Value & P-Value \\
\hline 51 & -1.776 & 0.4504 & -3.943 & 0.0006 \\
\hline 52 & -3.368 & 0.4504 & -7.477 & 0.0000 \\
\hline SIZE & subtra & cted from: & & \\
\hline & Difference & $S E$ of & & Adjusted \\
\hline SIZE & of Means & Difference & T-Value & P-Value \\
\hline 52 & -1.592 & 0.4504 & -3.535 & 0.0021 \\
\hline
\end{tabular}

\section{Residual Plots for Cement penetration from dome 1}

\section{General Linear Model: Cement penetration from dome 2 versus SIZE}

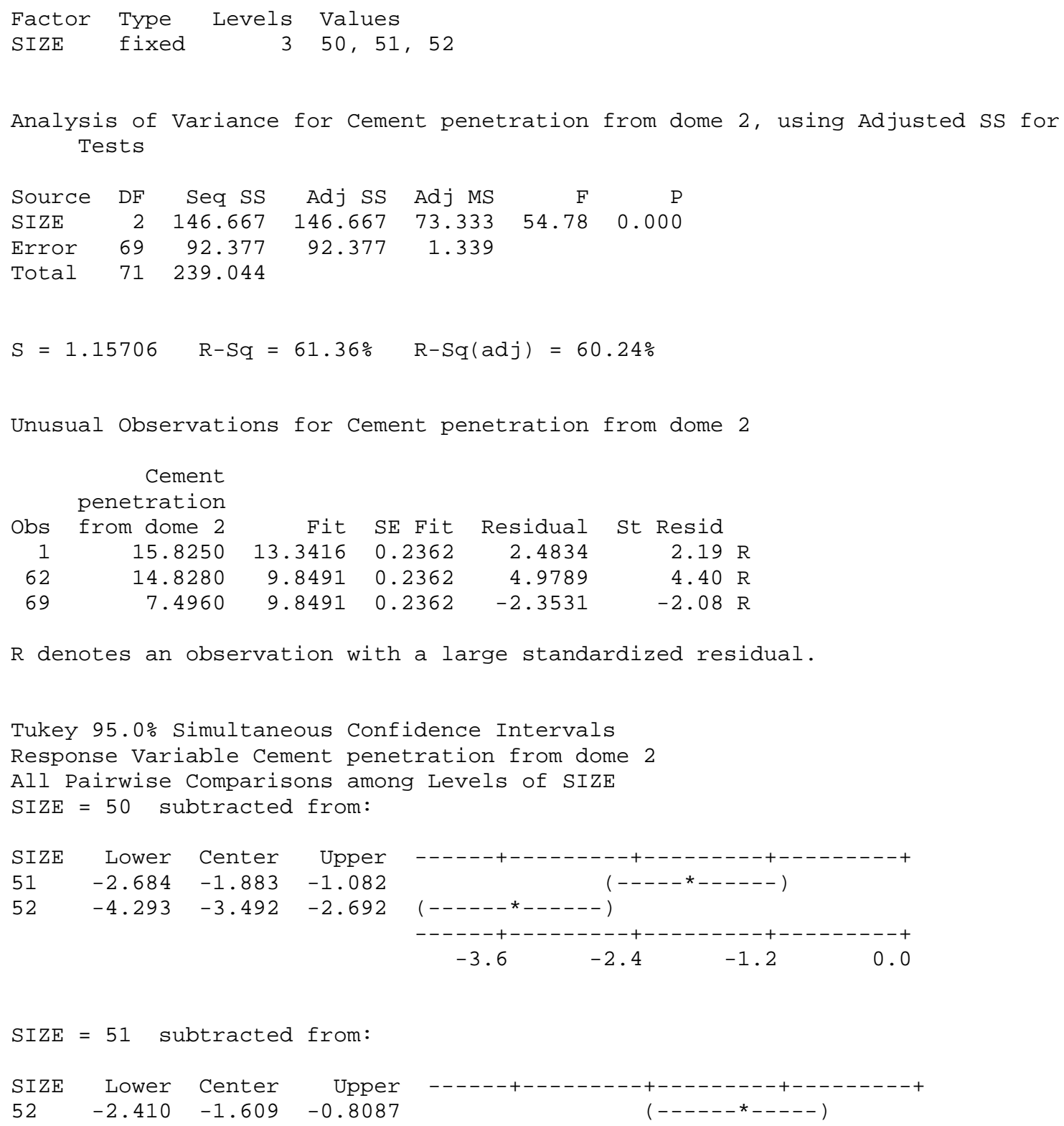




$$
\begin{array}{llll}
-3.6 & -2.4 & -1.2 & 0.0
\end{array}
$$

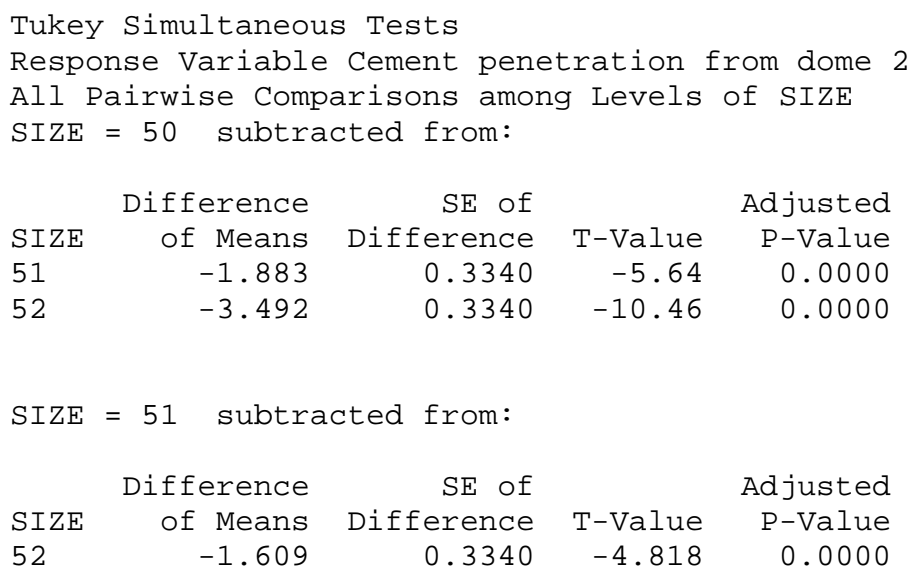

Residual Plots for Cement penetration from dome 2

\section{General Linear Model: cement penetration chamfer 1 versus SIZE}

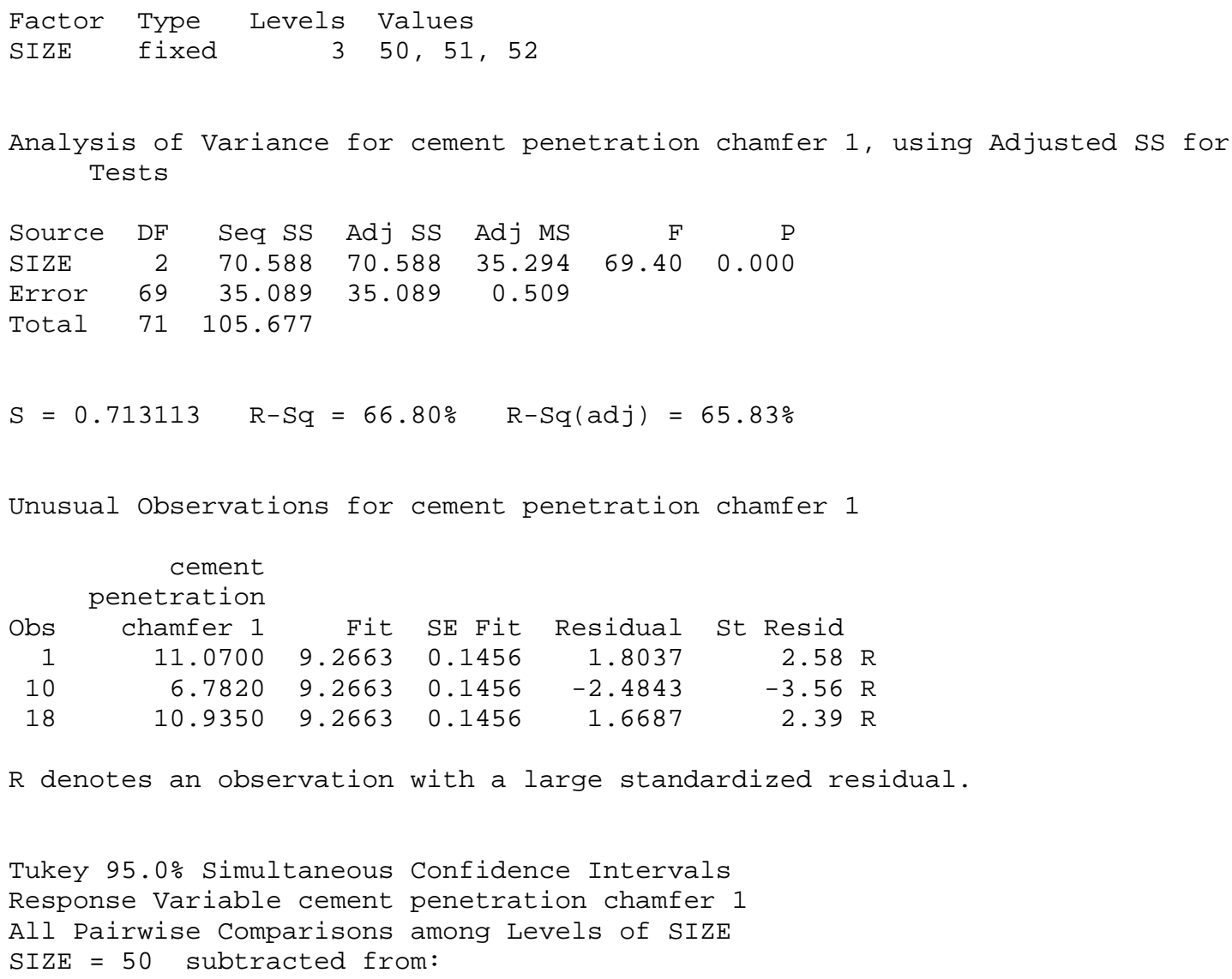

$\mathrm{R}$ denotes an observation with a large standardized residual.

Tukey 95.0\% Simultaneous Confidence Intervals

Response Variable cement penetration chamfer 1

All Pairwise Comparisons among Levels of SIZE

$\mathrm{SIZE}=50$ subtracted from: 

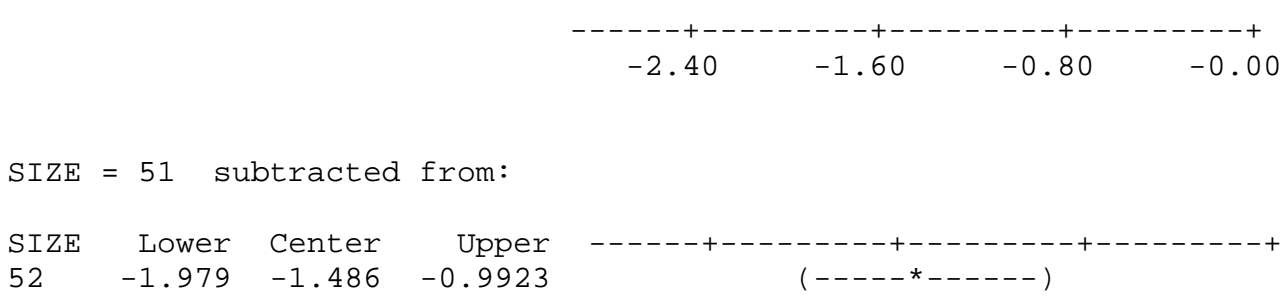

Tukey Simultaneous Tests

Response Variable cement penetration chamfer 1

All Pairwise Comparisons among Levels of SIZE

SIZE $=50$ subtracted from:

$\begin{array}{lrrrr} & \text { Difference } & \text { SE of } & & \text { Adjusted } \\ \text { SIZE } & \text { of Means } & \text { Difference } & \text { T-Value } & \text { P-Value } \\ 51 & -0.917 & 0.2059 & -4.46 & 0.0001 \\ 52 & -2.403 & 0.2059 & -11.67 & 0.0000\end{array}$

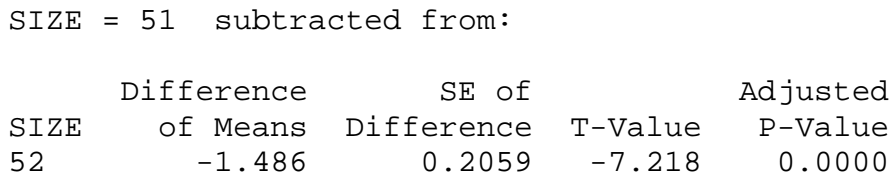

\section{Residual Plots for cement penetration chamfer 1}

\section{General Linear Model: cement penetration chamf 2 versus SIZE}

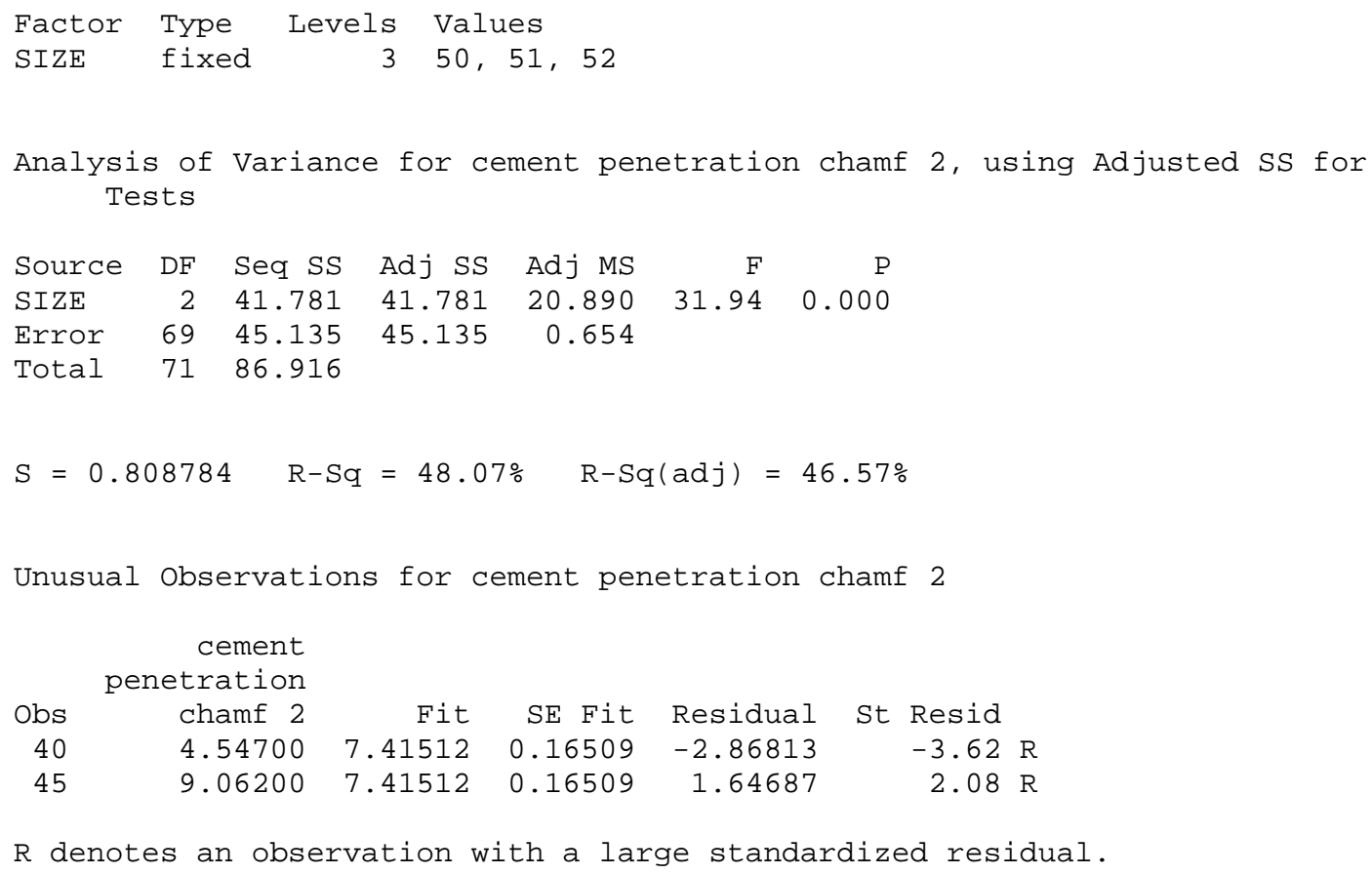




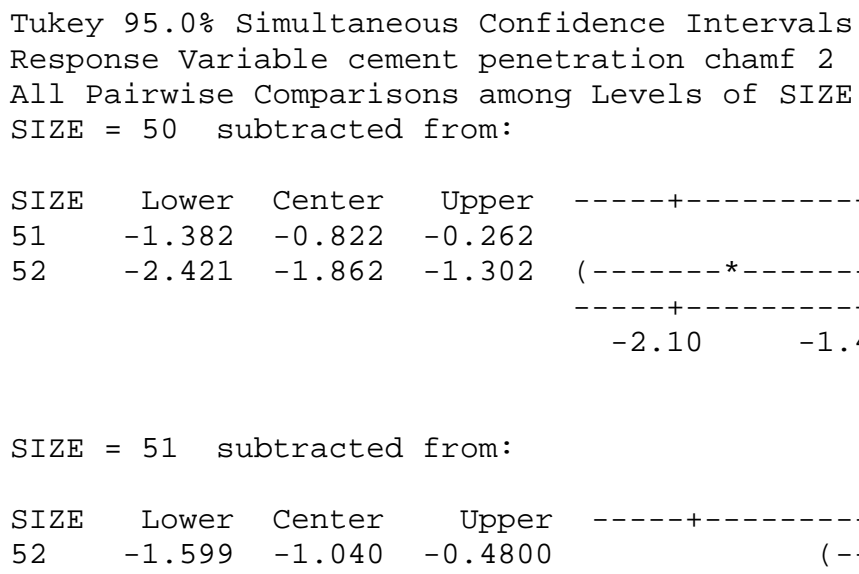

Tukey Simultaneous Tests

Response Variable cement penetration chamf 2

All Pairwise Comparisons among Levels of SIZE

SIZE $=50$ subtracted from:

$\begin{array}{lrrrr} & \text { Difference } & \text { SE of } & & \text { Adjusted } \\ \text { SIZE } & \text { of Means } & \text { Difference } & \text { T-Value } & \text { P-Value } \\ 51 & -0.822 & 0.2335 & -3.521 & 0.0022 \\ 52 & -1.862 & 0.2335 & -7.974 & 0.0000\end{array}$

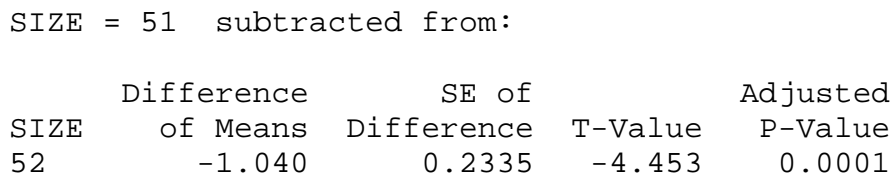

\section{Residual Plots for cement penetration chamf 2}

\section{General Linear Model: cement penetration from wall 1 versus SIZE}

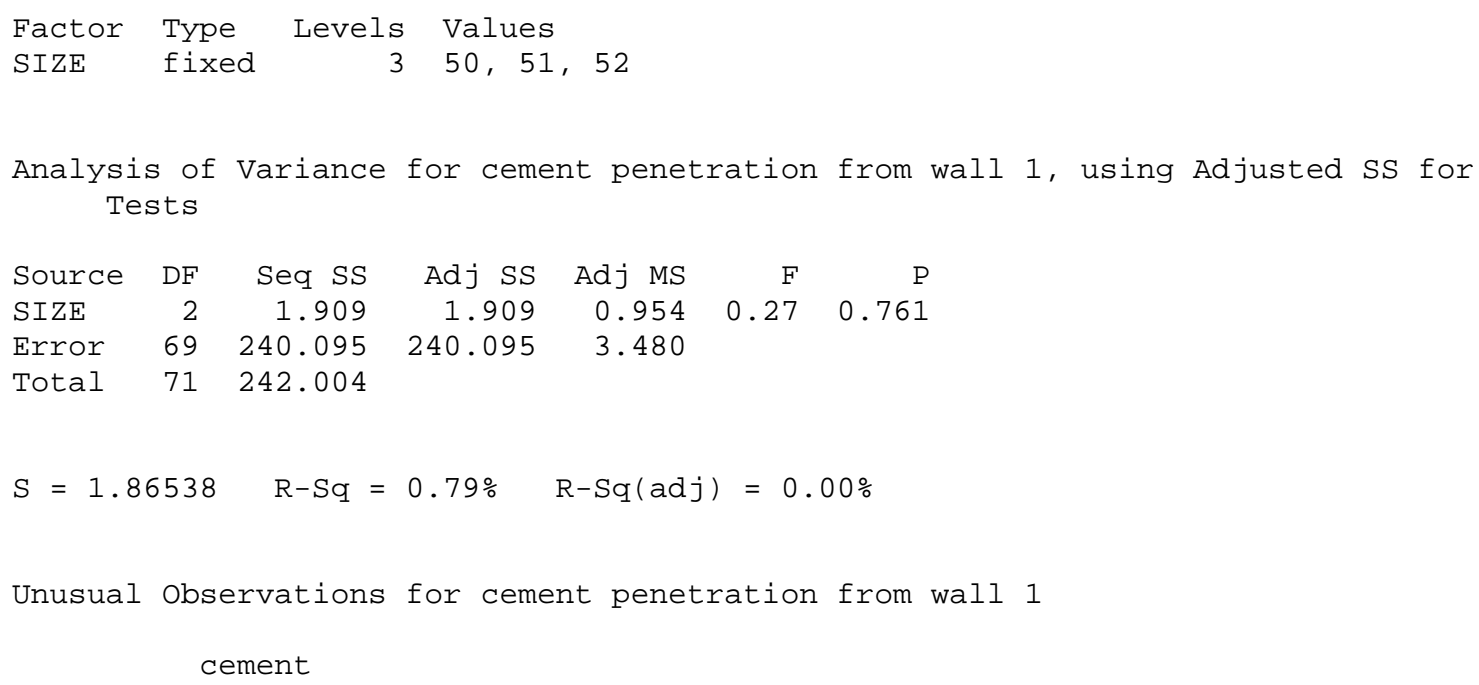




\begin{tabular}{|c|c|c|c|c|c|c|}
\hline Obs & from wall 1 & Fit & SE Fit & Residual & St & Resid \\
\hline 1 & 0.00000 & 4.73667 & 0.38077 & -4.73667 & & -2.59 \\
\hline 8 & 1.01700 & 4.73667 & 0.38077 & -3.71967 & & -2.04 \\
\hline 21 & 0.78200 & 4.73667 & 0.38077 & -3.95467 & & -2.17 \\
\hline 24 & 0.00000 & 4.73667 & 0.38077 & -4.73667 & & -2.59 \\
\hline
\end{tabular}

$\mathrm{R}$ denotes an observation with a large standardized residual.

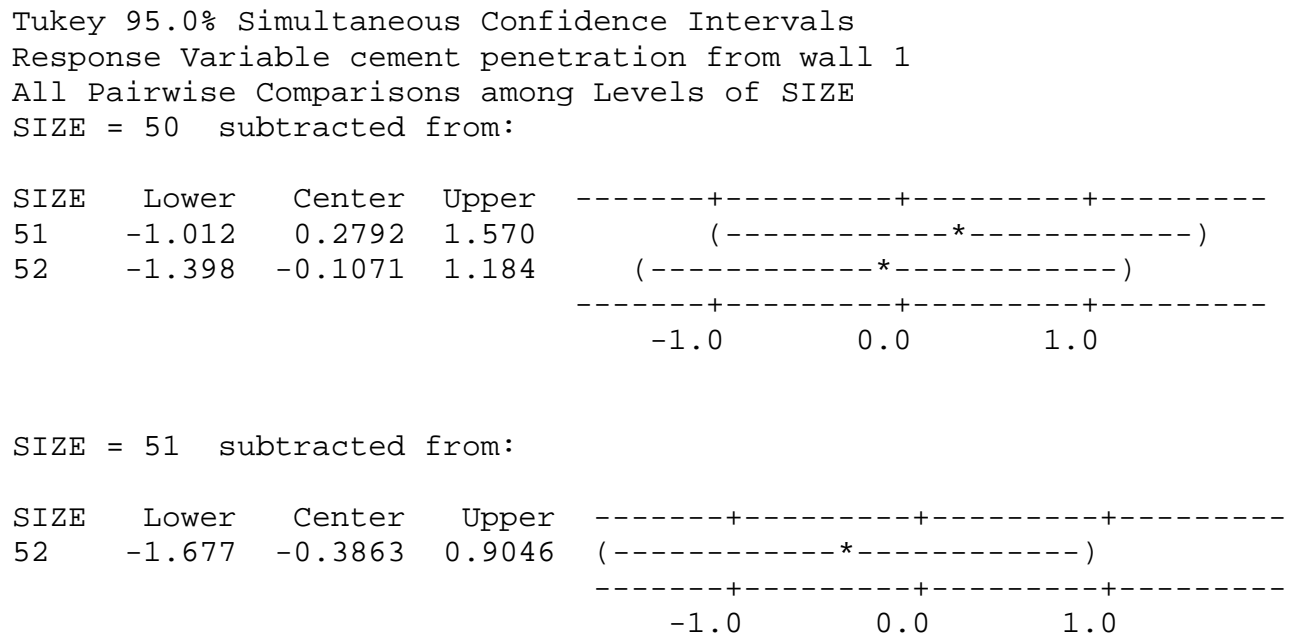

Tukey Simultaneous Tests

Response Variable cement penetration from wall 1

All Pairwise Comparisons among Levels of SIZE

$\mathrm{SIZE}=50$ subtracted from:

\begin{tabular}{|c|c|c|c|c|}
\hline & Difference & $S E$ of & & Adjusted \\
\hline SIZE & of Means & Difference & T-Value & $\mathrm{P}-\mathrm{Vall}$ \\
\hline 51 & 0.2792 & 0.5385 & 0.5184 & \\
\hline 52 & -0.1071 & 0.5385 & -0.1989 & 0.97 \\
\hline
\end{tabular}

SIZE $=51$ subtracted from:

$\begin{array}{lrrrr} & \text { Difference } & \text { SE of } & \text { Adjusted } \\ \text { SIZE } & \text { of Means } & \text { Difference } & \text { T-Value } & \text { P-Value } \\ 52 & -0.3863 & 0.5385 & -0.7173 & 0.7541\end{array}$

Residual Plots for cement penetration from wall 1

General Linear Model: 5a: Relative Penetration $(\mathrm{mm})$ versus Size $(\mathrm{mm})$

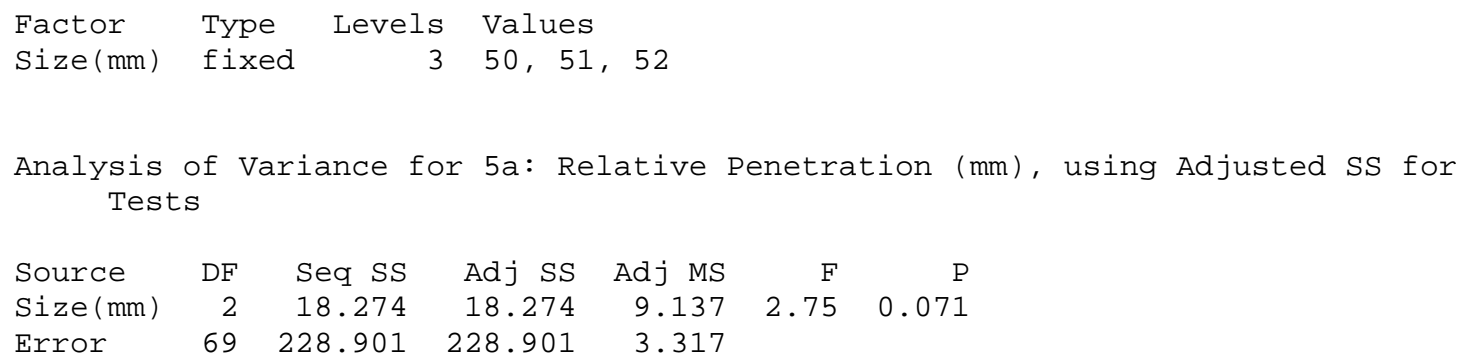




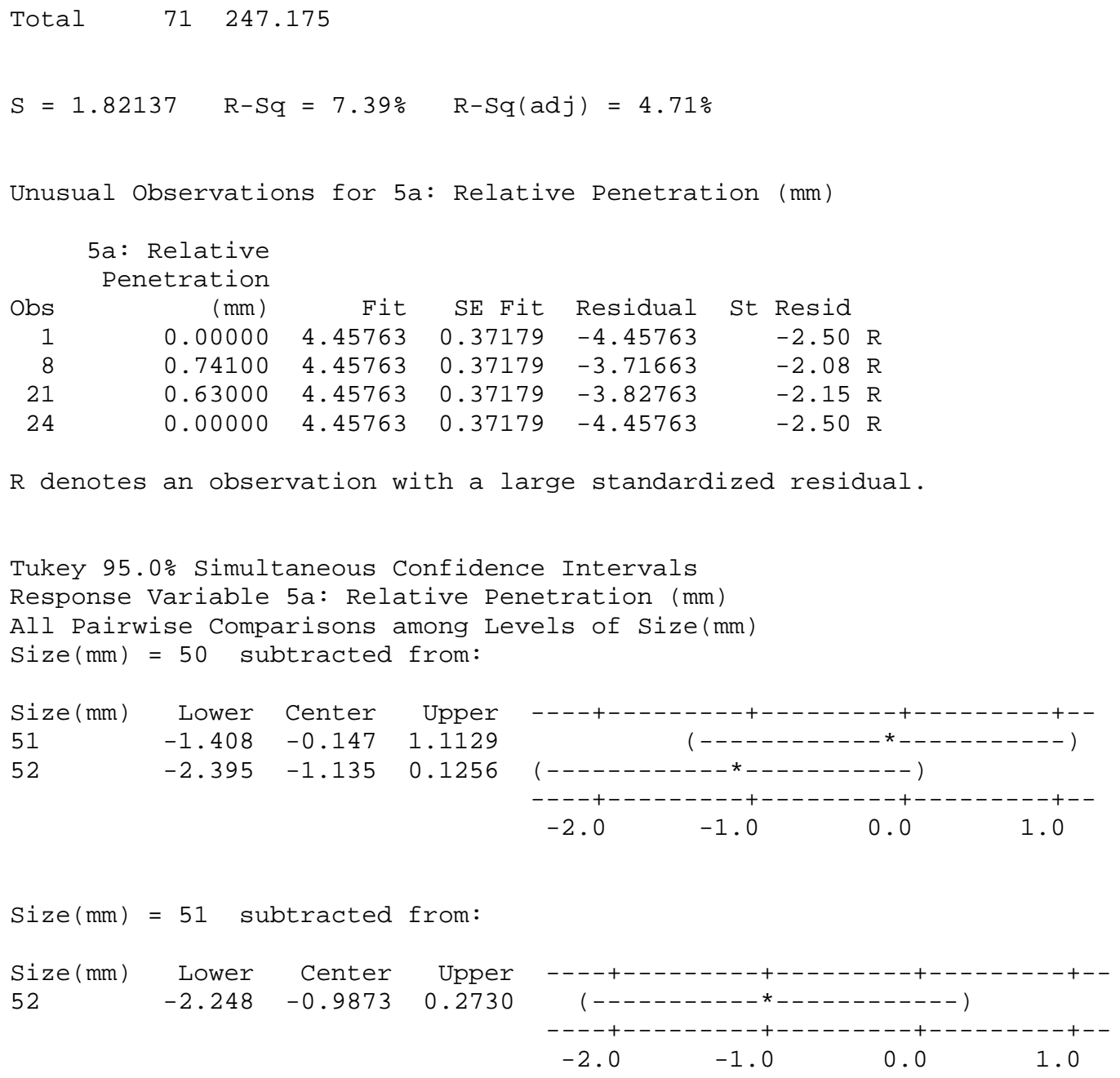

\begin{tabular}{|c|c|}
\hline-2.0 & -1.0 \\
\hline
\end{tabular}

Tukey Simultaneous Tests

Response Variable 5a: Relative Penetration (mm)

All Pairwise Comparisons among Levels of Size(mm)

Size $(\mathrm{mm})=50$ subtracted from:

$\begin{array}{lrrrr} & \text { Difference } & \text { SE of } & \text { Adjusted } \\ \text { Size }(\mathrm{mm}) & \text { of Means } & \text { Difference } & \text { T-Value } & \text { P-Value } \\ 51 & -0.147 & 0.5258 & -0.280 & 0.9576 \\ 52 & -1.135 & 0.5258 & -2.158 & 0.0858\end{array}$

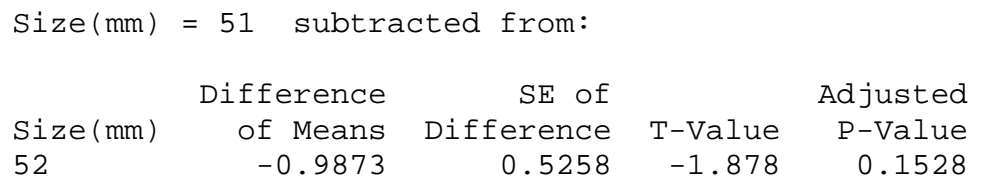

\section{General Linear Model: cement penetration from wall 2 versus SIZE}

$\begin{array}{llrl}\text { Factor } & \text { Type } & \text { Levels } & \text { Values } \\ \text { SIZE } & \text { fixed } & 3 & 50,51,52\end{array}$




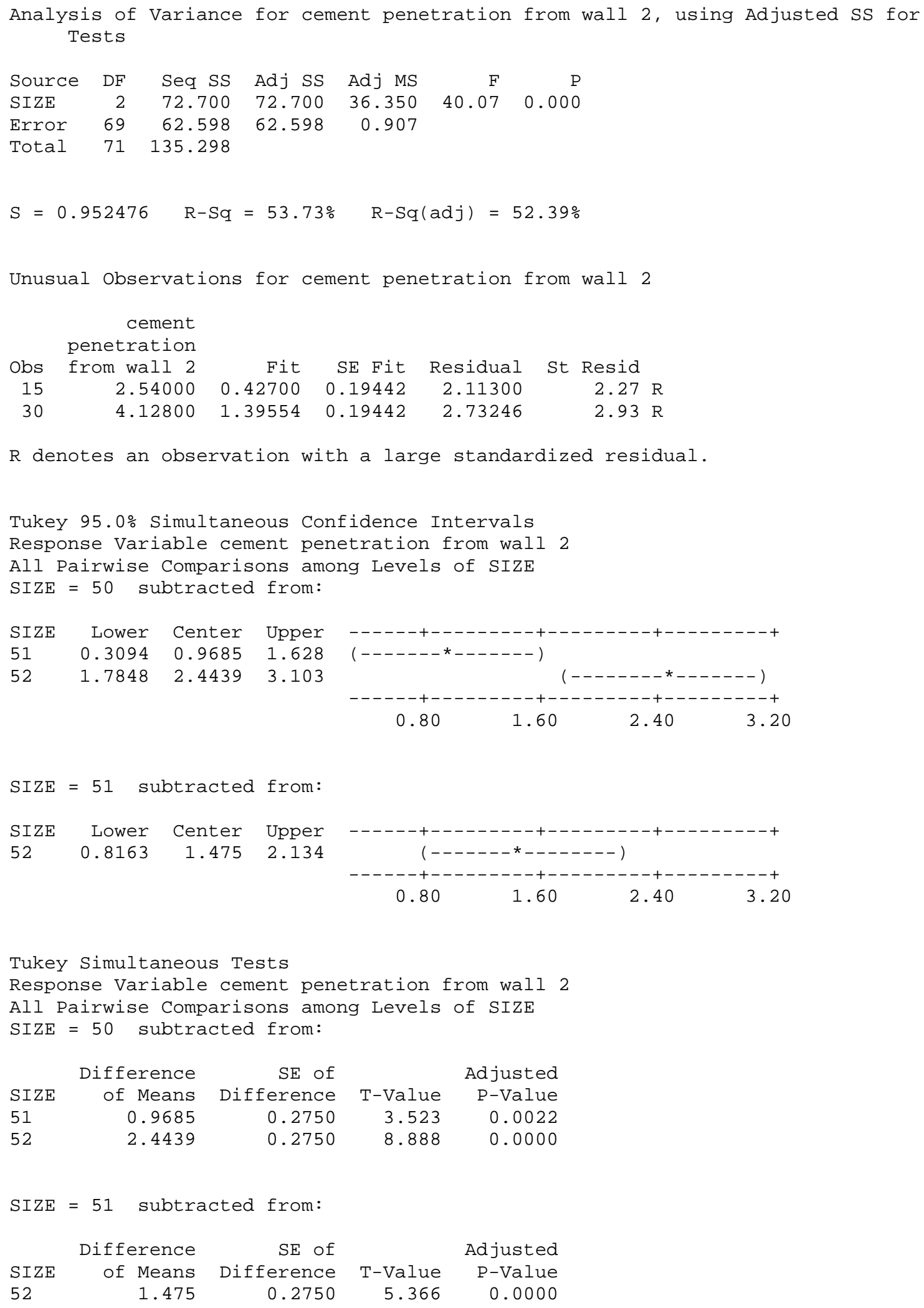

Tukey Simultaneous Tests

Response Variable cement penetration from wall 2

All Pairwise Comparisons among Levels of SIZE

SIZE $=50$ subtracted from:

$\begin{array}{lrrrr} & \text { Difference } & \text { SE of } & \text { Adjusted } \\ \text { SIZE } & \text { of Means } & \text { Difference } & \text { T-Value } & \text { P-Value } \\ 51 & 0.9685 & 0.2750 & 3.523 & 0.0022 \\ 52 & 2.4439 & 0.2750 & 8.888 & 0.0000\end{array}$

$\begin{array}{lrrrr}\text { SIZE }=51 & \text { subtracted from: } & \\ & \text { Difference } & \text { SE of } & & \text { Adjusted } \\ \text { SIZE } & \text { of Means } & \text { Difference } & \text { T-Value } & \text { P-Value } \\ 52 & 1.475 & 0.2750 & 5.366 & 0.0000\end{array}$

Residual Plots for cement penetration from wall 2 


\section{General Linear Model: 6a: Relative Penetration $(\mathrm{mm})$ versus Size $(\mathrm{mm})$}

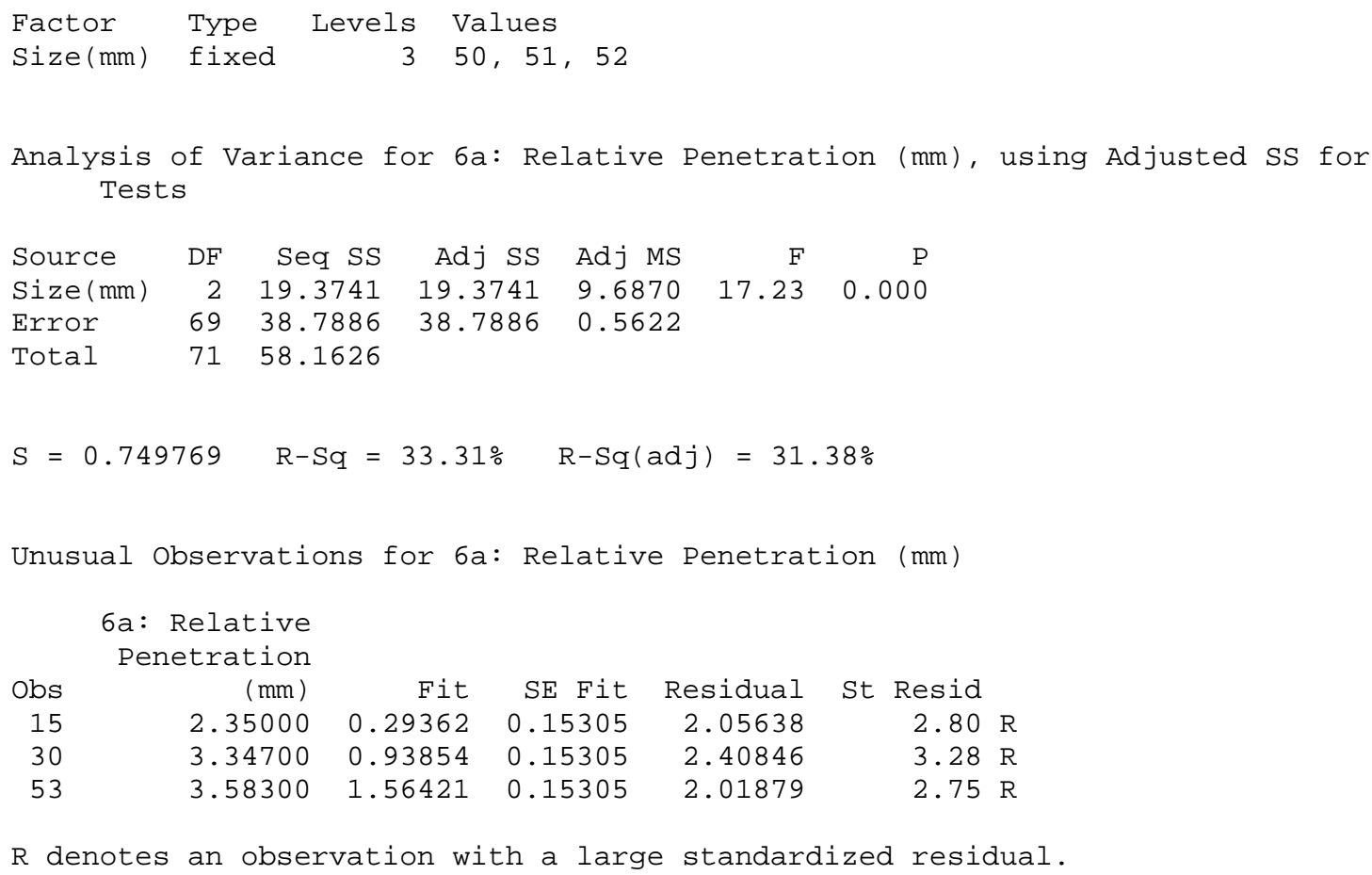

$\mathrm{R}$ denotes an observation with a large standardized residual.

Tukey 95.0\% Simultaneous Confidence Intervals

Response Variable 6a: Relative Penetration (mm)

All Pairwise Comparisons among Levels of Size(mm)

Size $(\mathrm{mm})=50$ subtracted from:

Size $(\mathrm{mm})$ Lower Center Upper

$\begin{array}{llll}51 & 0.1261 & 0.6449 & 1.164\end{array}$

$\begin{array}{llll}52 & 0.7518 & 1.2706 & 1.789\end{array}$
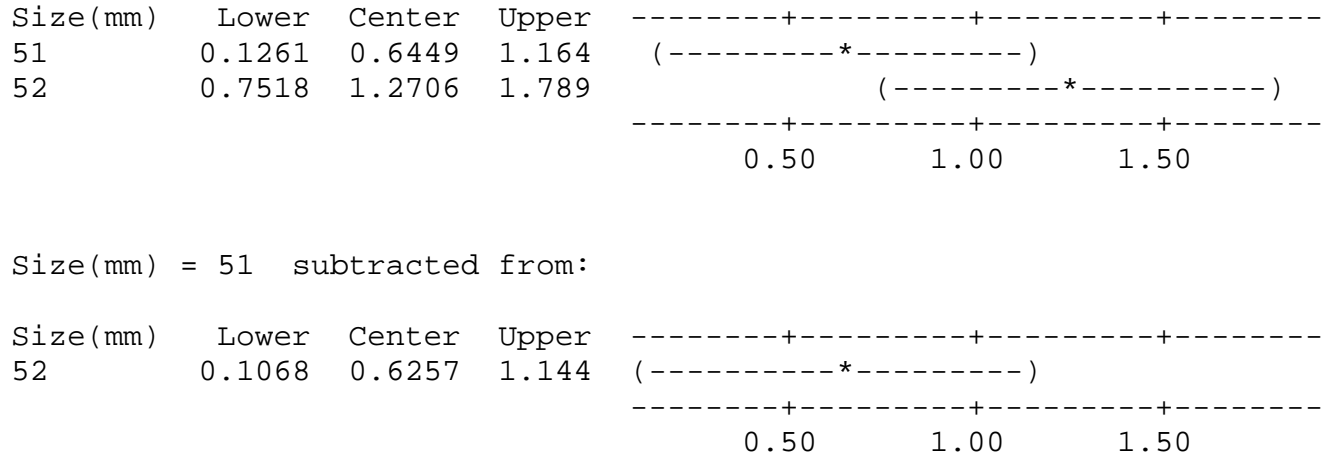

Tukey Simultaneous Tests

Response Variable 6a: Relative Penetration (mm)

All Pairwise Comparisons among Levels of Size(mm)

Size $(\mathrm{mm})=50$ subtracted from:

$\begin{array}{lrrrr} & \text { Difference } & \text { SE of } & \text { Adjusted } \\ \text { Size }(\mathrm{mm}) & \text { of Means } & \text { Difference } & \text { T-Value } & \text { P-Value } \\ 51 & 0.6449 & 0.2164 & 2.980 & 0.0110 \\ 52 & 1.2706 & 0.2164 & 5.870 & 0.0000\end{array}$

Size $(\mathrm{mm})=51$ subtracted from: 


$\begin{array}{lrrrr} & \text { Difference } & \text { SE of } & \text { Adjusted } \\ \text { Size }(\mathrm{mm}) & \text { of Means } & \text { Difference } & \text { T-Value } & \text { P-Value } \\ 52 & 0.6257 & 0.2164 & 2.891 & 0.0141\end{array}$

\section{Residual Plots for 6a: Relative Penetration (mm)}

\section{General Linear Model: actual offset at wall versus SIZE}

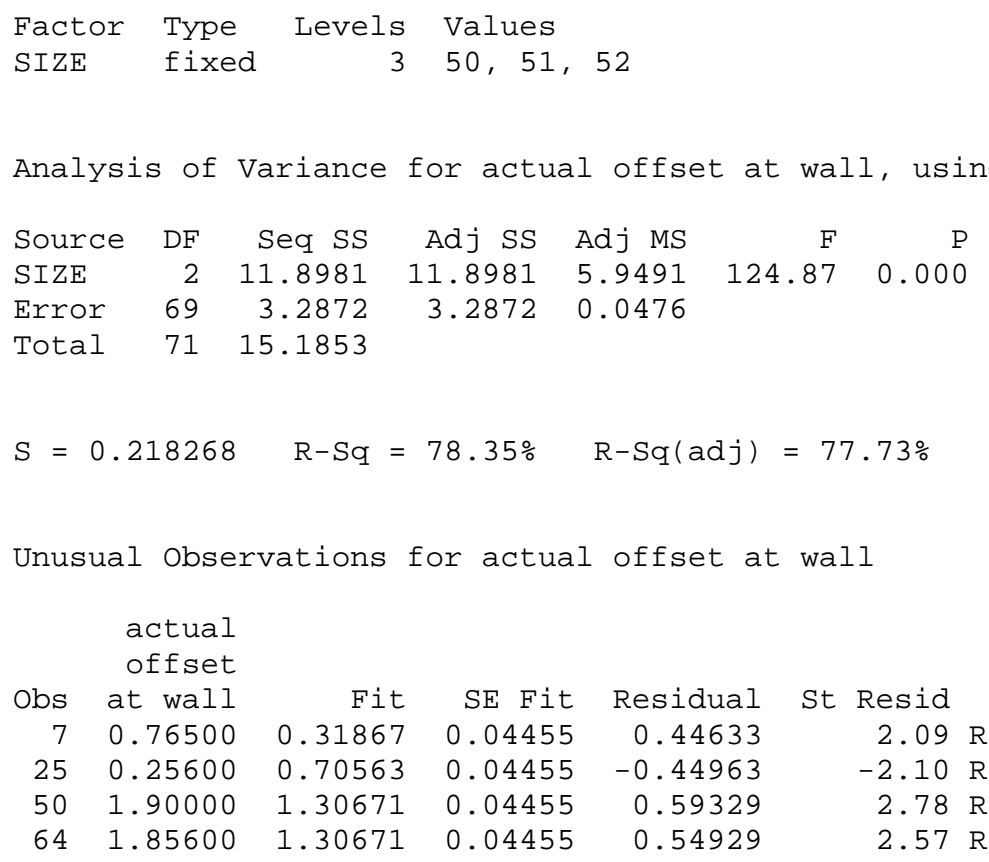

$\mathrm{R}$ denotes an observation with a large standardized residual.

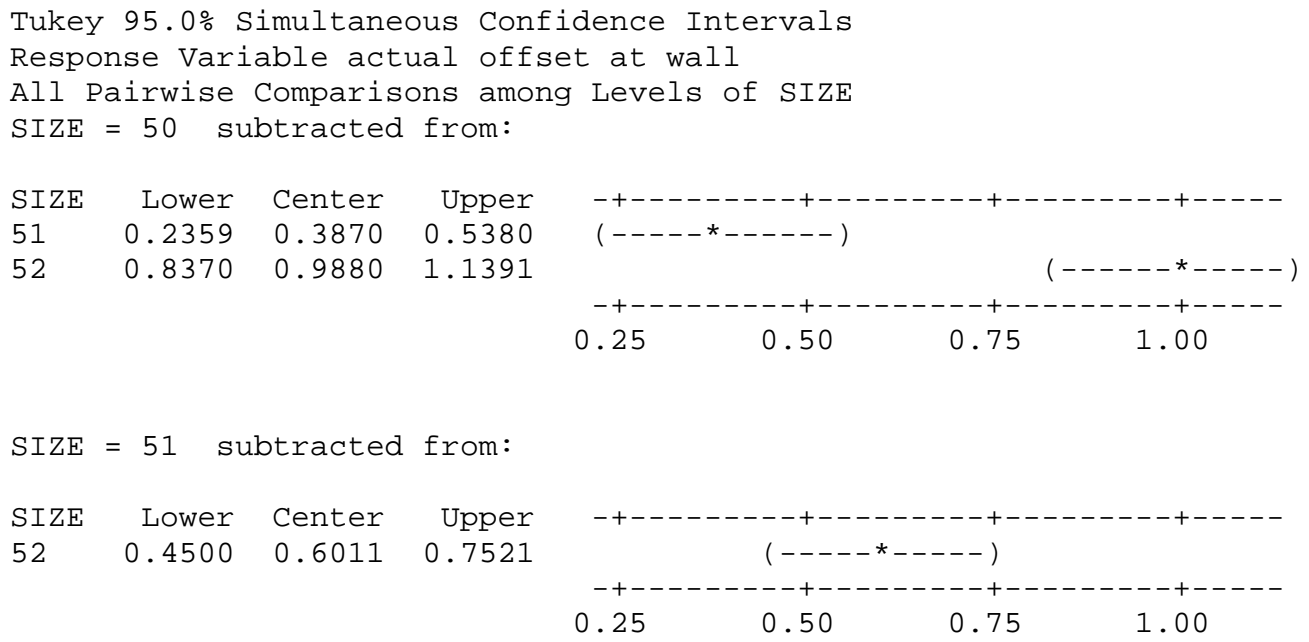

Tukey Simultaneous Tests Response Variable actual offset at wall All Pairwise Comparisons among Levels of SIZE $\mathrm{SIZE}=50$ subtracted from: 


\begin{tabular}{lrrrr} 
SIZE & $\begin{array}{r}\text { Difference } \\
\text { of Means }\end{array}$ & $\begin{array}{r}\text { SE of } \\
\text { Difference }\end{array}$ & $\begin{array}{r}\text { T-Value } \\
\text { P-Value }\end{array}$ \\
51 & 0.3870 & 0.06301 & 6.141 & 0.0000 \\
52 & 0.9880 & 0.06301 & 15.681 & 0.0000 \\
SIZE $=51$ & subtracted from: & & \\
\multicolumn{5}{c}{} \\
SIZE & Difference & SE of & & Adjusted \\
52 & 0.6011 & 0.06301 & 9.540 & 0.0000
\end{tabular}

\section{Residual Plots for actual offset at wall}

\section{General Linear Model: actual cement penetration heigh versus SIZE}

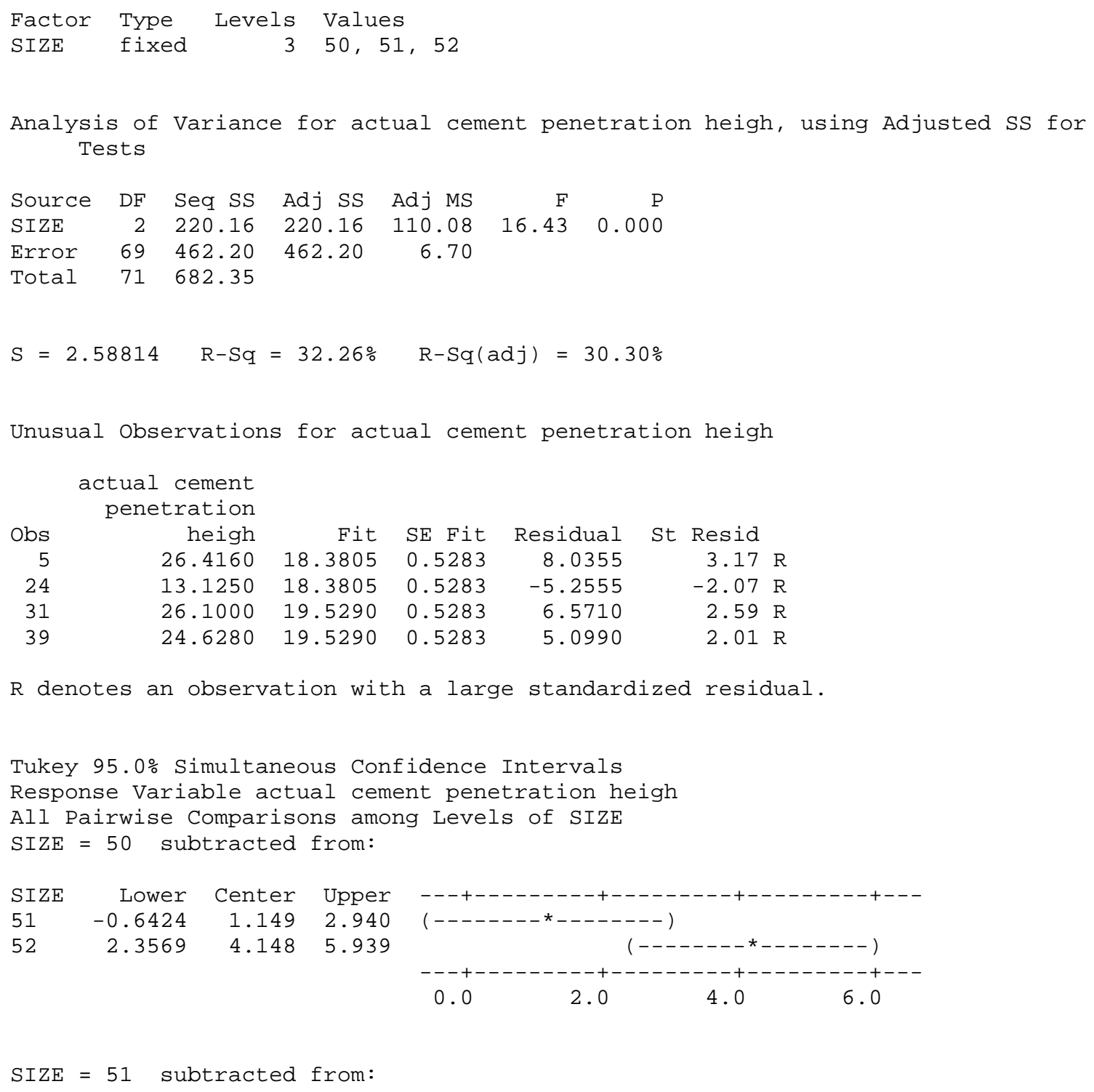




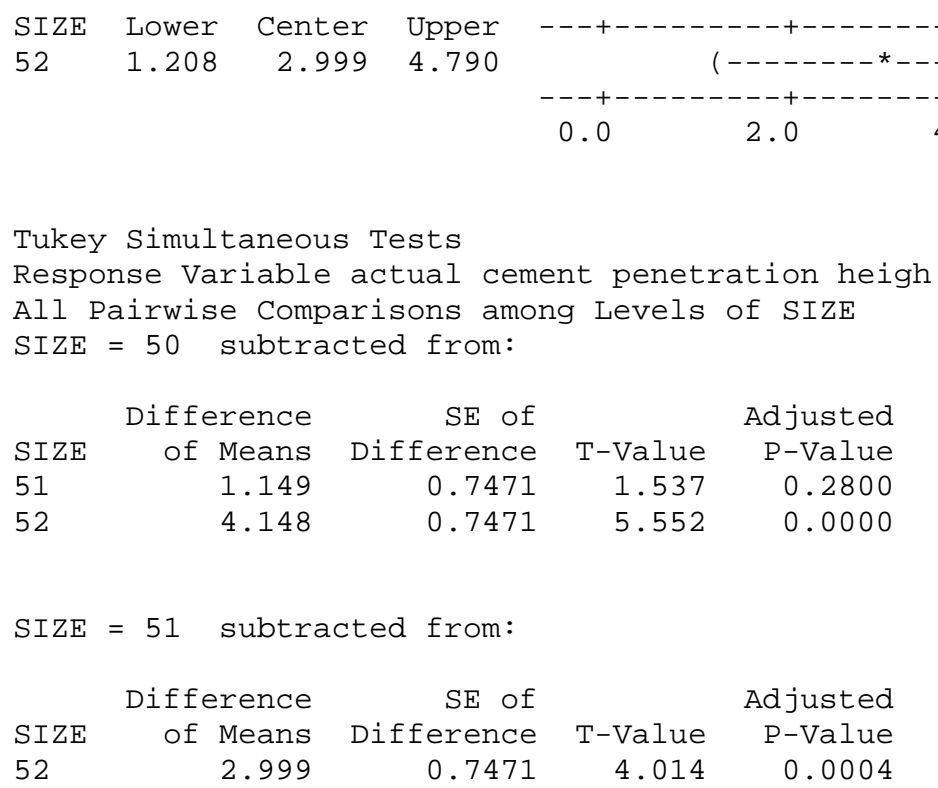

\section{Residual Plots for actual cement penetration heigh}

* NOTE * Distribution could not be fit. The number of distinct rows of data

* must be greater than or equal to the number of estimated

* distribution parameters.

General Linear Model: cement penetration height maxim versus SIZE

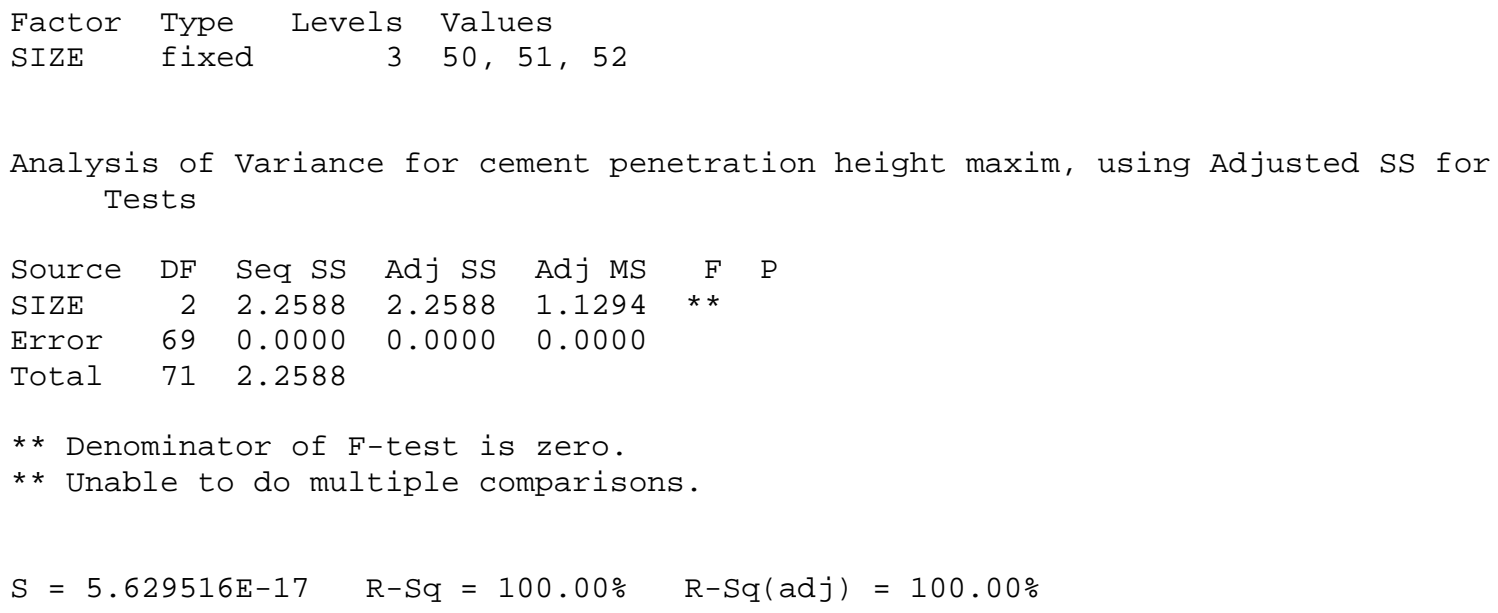

\section{Residual Plots for cement penetration height maxim}

\section{General Linear Model: crossectional area of penetrate versus SIZE}

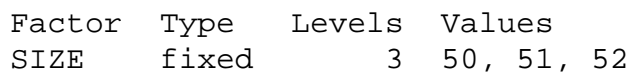




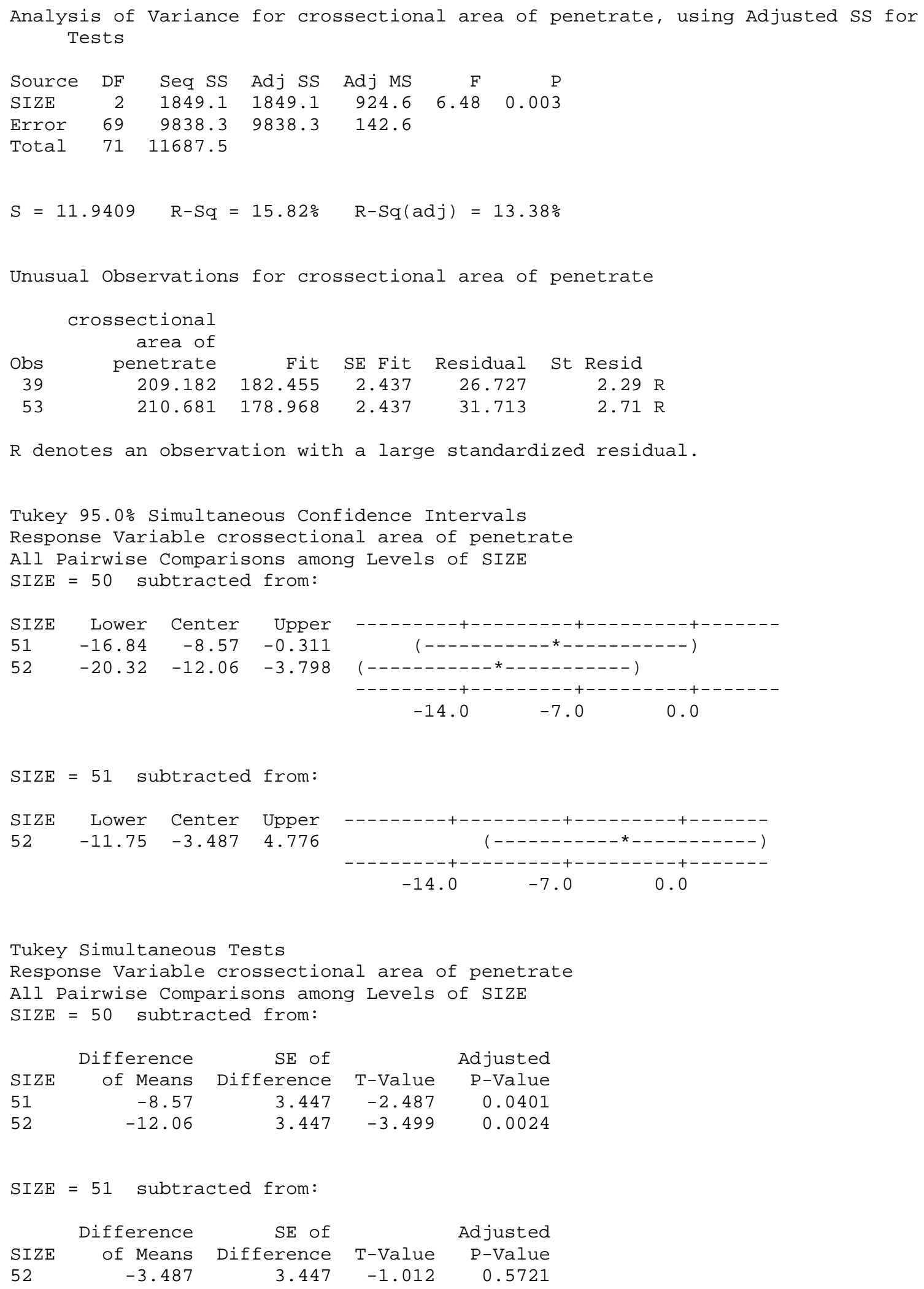

Residual Plots for crossectional area of penetrate 


\section{General Linear Model: Height \% SIZE}
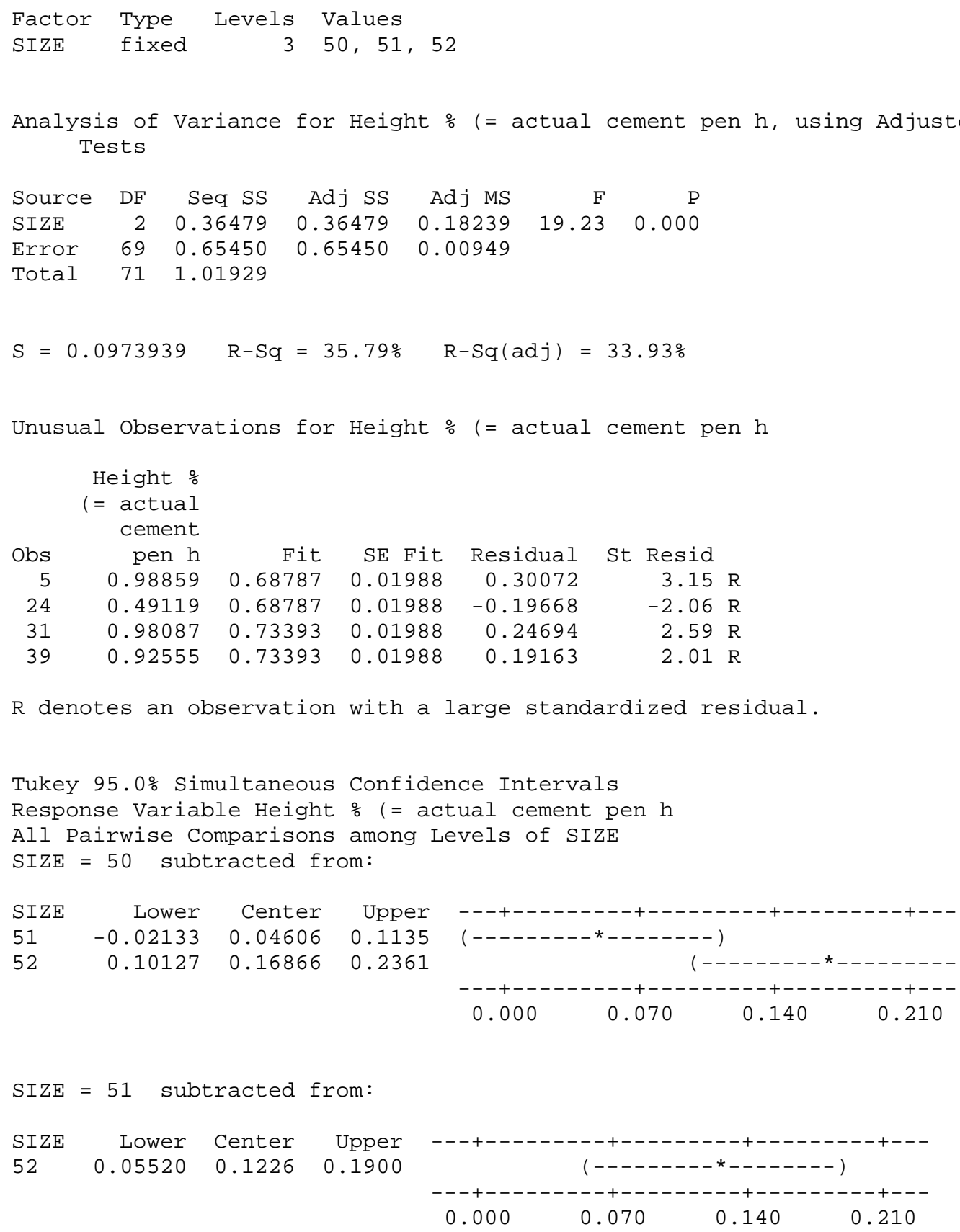

Tukey Simultaneous Tests

Response Variable Height $\frac{0}{\circ}$ (= actual cement pen $\mathrm{h}$

All Pairwise Comparisons among Levels of SIZE

$\mathrm{SIZE}=50$ subtracted from:

$\begin{array}{lrrrr} & \text { Difference } & \text { SE of } & & \text { Adjusted } \\ \text { SIZE } & \text { of Means } & \text { Difference } & \text { T-Value } & \text { P-Value } \\ 51 & 0.04606 & 0.02812 & 1.638 & 0.2367\end{array}$


SIZE $=51$ subtracted from:

$\begin{array}{rrrr}\text { Difference } & \text { SE of } & \text { Adjusted } \\ \text { of Means } & \text { Difference } & \text { T-Value } & \text { P-Value } \\ 0.1226 & 0.02812 & 4.361 & 0.0001\end{array}$

52

0.1226

0.02812

4.361

0.0001 